\title{
ASSESSING THE RESPONSE OF EMERALD LAKE, AN ALPINE WATERSHED IN SEQUOIA NATIONAL PARK, CALIFORNIA, TO ACIDIFICATION DURING SNOWMELT BY USING A SIMPLE HYDROCHEMICAL MODEL
}

By Richard P. Hooper, Christopher T. West, and Norman E. Peters

\section{U.S. GEOLOGICAL SURVEY}

Water-Resources Investigations Report 90-4000

Prepared in cooperation with the

CALIFORNIA AIR RESOURCES BOARD

Doraville, Georgia 
DEPARTMENT OF THE INTERIOR

MANUEL LUJAN, JR., Secretary

\section{U.S. GEOLOGICAL SURVEY}

Dallas L. Peck, Director

For additional information write to:

District Chief, WRD

U.S. Geological Survey

6481 Peachtree Industrial Blvd.

Suite B

Doraville, GA 30360
Copies of this report can be purchased from

Open-File Services Section Western Distribution Branch U.S. Geological Survey Box 25425, Federal Center Denver, CO 80225 


\section{CONTENTS}

Page

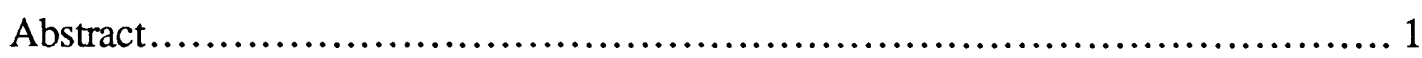

Introduction .................................................................... 1

Purpose and scope .................................................. 2

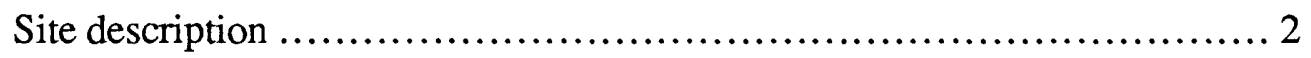

Background ......................................................... 5

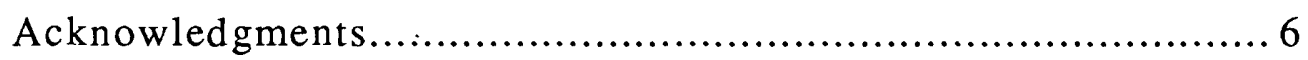

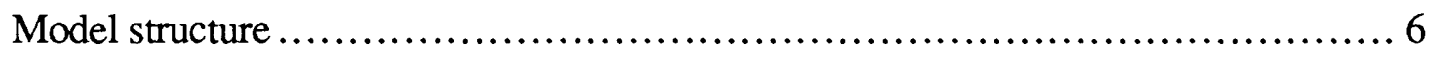

Hydrologic model .................................................. 6

Chemical model............................................................... 10

Alkalinity generation ........................................ 10

Nitrogen cycle .............................................. 12

Other chemical species..................................... 12

Solution technique.....................................................13

Model Inputs...................................................... 13

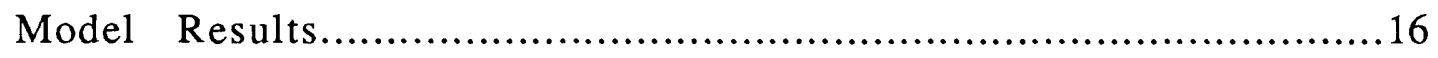

Nonreactive solutes .............................................. 16

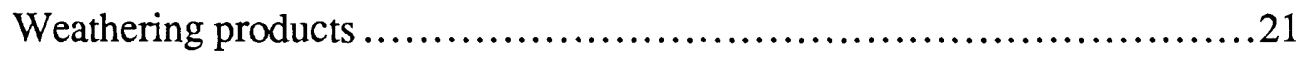

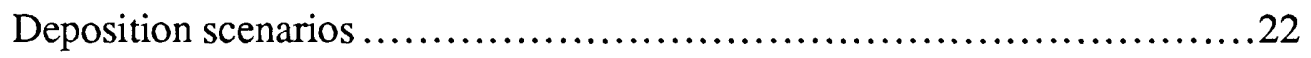

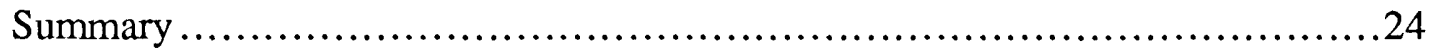

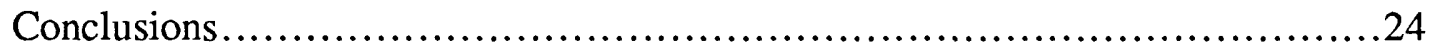

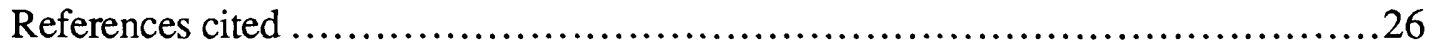

Appendix A. Sample input/output from computer model..................................28

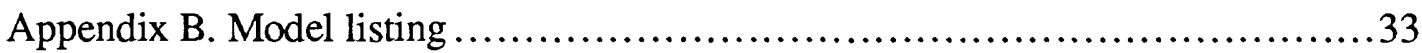




\section{ILLUSTRATIONS}

Page

Figure 1 Map showing location of study site............................. 3

2. Map showing subbasins in Emerald Lake watershed................... 4

3. Schematic diagram of hydrologic model.................................... 7

4. Volume of ice, epilimnion, and hypolimnion in 1986 and $1987 \ldots \ldots \ldots . . . .9$

5. Sum of base cations and silica concentration in stream-water samples collected from all sampled inlets to Emerald Lake in 1986.................11

6. Ratio of weathering products to hydrogen ion concentration and 10 -day average discharge .................................. 12

7. Laboratory and modeled solute release from snowpack................15

8. Observed and predicted concentrations of solutes at inflows 1 and $2 \ldots 19$

9. Observed and predicted concentrations of solutes in the lake outflow ...20

10. The effect of halving and doubling current nitrate and sulfate deposition under two different elution scenarios on alkalinity of the lake outflow .23

\section{TABLES}

Page

Table 1. Characteristics of terrestrial subbasins ............................. 8

2. Model inputs ..................................................... 14

3. Input-output budget for snowmelt season.........................17

4. Multiples of current deposition loadings of ammonium nitrate and sulfuric acid required to exhaust the alkalinity of Emerald Lake. 


\section{CONVERSION FACTORS}

For those readers who may prefer to use inch-pound units rather than metric (International System) units, conversion factors for the terms used in this report are listed below:

Multiply metric unit

millimeter $(\mathrm{mm})$

meter $(\mathrm{m})$

kilometer $(\mathrm{km})$

hectare (ha)

square meter $\left(\mathrm{m}^{2}\right)$

liter (L)

cubic meter $\left(\mathrm{m}^{3}\right)$

cubic meter per day $\left(\mathrm{m}^{3} / \mathrm{d}\right)$

liters per second $(\mathrm{L} / \mathrm{s})$ by

Length

0.03937

0.6214

Area

Volume

$$
0.2642
$$

\section{Flow}

264.2

0.0353
To obtain inch-pound units

inch (in.)

foot (ft)

mile (mi) acre

square foot $\left(\mathrm{ft}^{2}\right)$

gallon (gal)

cubic foot $\left(\mathrm{ft}^{3}\right)$

gallon per day (gal/d)

cubic feet per second

\section{Sea Level}

In this report, "sea level" refers to the National Geodetic Vertical Datum of 1929 (NGVD of 1929) - a geodetic datum derived from a general adjustment of the first-order level nets of both the United States and Canada, formerly called Sea Level Datum of 1929. 


\title{
ASSESSING THE RESPONSE OF EMERALD LAKE,
}

\author{
AN ALPINE WATERSHED IN SEQUOIA NATIONAL PARK, \\ CALIFORNIA, TO ACIDIFICATION DURING SNOWMELT \\ BY USING A SIMPLE HYDROCHEMICAL MODEL
}

\author{
By Richard P. Hooper, Christopher T. West, and Norman E. Peters
}

\begin{abstract}
A sparsely parameterized hydrochemical model has been developed by using data from Emerald Lake watershed, which is a 120-hectare alpine catchment in Sequoia National Park, California. Greater than 90 percent of the precipitation to this watershed is snow; hence, snowmelt is the dominant hydrologic event. A model which uses a single alkalinity-generating mechanism, primary mineral weathering, was able to capture the pattern of solute concentrations in surface waters during snowmelt. An empirical representation of the weathering reaction, which is based on rock weathering stoichiometry and which uses discharge as a measure of residence time, was included in the model. Results of the model indicate that current deposition levels would have to be increased between three- and eight-fold to exhaust the alkalinity of the lake during snowmelt if there is a mild acidic pulse in the stream at the beginning of snowmelt as was observed during the study period. The acidic pulse in the inflow stream at the onset of snowmelt was less pronounced than acidic pulses observed in the meltwater draining the snowpack at a point using snow lysimeters or in the laboratory. Sulfate concentrations in the streamwater were the most constant; chloride and nitrate concentrations increased slightly at the beginning of snowmelt. Additional field work is required to resolve whether the an acidic meltwater pulse occurs over a large area as well as at a point (implying sulfate-regulating mechanisms in the soil) or whether, due to physical and chemical processes within the snowpack, the acidic meltwater pulse is attenuated at the catchment scale. The modest data requirements of the model permit its applications to other alpine watersheds that are much less intensively studied than Emerald Lake watershed.
\end{abstract}

\section{INTRODUCTION}

The Emerald Lake watershed, an alpine catchment in Sequoia National Park in the Sierra Nevada of California, has been the subject of an intensive 5-year research effort under the Integrated Watershed Study (IWS) of the California Air Resources Board. All aspects of the watershed-its hydrology, geology, soils, vegetation and aquatic biota-were studied to gain an understanding of the sensitivity of the ecosystem to acidification (California Air Resources Board, 1986). Because over 90 percent of the precipitation in this watershed is in the form of snow, the emphasis of the field program was on the response of the catchment to snowmelt. Field data were collected starting in October, 1985, but data from 1986 and 1987 are more complete than from the first year and they reflect the refinement of snow-measurement techniques from information gained during the first year of sampling. 


\section{Purpose and Scope}

One phase of the IWS was the development of simulation models to predict surface-water chemistry. These models were to serve as research tools to integrate information gained from the field program and to identify gaps in understanding the chemical mechanisms controlling surfacewater chemistry, and as predictive tools to provide a means for forecasting the chemical response of the watershed to different depositional loadings of atmospheric acidity. This paper presents a lumped, sparsely parameterized simulation model, called the Alpine Lake Forecaster, or ALF, that was developed from the IWS data. ALF is a model of intermediate complexity when compared with a fully distributed model (Sorooshian and others, 1989) and a regional lake acidification model (Nishida and others, 1989), which also were developed from this data set.

ALF was designed and calibrated from data collected during water year 1986, which extended from October 1, 1985, to September 30,1986. This year was an exceptionally heavy snow year, with twice the usual snow accumulation, and a maximum snow depth of more than 5 meters (m). Water-quality samples of surface water were taken on a biweekly basis from the onset of snowmelt throughout summer and fall (Dozier and others, 1989). Intensive sampling of infrequent summer rainstorms was performed only opportunistically (Melack and others, 1989). Snow samples were taken on an event basis during winter, and a whole-basin survey was performed at maximum snow accumulation to estimate the water volume and ionic loadings to the catchment. Data from 1987, a light snow year with one-quarter the amount of snow as 1986, were used for validation of the model. The sampling regime was for surface water samples was similar to that in 1986. Based upon the experience gained from the previous year, only a snow survey at maximum accumulation was performed; no event snow samples were collected. Data considered in construction of the model included stream- and lake-water quality and quantity, snowpack quality and quantity, soil column studies, and geochemical characterizations of the bedrock.

\section{Site Description}

The following site description, except where noted, is excerpted from Dracup and others (1989) to which the reader is referred for more details. The Emerald Lake watershed (36 $35^{\prime}$ ' $49^{\prime \prime}$ $\mathrm{N}, 118^{\circ} 40^{\prime} 30^{\prime \prime} \mathrm{W}$ ) is within Sequoia National Park on the western slope of the Sierra Nevada in the Marble Fork of the Kaweah River drainage, approximately 5 kilometers $(\mathrm{km})$ east-southeast of Lodgepole (fig. 1). The area of the watershed is about 120 hectares (ha) and altitudes range from $2,800 \mathrm{~m}$ at the lake outlet to $3,416 \mathrm{~m}$ at the top of Alta Peak. The watershed is an alpine cirque that has the typical bowl shape and more than 180 degrees of aspect. The long axis of the watershed (approximately $1.7 \mathrm{~km}$ in length) is oriented from southeast to northwest, and more than half of the watershed has a north to northeast aspect (fig. 2).

Bedrock underlying the Emerald Lake watershed consists of granite, granodiorite, and aplite (Clow, 1987). The granite consists of 2 to 7 percent biotite and hornblende by volume; however, the percentage of these more readily weathered minerals in the granodiorite ranges between 12 and 17 percent by volume. More than one-third of the basin consists of exposed bedrock, and most of the remainder is covered by a thin mantle of talus or colluvium. Only 20 percent of the basin is covered by soils (Lund and others, 1987). Bedrock comprising the basin floor and cliffs has been exposed recently by glacial erosion and frost action and, thus, is weathered only slightly. Both subalpine and alpine vegetation are present; western white pine (Pinus monticola) is the predominate tree species and willows (Salix $s p$.) are the dominant shrub. 


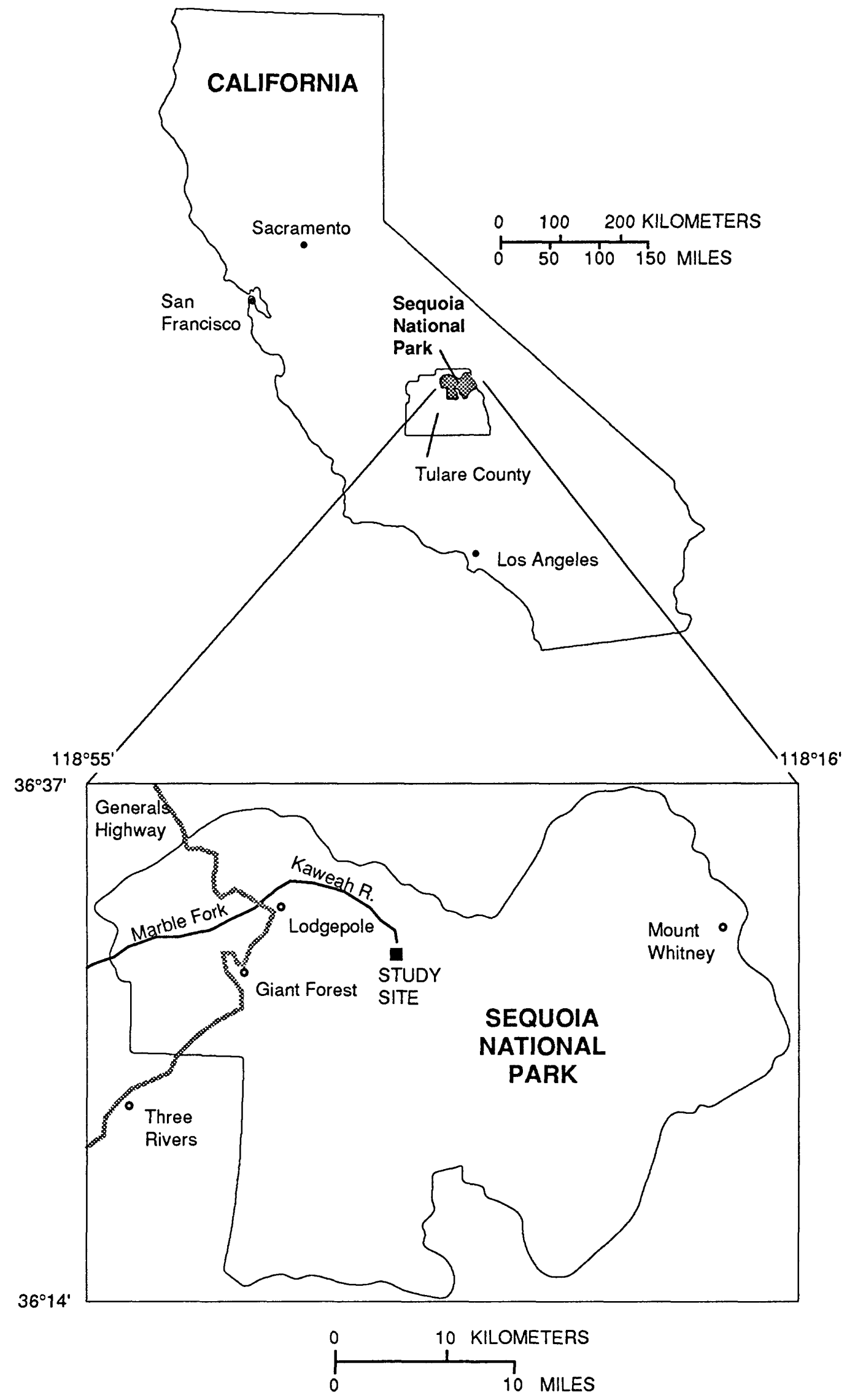

Figure 1.- Map showing location of study site. 


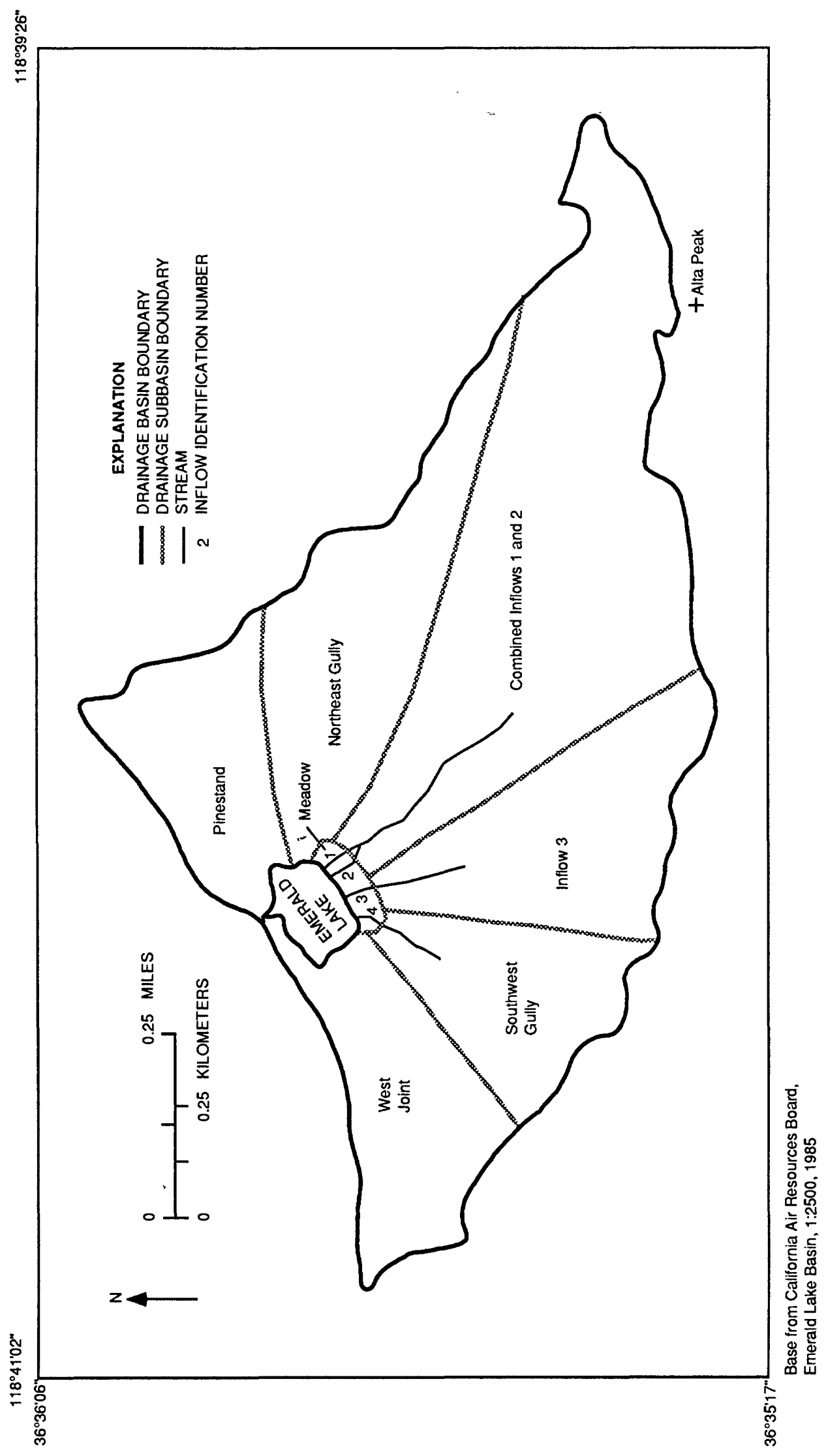

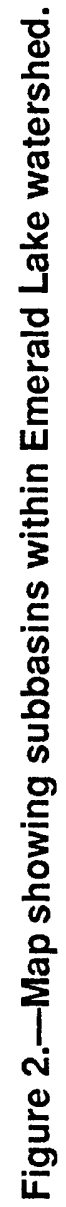


Precipitation is seasonal in the alpine regions of Sequoia National Park. Stephenson (1988) estimated that 18 percent of the annual precipitation falls from September through November, 50 percent from December through February, 30 percent from March through May, and only 2 percent from June through August. Snowmelt begins in March or April and continues through June, except in the heaviest snow years when melt continues through August. Consequently, few rain-on-snow events occur. More commonly during late spring and early summer, snowstorms occur after the melt has begun.

Emerald Lake is a tarn fed by three major and five minor stream channels; only inflows 1, 2, and 4 (fig. 2) continue to flow after the snow has melted in their respective drainage basins. Two of these perennial or nearly perennial streams (inflows 1 and 2, fig. 2) are split parts of a larger stream that drains along the main axis of the basin; this drainage accounts for 60 percent of the total inflow area. For modeling purposes, the drainage area of inflows 1 and 2 was designated as a single unit. Outflow from the watershed seems to occur only through the lake outlet. The geomorphometry of the lake suggests that the low, transverse ridge of bedrock that runs along the master joint trace on the valley floor dams the lake and is impermeable. There is no visual evidence of ground-water seepage at land surfaces downslope of the lake. Seepage losses from the watershed are assumed to be negligible.

\section{Background}

Alpine watersheds pose a number of challenges to the construction of hydrochemical models. Snow accounts for the vast majority of the hydrologic inputs to these systems, and therefore, snowmelt and not rain, is the important hydrologic event to be modeled. Previous models, such as the Birkenes model (Christophersen and others, 1984) and the Integrated Lake-Watershed Acidification Study (ILWAS) model (Chen and others, 1983), have used degree-day formulations to predict snowmelt. These models are appropriate for forested catchments where solar radiation and wind are not substantial components in the energy budget of the snowpack (Miller, 1950). In sparsely vegetated alpine watersheds, a more complete evaluation of the energy budget is required, but measurement of the necessary radiation values is logistically difficult. A major part of the field effort at Emerald Lake was devoted to obtaining these data, which have been used in an energy balance model of snowmelt at one point (Marks, 1988). The application of the point model to the complex terrain of the Emerald Lake watershed is an area of active research (Dozier, 1988).

Even with the prediction of meltwater generation at the surface of the snowpack, routing of water through the pack is difficult to simulate. In watersheds for which models have been developed (for example, the Adirondacks, southern Norway) and where snowpacks are on the order of $1 \mathrm{~m}$ deep, observations can be made as to whether the majority of snowmelt infiltrates the soil (i.e., there is no basal ice layer) or flows overland. Such observations are difficult, if not impossible, to make in alpine terrain; thus water movement through the pack is not well understood and modeling this process remains a matter of conjecture.

Moreover, existing process-oriented hydrochemical models (the ILWAS and Birkenes models) rely on a hydrologic accounting scheme that requires an accurate measure of the timing and quantity of the entry of snowmelt or rain into the watershed. Predicting or measuring snowmelt is much more difficult than rainfall, particularly in deep snowpacks. Any error in the estimates of timing and magnitude of meltwater generation will lead to errors in parameterization of the hydrologic part of the model, such as the capacity of soil layers or the rates of release from the soil layers (for example, their conductivity or other rate constant). Thus, errors in the hydrologic model can influence chemical parameterization and predictions. 
A hydrologic accounting model also requires that a hydrologic budget, which divides the water input to the watershed into outflow, evapotranspiration losses and change in storage within the watershed, can be constructed with little error. For water year 1986, an acceptably precise hydrologic budget (less than 5 percent error) was obtained for the entire melt period (Dozier and others, 1989). However, when finer time steps were considered, the errors were too large for modeling purposes. A simple extrapolation of the point-snowmelt model (Marks, 1988) to the entire watershed yielded incorrectly timed meltwater inputs. Furthermore, the water yield from the snowpack, as determined from sequential snow surveys, was inconsistent with the measured lake outflow (Dozier and others, 1989). This lack of agreement probably was due both to errors in the snow survey, which were exacerbated owing to the great depth of the pack, and to errors in the stage-discharge relation, which had to be extrapolated to high stage values that were beyond the range of calibration. The difficulties in achieving an acceptable hydrologic budget led to consideration of a simpler model structure that did not depend on a hydrologic budget, but that could still be used to achieve the objectives of the modeling program.

\section{Acknowledgments}

The authors would like to thank K.A. Tonnessen of the California Air Resources Board for her persistence and organizational abilities. J.M. Melack and Jeffrey Dozier provided useful criticisms of the model and insights into the hydrologic and chemical mechanisms operating at Emerald Lake. Mark Williams, Richard Kattelmann, and J.O. Sickman responded to our many data requests and assisted in the interpretation of these data. This work was performed in cooperation with the California Air Resources Board.

\section{MODEL STRUCTURE}

ALF consists of a coupled hydrologic and chemical model. The hydrologic model, which provides the basic structure for the model, determines the quantity of discharge from each terrestrial subbasin to the lake and the volume of the lake epilimnion into which the streamwater mixes. The chemical model calculates the equilibrium concentration of the solutes for the streamwater and the lake water based upon primary mineral weathering and dissolution of carbon dioxide. These models are described in more detail in the following sections.

\section{Hydrologic Model}

To eliminate the need for a hydrologic accounting model, discharge was assumed to equal snowmelt on a daily basis. This assumption implies that there is no change in lake or ground-water storage during the snowmelt period, which is not so unrealistic as it may seem. The lake stage varies between 1 and 2 millimeters $(\mathrm{mm})$ on a weekly basis (Richard Kattelmann, Univ. of California, Santa Barbara, written commun., 1987), which is equivalent to a volume of approximately 50 cubic meters $\left(\mathrm{m}^{3}\right)$. Daily outflow from the lake during snowmelt ranges between 1,000 and $35,000 \mathrm{~m}^{3}$. Ground-water storage in unconsolidated surficial deposits has been estimated at $100,000 \pm 50,000 \mathrm{~m}^{3}$ (Dracup and others, 1989). During the first part of snowmelt, some meltwater recharges the ground-water system, which is depleted during winter. A schematic of this simple hydrologic model is shown in figure 3 . The total daily runoff from the terrestrial part of the watershed is set equal to the measured daily discharge from the lake. 


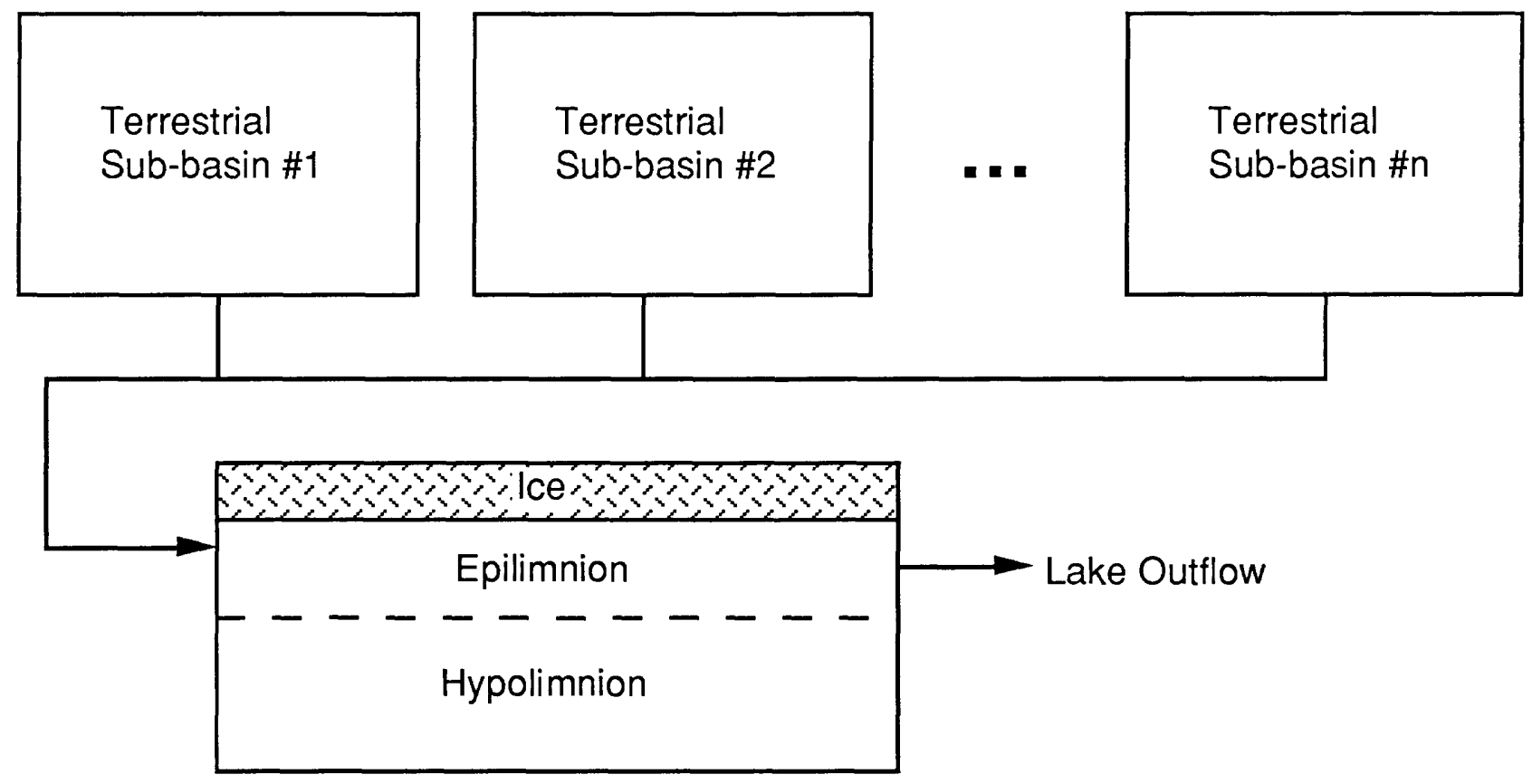

Figure 3.-Schematic diagram of hydrologic model.

Because the snowpack melts at different rates depending on the aspect and slope of the land surface, the watershed was divided into seven subbasins (fig. 2). The proportion, $\mathrm{P}_{\mathrm{i}}(\mathrm{t}$ ), of total discharge, $\mathrm{Q}(\mathrm{t})$, for each subbasin $i$ on day $t$ is determined by the relative amount of solar radiation to that subbasin

$$
P_{i}(t)=\frac{r_{i}(t) A_{i}}{\sum_{i=1}^{n} r_{i}(t) A_{i}}
$$

The variable $r_{i}$ is the potential solar radiation per unit area as determined by an algorithm of Swift (1976), and it is a function of latitude, slope inclination, aspect, and day of year. The variable $A_{i}$ is the snow-covered area of the $i^{\text {th }}$ subbasin; and $n$ is the total number of subbasins in the watershed. Each subbasin is credited at the start of the snowmelt season with part of the total seasonal discharge from the lake during the entire snowmelt period based on the proportion of the subbasin area; and each subbasin meets the discharge demand (i.e., $\mathrm{P}_{\mathrm{i}}(\mathrm{t}) \mathrm{Q}(\mathrm{t})$ ) as long as enough water remains in the subbasin. After the subbasin depletes its store of water, the discharge is apportioned among the remaining subbasins. If the snow-covered area is not known, the subbasin area can be used, although this tends to overestimate the contribution from subbasins with relatively less snow-covered area than other subbasins. Snow-covered area was measured at Emerald Lake, but the values by subbasin were not available in time for this modeling exercise; therefore, the subbasin area was used for the results presented in this report. The values required for the application of equation (1) to the seven subbasins are shown in table 1. 


\section{Table 1. Characteristics of terrestrial subbasins}

$\left[10^{3} \mathrm{~m}^{2}\right.$, thousands of square meters $]$

\begin{tabular}{lcccc}
\hline Subbasin & $\begin{array}{c}\text { Area } \\
\left(10^{3} \mathrm{~m}^{2}\right)\end{array}$ & Percent of total area & $\begin{array}{c}\text { Slope } \\
\text { (degrees) }\end{array}$ & $\begin{array}{c}\text { Aspect } \\
\text { (degrees) }\end{array}$ \\
\hline West joint & 140 & 12 & 34 & 43 \\
SW gully & 133 & 11 & 31 & 27 \\
Inflow 3 & 141 & 12 & 28 & 10 \\
Inflow 1\&2 & 396 & 33 & 34 & 305 \\
NE gully & 245 & 20 & 27 & 275 \\
Pinestand & 135 & 11 & 34 & 253 \\
Meadow & 9.28 & 0.8 & 14 & 327 \\
\hline
\end{tabular}

Because there is not an accounting model with explicit reservoirs, routing of rainfall that occurs during the melt period had to be determined from the discharge. If the discharge increased on a day when rain was recorded, all of the increase in discharge was assumed to be rain, if there was a sufficient volume of rain. If not, the volume unaccounted for was supplied from the snow pack. If more rain fell than the discharge increased (as was usually the case), the "excess" rain was areally proportioned among the subbasins and added to the snowpack. Rainfall volume was minor in 1986 but provided more than 10 percent of the precipitation in 1987.

The thermocline and ice depth in the lake are determined by linearly interpolating the field values that were measured monthly in winter and biweekly during the melt period and summer. The depths are converted to volumes by using the lake bathymetry provided by J.O. Sickman (Univ. of California, Santa Barbara, written commun., 1987). The ice layer is assumed to be completely contained within the epilimnion, thus reducing the volume of this layer. The volumes of all three layers for the years that were modeled are shown in figure 4 . Streams from the terrestrial part of the watershed flow into the epilimnion and the lake outflow is from the epilimnion; the hypolimnion is hydraulically separated from the surface water, and does not contribute to streamflow. Each layer is assumed to be completely mixed.

This simple hydrologic model structure eliminated artificial parameters that would have had to be fitted to the data, as is the case with the previously mentioned hydrochemical models. As long as the assumption holds that there is no change in storage of water in the lake or in the aquifers, this hydrologic model will provide a more powerful test of the proposed chemical mechanisms, in terms of a hypothesis test, than a model that contains artificial parameters. 

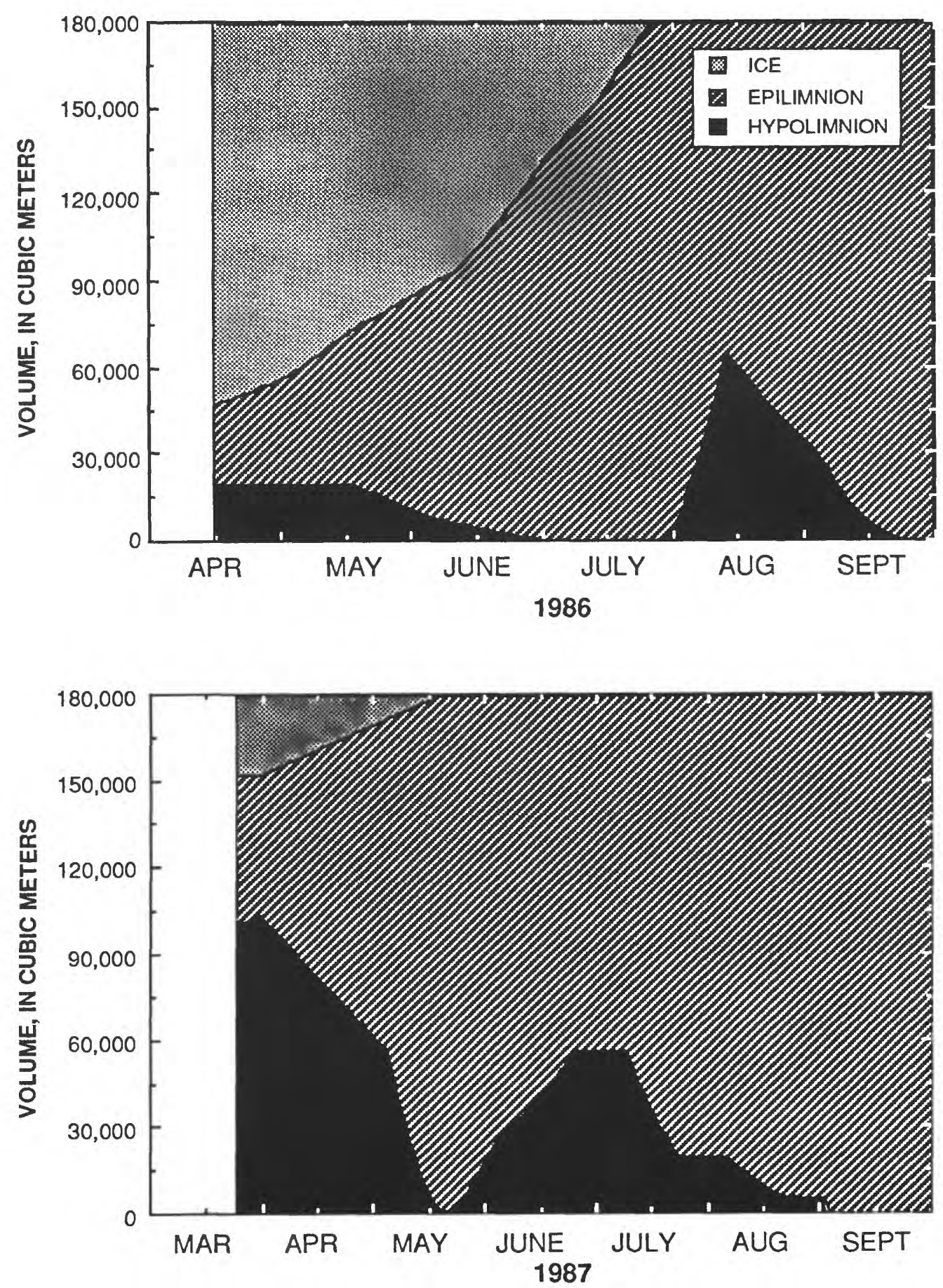

Figure 4.-Volume of ice layer, epilimnion and hypolimnion, 1986 and 1987. 


\section{Chemical Model}

The chemical reactions that are contained in ALF can be divided into those which generate alkalinity, those which are part of the biological nitrogen cycle, and others which include carbonate buffering and non-reactive solutes. The representation of these reactions included within ALF are described in the next three sections. The description of the chemical model concludes with a discussion of the numerical techniques used to solve to simultaneous equations which constitute the chemical model.

\section{Alkalinity generation}

The dominant sources of alkalinity in watersheds with young soils that contain fresh mineral faces and few sesquioxides, are primary mineral weathering and cation exchange (Drever, 1988, p. 207-231). Weintraub (1986) characterized the mineralogy and chemistry of soils, surficial material, and bedrock from Emerald Lake, and conducted laboratory leaching studies of undisturbed soil columns. Weintraub (1986) concluded that weathering was the dominant alkalinity-generating mechanism in the watershed. Lund and others (1987) further characterized the soil chemical characteristics and they concluded that the Emerald Lake soils are acidic $\mathrm{pH}$ from 4.4 to 4.8 ) and have very low percent base saturation, which may only provide limited buffering of acidic inputs. In addition, the interrelation of solute compositions of streamwaters were evaluated by Lund and others (1987) from which they concluded that primary mineral weathering is a primary source of alkalinity. We, therefore, included mineral weathering in the model but did not include cation exchange.

The mineralogy of the bedrock, which determines the rate and stoichiometry of primary weathering, is dominated by quartz and feldspar and contains minor amounts of biotite and hornblende (Weintraub, 1986). A variety of secondary vermiculite minerals were identified in Emerald Lake soils (Weintraub, 1986). Incongruent weathering of aluminosilicate minerals produces secondary minerals, base cations, and dissolved silica $\left(\mathrm{SiO}_{2}\right)$ either while consuming hydrogen ion or releasing alkalinity. In the absence of detailed mineral-weathering information, the stoichiometry of the mineral weathering was simplified by combining the individual aluminosilicate minerals into one reactant called rock. Rather than tracking each base cation individually, the base cations $\left(\mathrm{Na}^{+}, \mathrm{K}^{+}, \mathrm{Ca}^{2+}\right.$, and $\mathrm{Mg}^{2+}$ ) were combined as the sum of base cations, herein called SBC. The slope of the least squares regression of SBC concentration (in microequivalents per liter $(\mu \mathrm{eq} \mathrm{L}-1)$ ) on dissolved silica (in micromoles per liter $\left(\mu \mathrm{mol} \mathrm{L}^{-1}\right)$ ) for the 1986 inflow data (fig. 5) is $1.2\left(\mathrm{r}^{2}\right.$ is 0.77$)$, and therefore, the following incongruent dissolution reaction is consistent with these data

$$
\text { Rock }+1.2 \mathrm{H}^{+} \rightarrow 1.2 \mathrm{SBC}^{+}+\mathrm{SiO}_{2}(\mathrm{aq})+\text { secondary mineral. }
$$

This reaction, however, is subject to kinetic constraints. The hydrologic model does not permit an explicit calculation of the residence time of water within the terrestrial system, so a standard kinetic model cannot be fit to the data. Instead, we use the lake discharge, averaged over the 10 days prior to the sample collection, as a surrogate for residence time. A regression of the log of the reaction constant, $\mathrm{K}$, where 


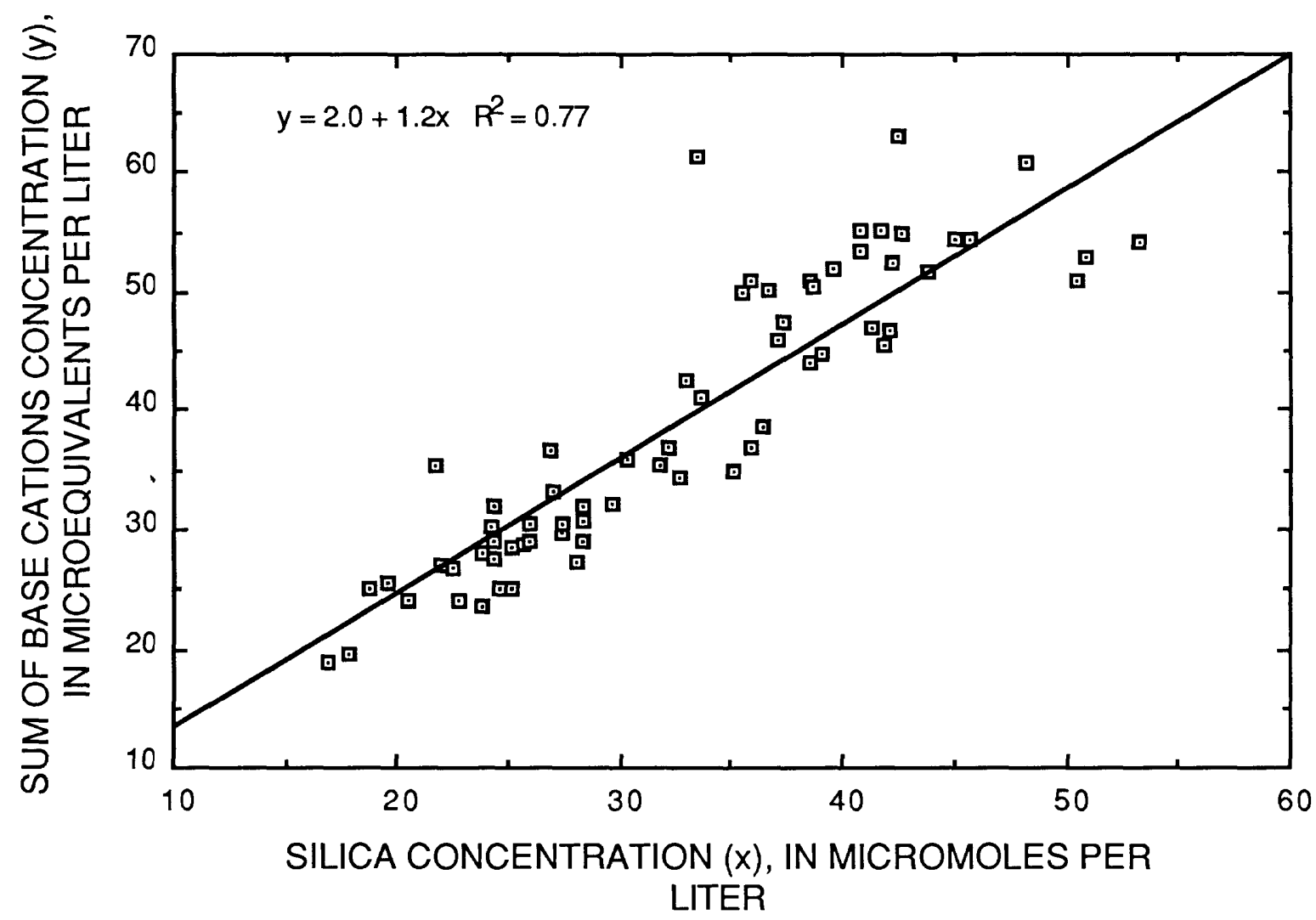

FIGURE 5.-Sum of base cations and silica concentration in streamwater samples collected from all sampled inlets to Emerald Lake in 1986.

$$
\mathrm{K}=\frac{\left[\mathrm{SBC}^{+}\right]^{1.2}\left[\mathrm{SiO}_{2}\right]}{\left[\mathrm{H}^{+}\right]^{1.2}}
$$

on the average discharge (fig. 6) yields the following equation,

$$
\mathrm{K}=0.0082 \cdot 10^{-0.000044 \mathrm{Q}^{\prime}}
$$

where $\mathrm{Q}^{\prime}$ is the 10-day average discharge. Equation 4 explains 80 percent of the variation in the data. Because this is the central equation in the model, two different intercepts, 0.005 and 0.02 , that bracket the observations were used to assess the sensitivity of the results to this equation (fig. 6). Model results based on the lower line are referred to as the "lower bound" case because these results have lower concentrations of alkalinity, SBC, and silica than the "upper bound" case. The watershed is more sensitive to acidification under the lower bound case because less of the hydrogen ion is neutralized by the weathering reaction. 


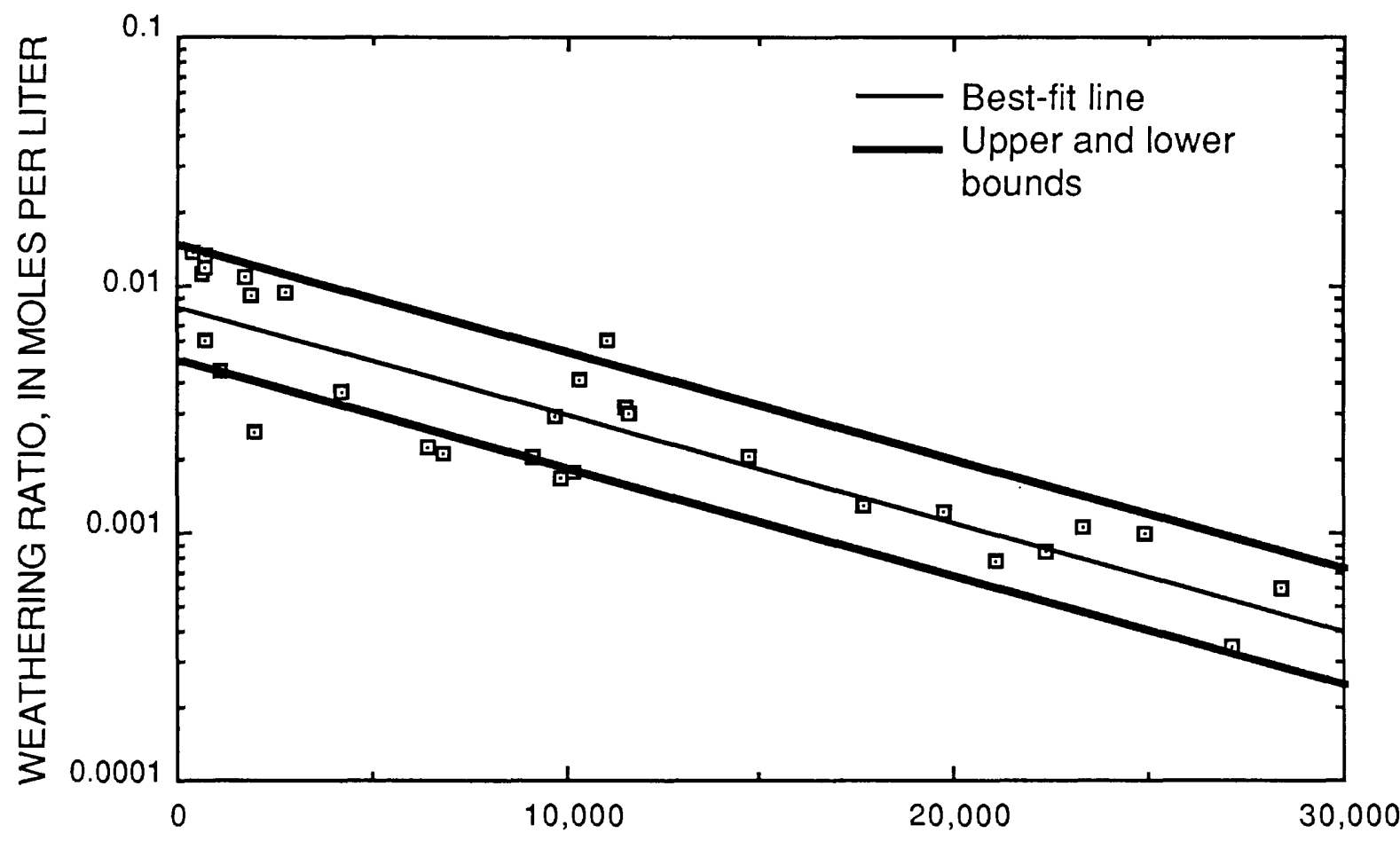

10-DAY AVERAGE DISCHARGE, IN CUBIC METERS PER DAY

\section{FIGURE 6.- Ratio of weathering products to hydrogen ion concentration and 10-day average discharge.}

\section{Nitrogen cycle}

A simplified representation of the nitrogen cycle is included in the model. Ammonium concentration in the main inflow is very low, generally much less that $1 \mu \mathrm{eq} / \mathrm{L}$. Therefore during biotically active seasons, all ammonium is assumed to be taken up by the biota; each mole of ammonium is exchanged for one mole of hydrogen ion. In addition, a part of the nitrate, $v$, also is retained along with an equivalent amount of hydrogen ion. When the biota are not active, all the ammonium is oxidized to nitrate, which is passed through the system, and to two moles of hydrogen ion; no nitrate is taken up by the biota. After biotic uptake, if any, nitrate is treated as a conservative species. We assumed that the biota were active throughout the snowmelt period and set $v$ to 0.10 (that is, 10 percent of the nitrate is retained by the biota).

\section{Other chemical species}

A standard representation of the carbonate buffering system is included. When the lake is covered by ice, the system is assumed to be closed to the atmosphere; during the lake's ice-free season and during all times in the terrestrial part of the watershed, the system is assumed to be open to the atmosphere. The partial pressure of carbon dioxide $\left(\mathrm{CO}_{2}\right)$, to which water equilibrates in the open system, is a parameter in the model to be fit. Chloride and sulfate are treated as conservative species in the model. 


\section{Solution technique}

A modified Newton's method (Morel and Morgan, 1972) was used to solve the system of nonlinear simultaneous equations that describe weathering and carbonate buffering in the terrestrial subbasins. There are four variables in the system, hydrogen ion, bicarbonate, silica, and SBC, that are determined from charge balance constraint, weathering equilibrium, weathering stoichiometry, and carbonate equilibrium. Temperature corrections are made for the carbonate system and for the hydrolysis of water; activity corrections are not made owing to the low ionic strength of the surface waters. The mathematical solution seems to be identical to an equilibrium solution, yet the equilibrium "constant" for the weathering reaction changes as discharge changes. These equations are solved on a daily time step by using the input concentration of the meltwater. On days when rain fell, the "excess" rain, whose chemistry is an input to the model, is assumed to react with the rock and then mix with the meltwater which has also reacted with the rock. This mixture is then reequilibratęd before flowing into the lake.

Within the lake, no chemical reactions other than carbonate buffering occur. The volume of the epilimnion is increased by inflow from the terrestrial system, thinning of the ice layer, and deepening of the thermocline. The appropriate quantities of solutes are advected with the water, and the system is re-equilibrated assuming that the epilimnion is completely mixed. The time step concludes with water of the same quality as the epilimnion flowing out of the lake.

Within the chemical model, there are only five parameters that must be calibrated: the two regression coefficients for the weathering reaction (equation 4 ), that part of nitrate retained by the biota $(v)$, the date at which the biota become active, and the partial pressure of $\mathrm{CO}_{2}$. This latter parameter must be fitted because surface waters frequently contain more dissolved $\mathrm{CO}_{2}$ than would be predicted from equilibrium with atmospheric levels of $\mathrm{CO}_{2}$. Typical partial pressures range from two to five times the atmospheric partial pressure of $\mathrm{CO}_{2}$. Dissolved inorganic carbon was not measured in surface-water samples collected from Emerald Lake. The equilibrium constants and enthalpy values (used for temperature correction) for the carbonate system and for water hydrolysis are considered to be well known and are not subject to calibration.

\section{Model Inputs}

ALF was designed to utilize data collected for the Integrated Watershed Study. However, its input requirements are modest enough to allow its application to less intensively studies sites. Table 2 shows the hydrologic and chemical inputs necessary to run the model. The most critical measurements are the daily discharge from the lake and the mass of solutes contained in the snowpack at maximum accumulation. Rain water quality primarily affects stream and lake water quality on the day which the event happens. However, if these is any "excess" rain as defined above, the solutes associated with this rain are incorporated into the snowpack. Thermocline depth and ice thickness determine the hydraulic mixing volume of the lake and are of secondary importance. Water temperatures are used to correct thermodynamic equilibrium constants and also are not critical. The remaining inputs are used to determine initial conditions for the model. 
Table 2. Model Inputs

Hydrologic Chemical

Daily discharge from lake

Thermocline depth ${ }^{1}$

Ice thickness ${ }^{1}$

Temperature of inflows 1

Temperature of epilimnion 1
Total mass of solutes at maximum

snowpack accumulation

Rainwater quality

Initial lake water quality

Initial chemical composition of ice on lake

1 May be interpolated from field measurements to derive daily values necessary to run model.

Although the mass of solutes in the snowpack is an input to the model, the meltwater quality during the snowmelt must be calculated. The first meltwater from the snowpack typically contains a high concentration of solutes (Johannessen and Henriksen, 1978). This first "pulse" of solutes from acidic snowpacks is believed to be the cause for the sharp $\mathrm{pH}$ depressions during the spring snowmelt (Skartveit and Gjessing, 1979), and has been linked to fish kills in Norway (Leivested and Muniz, 1976). Therefore, the intensity of the acidic pulse is a key factor in determining the impact of acidic pollutants contained within the snowpack on aquatic biota. Both the Birkenes and ILWAS models assume an exponential decline in the release of solutes from the snowpack. Specifically, the concentration factor (the ratio of the concentration of the meltwater to the bulk concentration of the snowpack) is assumed to decline exponentially. Because the pattern of solute release is so critical, particularly when considering different depositional scenarios, we chose to parameterize the solute release differently. An elution rule in the form of $x$ percent of the solutes released in the first $y$ percent of the meltwater (for example, 80/20 rule means 80 percent of the solutes are released in the first 20 percent of the meltwater) and a maximum concentration factor for the first day (the ratio of concentration on that day to the average concentration of the solute in the snowpack) are specified. Two exponential curves, one for the period when the first $y$ percent of the water drains from the pack and a second curve for the remainder of the melt period, define the meltwater concentration. These curves meet the specified elution rule and concentration factor along with a continuity condition that the concentration does not change abruptly between the two curves. The results of this approach are compared with the experimental data of R. C. Bales (Univ. of Arizona, written commun., 1988) on a cumulative basis in figure 7. All solutes are treated identically; no provisions are made for "preferential" elution (that is, different solutes being released at different rates), which has been reported by Brimblecombe and others (1987). 


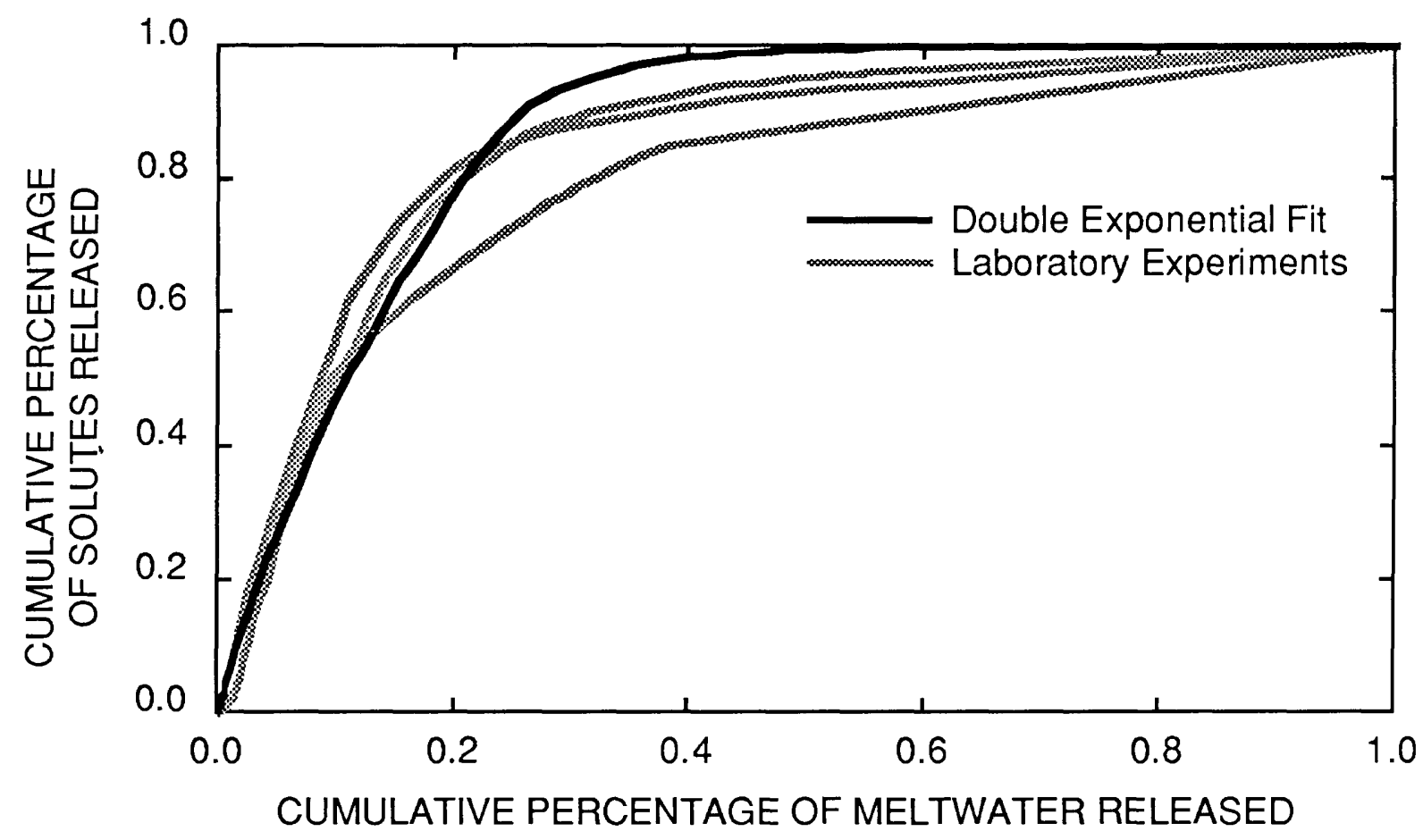

Figure 7.-Laboratory and modeled solute release from snowpack.

Because snowpacks melt at different rates in each subbasin owing to different radiation inputs, meltwater concentration curves are calculated for each subbasin. Consequently, ionic pulses from subbasins where snowmelt occurs later in the season are contributed to surface waters after earlier ionic pulses from subbasins where snowmelt has already occurred. This distribution of meltwater generation leads to a much less intense ionic pulse to the lake than if the entire snowpack melted as one unit. The total ionic loading in the snowpack for all ions was estimated by Dozier and others (1987) from field observations (table 3). An artificial solute called was created to create an exact charge balance. Typically there is a small cation charge excess which arises from the unmeasured contribution of organic anions to the charge balance of the solution. If this solute were not created, the charge balance constraint in the chemical model would adjust the hydrogen ion concentration to meet the charge balance. The concentration of this artificial solute was always very small. 


\section{MODEL RESULTS}

Errors in the prediction of one charged solute will affect predictions of other solutes owing to the electroneutrality constraint. Therefore, predictions for the nonreactive solutes, those that were modeled as not participating in any chemical reaction, will be discussed first. Then, solutes which are the products of the weathering reactions will be considered. Finally, the result of different deposition scenarios will be presented.

\section{Nonreactive Solutes}

The ionic loadings in the snowpack from field estimates are compared in table 3 with the measured export from discharge through the lake outlet during the snowmelt period. There are large differences between 1986 and 1987 both in the amount of precipitation and in its form. Rain inputs of water and solutes were negligible in 1986, but accounted for 18 percent of the water in 1987 and more than half the deposition of all solutes, except chloride. For the nonreactive solutes (sulfate and chloride in this model), the input should equal the output; clearly, this is not the case for sulfate and chloride during 1986 and 1987. The ionic deposition is calculated as the product of the ionic concentration and the volume of water, both of which are subject to measurement error.

Extensive snow surveys were performed to estimate the water volume of the snowpack. Techniques were refined and sampling intensity increased during 1986 and 1987 over the initial effort in 1985, as is evidenced by the good agreement in the water budget. Snowpack solute concentration was measured at eight points throughout the watershed, although not all sites were sampled for all events. Therefore, the discrepancy in the ionic budgets must be due either to sampling and analytical errors or to additional sources and mechanisms that regulate solute concentrations.

Sulfate input is less than one-half the sulfate output for 1986; yet the output exceeds the input for 1987. The difference between the form of the input (snow in 1986 and predominantly rain in 1987) may account for the difference, but there is insufficient data to make any conclusions. These budgets ignore input due to atmospheric dry deposition of sulfate and internal sources of sulfate. Contributions of sulfate by dry atmospheric deposition were evaluated using deposition to pine branches by Bytnerowicz and Olszyk (1988). An upper-bound estimate for the dry deposition of sulfur would result in only a 10 percent increase in the atmospheric inputs of table 3 . A internal source of sulfate may exist. Volcanic glass was identified in the coarse silt fraction of soils at Emerald Lake (Wyles, 1986). Strong acid treatment of these soils resulted in sulfate release, which was attributed to the breakdown of vesicles that possibly contain sulfur dioxide. However, no quantitative estimate of this contribution to the sulfur budget has been made. Modifications to the model await further field observations of sulfur sources and regulating mechanisms.

The chloride budget is also variable, as might be expected, given the numerous opportunities for contamination during sample handling and the analytical precision at the low concentrations. The snow input number for 1986 may be somewhat high because there was a known chloride contamination from the plastic bags used for sampling that year. It was not possible to determine quantitatively the amount of contamination (M.W. Williams, Univ. of California, Santa Barbara, written commun., 1989). The chloride budget for 1987 would suggest, however, that the precision of these load estimates may be as low as \pm 50 percent if the variation in the chloride estimates arise primarily from sampling error and not from contamination or analytical imprecision.

Despite these differences in the budgets, the measured snowpack loadings for all solutes were used in the model. Although the differences on a seasonal basis appear to be large, the amount of error introduced in daily concentrations is only a few microequivalents per liter. 
Table 3. Input-output budget for snowmelt season

[ $10^{6} \mathrm{~m}^{3}$, millions of cubic meters; $10^{3} \mathrm{eq}$, thousands of equivalents]

\begin{tabular}{|c|c|c|c|c|c|c|c|}
\hline Year & & $\begin{array}{l}\text { Water Volume } \\
\left(10^{6} \mathrm{~m}^{3}\right)\end{array}$ & $\begin{array}{c}\mathrm{SBC} \\
\left(10^{3} \mathrm{eq}\right)\end{array}$ & $\begin{array}{l}\mathrm{NH}_{4}{ }^{+} \\
\left(10^{3} \mathrm{eq}\right) \\
\end{array}$ & $\begin{array}{l}\mathrm{NO}_{3}^{-} \\
\left(10^{3} \mathrm{eq}\right)\end{array}$ & $\begin{array}{l}\mathrm{SO}_{4}{ }^{2-} \\
\left(10^{3} \mathrm{eq}\right)\end{array}$ & $\begin{array}{l}\mathrm{Cl}^{-} \\
\left(10^{3} \mathrm{eq}\right)\end{array}$ \\
\hline \multirow[t]{6}{*}{1986} & Snow input ${ }^{1}$ & $1 \quad 2.4$ & 7.5 & 2.9 & 4.1 & 3.4 & 7.4 \\
\hline & Rain input ${ }^{2}$ & $\underline{0.05}$ & $\underline{0.69}$ & $\underline{0.82}$ & $\underline{0.82}$ & $\underline{0.66}$ & $\underline{0.24}$ \\
\hline & Total input & 2.4 & 8.2 & 3.7 & 4.9 & 4.1 & 7.7 \\
\hline & Output $^{3}$ & $\underline{\underline{2.3}}$ & $\underline{\underline{63}}$ & $\underline{\underline{0.1}}$ & $\underline{\underline{9.1}}$ & $\underline{\underline{9.9}}$ & $\underline{\underline{5.6}}$ \\
\hline & Difference ${ }^{4}$ & 0.1 & -55 & 3.6 & -4.2 & -5.8 & 2.1 \\
\hline & Ratio $^{5}$ & .96 & 7.7 & .027 & 1.9 & 2.4 & 0.73 \\
\hline \multirow[t]{6}{*}{1987} & Snow input ${ }^{1}$ & 0.80 & 3.2 & 3.0 & 3.4 & 2.3 & 1.2 \\
\hline & Rain input ${ }^{2}$ & $\underline{0.17}$ & $\underline{7.3}$ & $\underline{6.8}$ & $\underline{5.9}$ & $\underline{5.6}$ & $\underline{0.85}$ \\
\hline & Total input & 0.97 & 10. & 9.8 & 9.3 & 7.9 & 2.0 \\
\hline & Output $^{3}$ & $\underline{.75}$ & $\underline{\underline{34 .}}$ & $\underline{\underline{0.01}}$ & $\underline{\underline{6.3}}$ & $\underline{\underline{5.2}}$ & $\underline{\underline{3.2}}$ \\
\hline & Difference 4 & 0.22 & -24 & 9.8 & 3.0 & 2.7 & -1.2 \\
\hline & Ratio $^{5}$ & 0.80 & 3.4 & .001 & 0.68 & 0.66 & 1.6 \\
\hline
\end{tabular}

${ }^{1}$ As determined from snowpack loadings at maximum accumulation (Dozier and others, 1989).

2Includes rain and mixed rain and snow events that occurred during the melt period (Dozier and others, 1989) which ran from April 16, 1986 to September 30, 1986 and from March 25, 1987 to July $21,1987$.

${ }^{3}$ As determined from mass export through lake outlet; water-quality observations were linearly interpolated to a daily basis.

${ }^{4}$ Input less output; a positive value indicates net retention in the watershed and a negative value, a net release.

${ }^{5}$ The ratio of output to input; values greater than one indicate that the watershed is a source of the solute and values less than one indicate that the watershed is a sink. 
The results of the model simulations are presented in figures 8 and 9 for the combined inflows 1 and 2 and the lake outflow, respectively. Model results for streamwater quality cease when the model calculates that all the snow in the subbasin has melted; this occurred in mid July 1987. The "spikes" in concentration during the simulation period occur on during rain storms. Clearly these events were more important during 1987 than during 1986 as was also indicated by the budgets. The observations for the combined inflows (fig. 8) are an average of the measurements taken on the individual streams if more than one inflow was sampled on a particular day, or if more than one sample were collected during the day.

The upper three panels of each plot are for solutes that do not participate in the weathering reaction $\left(\mathrm{Cl}^{-}, \mathrm{NO}_{3}{ }^{-}\right.$, and $\mathrm{SO}_{4}{ }^{-2}$ ). Three different elution scenarios are considered: an 80/20 release ( 80 percent of the solutes in the first 20 percent of the meltwater) with a maximum concentration factor (CF) of 8; a 40/20 release with a CF of 3; and a uniform release. For chloride, the 40/20 release rule seems to fit best; for nitrate, either the $40 / 20$ for 1987 or $80 / 20$ release rule for 1986 fits best. For sulfate, a uniform release fits the pattern best in 1986, although there is a systematic underprediction due to the net export of sulfate during this year. In 1987, the 40/20 rule appears to fit the initial stage of snowmelt best, yet during the rain events, the sulfate concentration does not respond as much as would be predicted by the model using either the $40 / 20$ or $80 / 20$ rule. The uniform release also does not describe the observations. In this case the sulfate added by the rain (twice as much as was in the snow, see table 3), continues to increase the stream concentration to levels above those observed. If there is a differential elution of sulfate (that is the $40 / 20$ or $80 / 20$ rule), then the stream sampling missed extreme changes in concentration. However, these concentrations would have to be much larger than those ever observed at Emerald Lake. Alternately, sulfate is not a nonreactive solute and is being retained in the watershed in 1987. Among the three solutes, sulfate exhibits the smallest range in concentration. This pattern with sulfate showing the least pronounced elution is opposite the preferential elution patterns observed by Brimblecombe and others (1987) where sulfate eluted first.

Putting aside the large rain-on-snow events in 1987 for the moment, consider 1986 and the April 1987 when an initial pulse from the snowpack would have been expected but did not occur. Two possible explanations can be advanced. One explanation is that solutes are eluted uniformly from the snowpack and that there are additional sources of nitrate and chloride, which account for the observed increases in concentration in the streamwater. Supporting this explanation is the observation that the peak nitrate concentrations observed in the inflow streams are roughly equivalent in 1986 and April, 1987 (approximately $12 \mu \mathrm{eq} \mathrm{L}-1$ ), yet the average concentration in the snowpack (assuming 10 percent and 100 percent biotic retention of nitrate and ammonium, respectively) is twice as large in $1987(5 \mu \mathrm{eq} \mathrm{L}-1)$ as in $1986(2.5 \mu \mathrm{eq} \mathrm{L}-1)$. The observed chloride pulse also may come from the soil solution where chloride from weathering or from the decomposition of organic matter may be concentrated during the winter (Peters, 1987).

A second explanation is that chloride and nitrate pulses arise from differential elution from the snowpack, but sulfate pulses from the pack are not observed in the stream owing to regulation by adsorption/desorption processes in the soils. Although soils cover only a small part of the watershed area, most flowpaths to the lake probably intersect the soils at some point. The constancy of the sulfate concentrations during the rain events in 1987 would also support sulfate regulation by the soils. However, such a regulating mechanism for sulfate has not been identified at Emerald Lake and would be unusual in such young soils.

The fundamental conclusion, regardless of the specific mechanism that accounts for the observed concentrations, is that the effective "acid pulse" to surface waters from this alpine snowpack is not as severe as would be predicted from laboratory studies or from point measurements as determined by snow lysimeters. For evaluation of the weathering model and the subsequent scenario analysis, the uniform and the 40/20 release rules will be considered. 

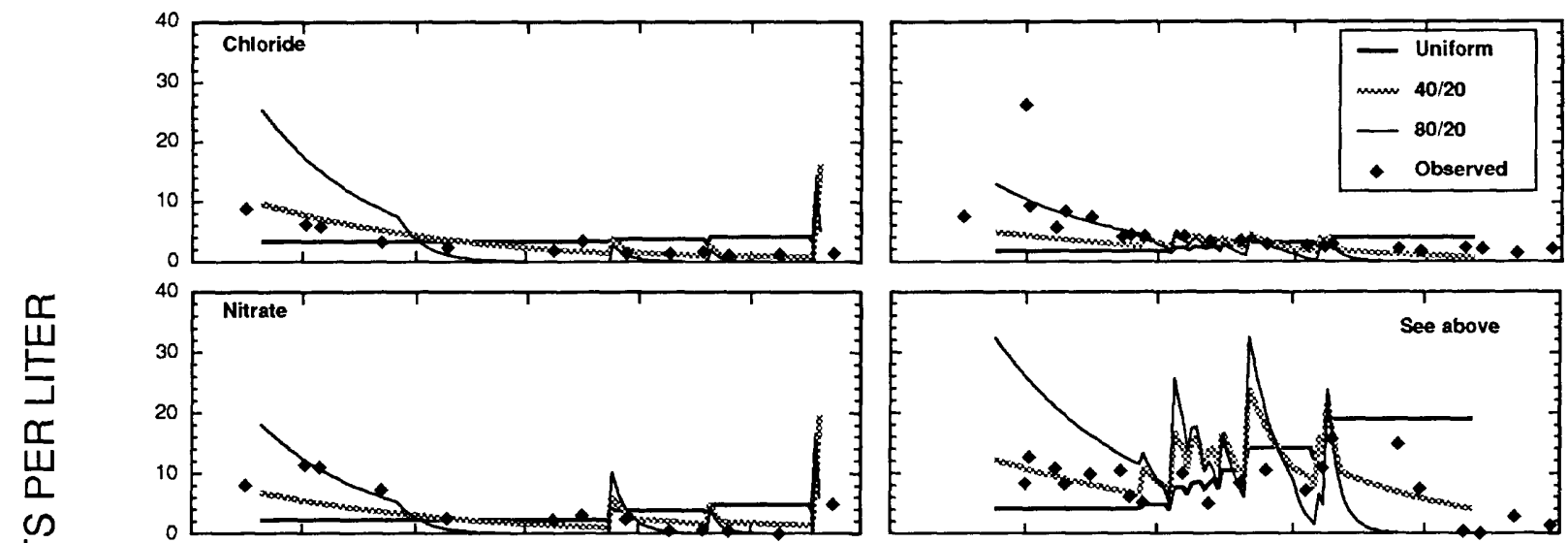

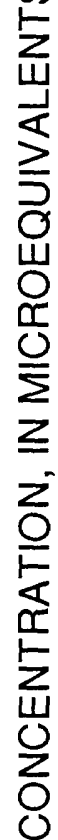
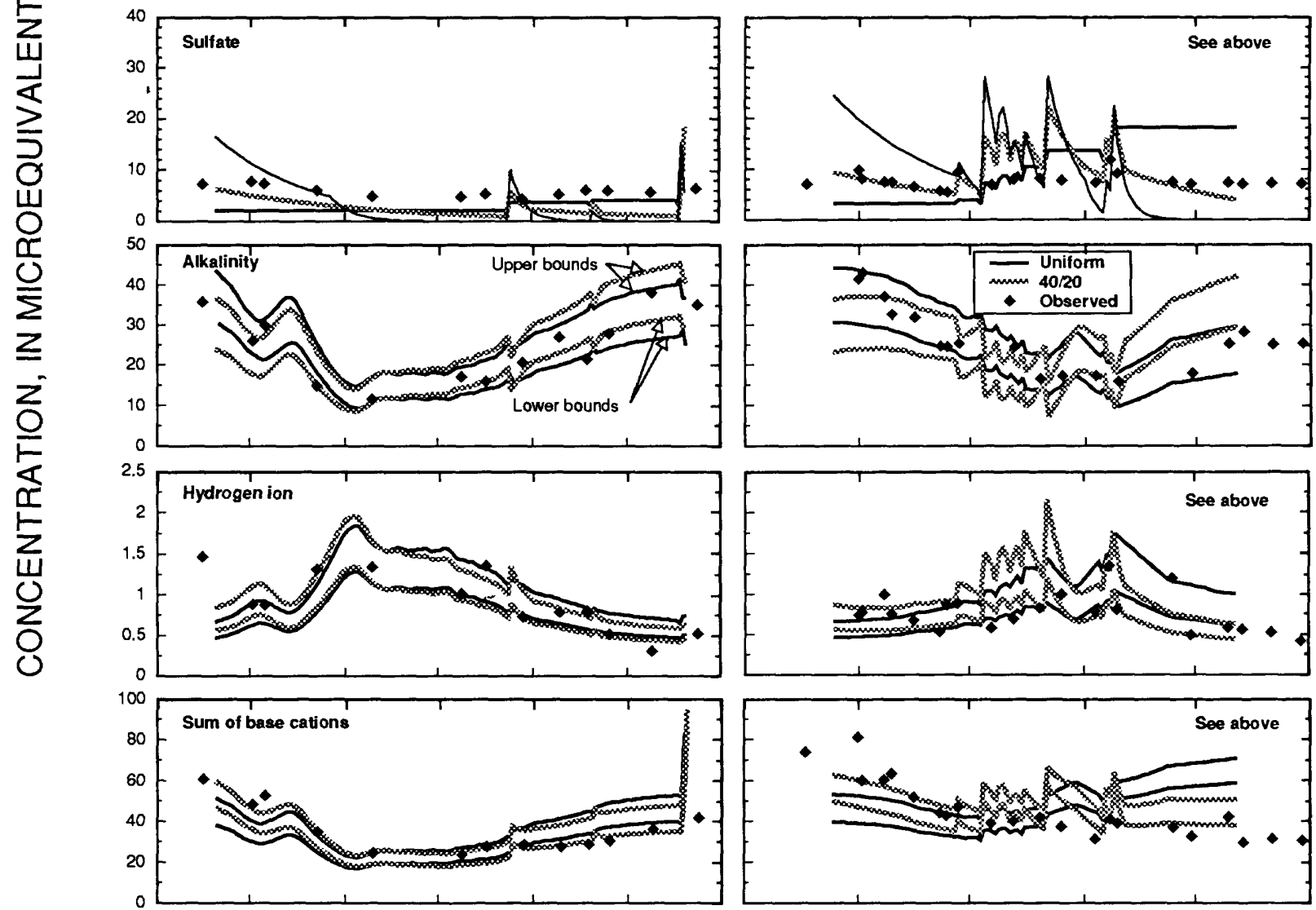

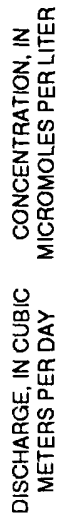
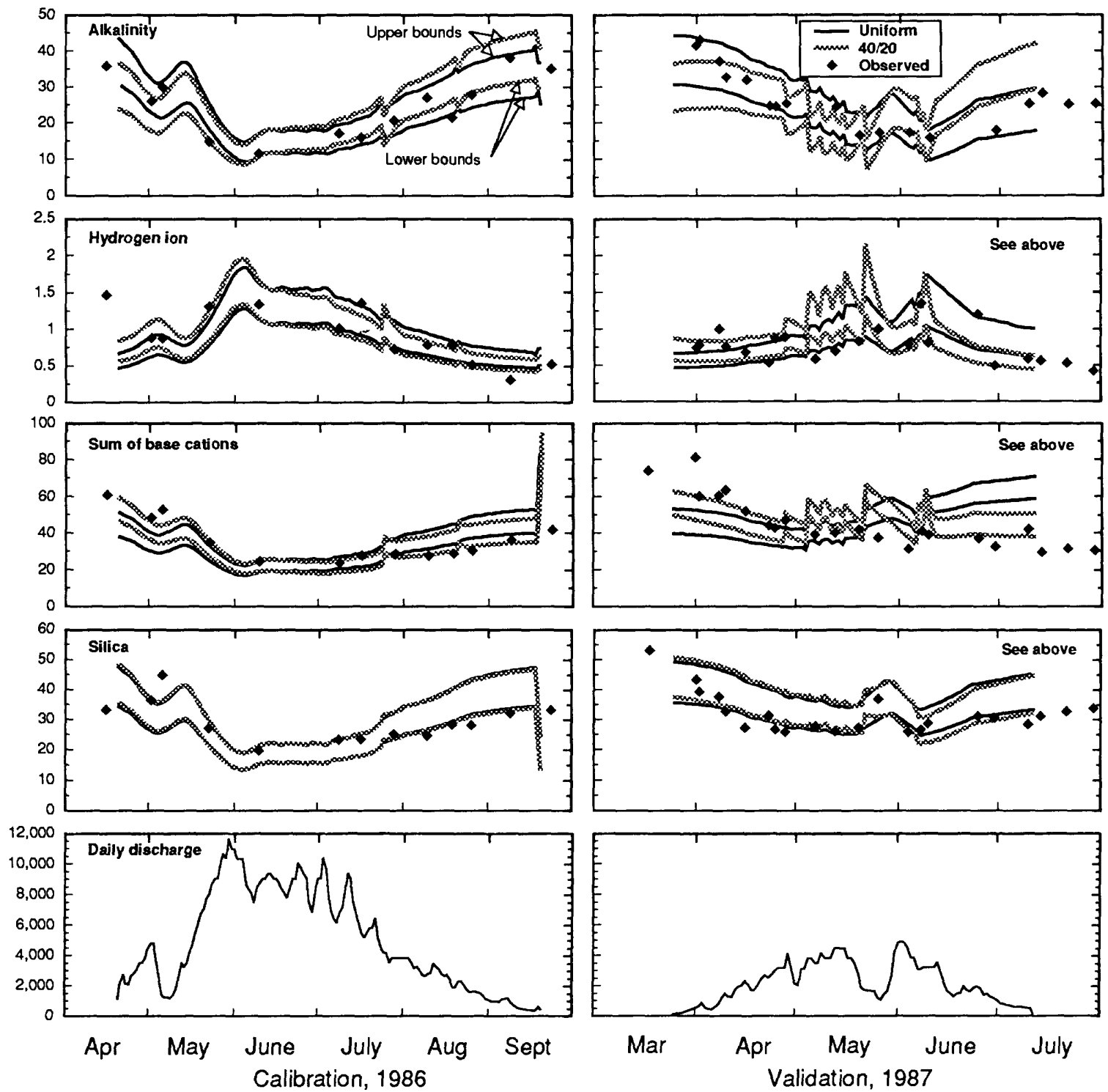

Figure 8.- Observed and predicted concentrations of solutes at inflows 1 and 2 . 

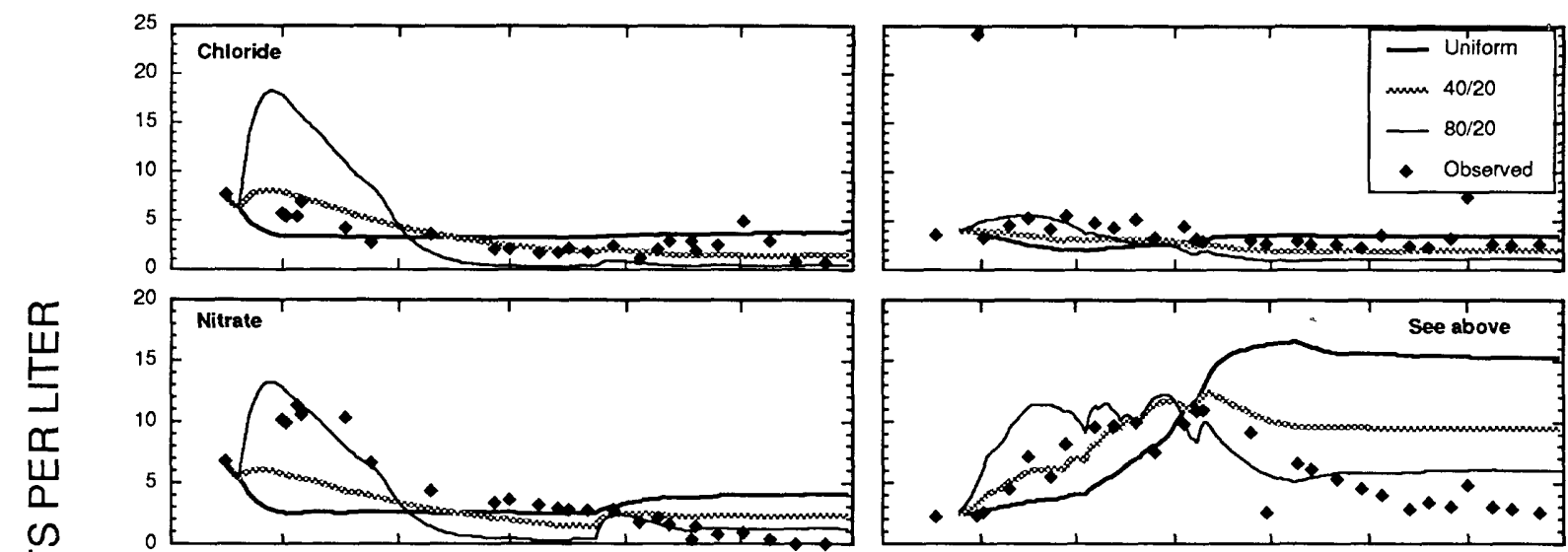

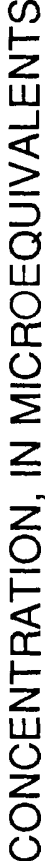
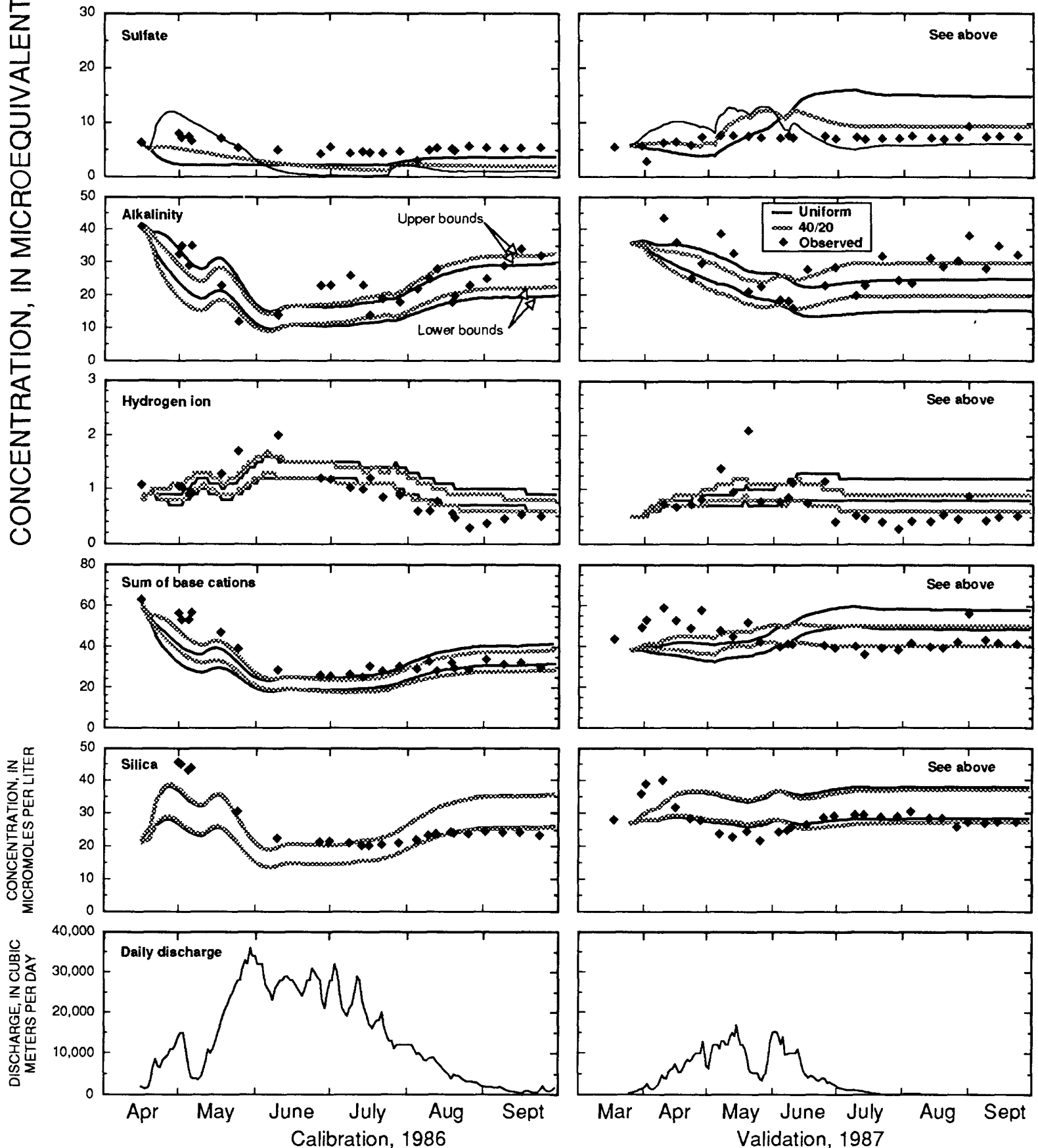

Figure 9.-Observed and predicted concentrations of solutes in the lake outflow 


\section{Weathering Products}

The fourth through the seventh panels in figures 8 and 9 show the observed and the model predicted values for solutes affected by the weathering reactions (alkalinity, hydrogen ion, SBC, and silica). Two different solute release rules, uniform release and 40/20 release with a CF of 3 , are considered. Model predictions are depicted as two lines that represent the upper and the lower bounds for predictions when the two different intercepts are used in the empirical weathering formulation as described above. As would be expected, the lines for the two different release rules cross each other during the melt. The 40/20 rule is lower at the beginning of the season for alkalinity because of the initial acid pulse, but ends higher than the uniform rule because the solutes already have been eluted, thus leaving less acidic water than the uniform elution case. Similarly, the 40/20 rule exhibits larger changes in concentration during rain events than the uniform release rule.

Considering the model predictions for the inflows during the calibration year 1986, the general pattern of dilution and recovery is reproduced for all solutes (fig. 8). Both silica and SBC are overpredicted during the latter part of the melt period by approximately $10 \mu \mathrm{eq} \mathrm{L}^{-1}$; this overprediction could reflect biotic influences which are not included in the model such as diatomaceous uptake of silica and biotic uptake of calcium, magnesium and potassium during this period. Similarly, model predictions for the lake outflow (fig. 9) show the same general patterns, although SBC and silica are systematically underpredicted by 5 to $10 \mu \mathrm{eq} \mathrm{L} \mathrm{L}^{-1}$ during the first three months of the simulation. This underprediction may result from errors in the distributed melt formulation or may indicate an additional source for these solutes such as ground water.

During the validation year 1987, however, the observed patterns of solute concentrations are not so well reproduced. The minimum alkalinity observed during snowmelt is correctly predicted, but the pattern of dilution during the initial phases of snowmelt is not captured correctly. In the inflows for the uniform release case (which better predicts alkalinity), silica is slightly overpredicted and SBC is substantially underpredicted. In addition, alkalinity is underpredicted during the early part of the snowmelt. These observations taken together suggest that cation exchange, not weathering, is supplying SBC and alkalinity (through consumption of hydrogen ion) during this first phase of melt. Cation exchange was not obvious during 1986 owing to the large volume of water that flowed through the system and to less intensive sampling of surface waters during the beginning of snowmelt. This additional alkalinity-generating mechanism would further ameliorate the acid pulse at the onset of snowmelt. Current model predictions overestimate the loss of alkalinity, and hence, provide a conservative prediction. 


\section{Deposition Scenarios}

To assess the sensitivity of the watershed to different loadings of acidic solutes, two different atmospheric deposition scenarios were considered: one in which both sulfuric acid and ammonium nitrate loadings were doubled, and one in which both of these loadings were halved. Factor analysis indicates that the cations associated with sulfate and nitrate are hydrogen and ammonium, respectively (Lowell Ashbaugh, California Air Resources Board, written commun., 1988). Owing to the nitrogen cycle representation in ALF in which ammonium is exchanged for hydrogen ion, the scenarios are equivalent to changing the nitric acid loading to the system for this model. The results of these scenarios for the lake outlet are shown in figure 10. Again, each case is represented with a pair of lines bounding the predictions. The solid line is the half-loading case and the stippled line is the double-loading case. In figure 10, 1986 is indicative of a heavy snow year and 1987 represents a light snow year. The alkalinity of the system is not very sensitive to changes in loadings. The initial acid pulse causes the alkalinity in the outflow to decrease from about $20 \mu \mathrm{eq} \mathrm{L} \mathrm{L}^{-1}$ under current loadings (uniform release case in figure 9) to about $15 \mu \mathrm{eq} \mathrm{L} \mathrm{L}^{-1}$. The acid pulse is more pronounced under the 40/20 release, as expected, with a minimum observed alkalinity of $8 \mu \mathrm{eq} \mathrm{L}-1$ for 1986 conditions and $12 \mu \mathrm{eq} \mathrm{L}-1$ for 1987 conditions as compared with minimum predicted alkalinities under current deposition of 10 and $15 \mu \mathrm{eq} \mathrm{L}-1$ for 1986 and 1987, respectively. The snowpack loadings required to exhaust the alkalinity of the lake epilimnion, expressed in multiples of the current snow loading for 1986 and 1987, are summarized in table 4. No rain-on-snow events are assumed to occur.

\section{Table 4. Multiples of current deposition loadings of ammonium nitrate} and sulfuric acid required to exhaust alkalinity of Emerald Lake

Solute release rule

Uniform release

40/20 release

$80 / 20$ release
Heavy snow year (1986)

Light snow year (1987)
$11-18$

$7-11$

2-5 

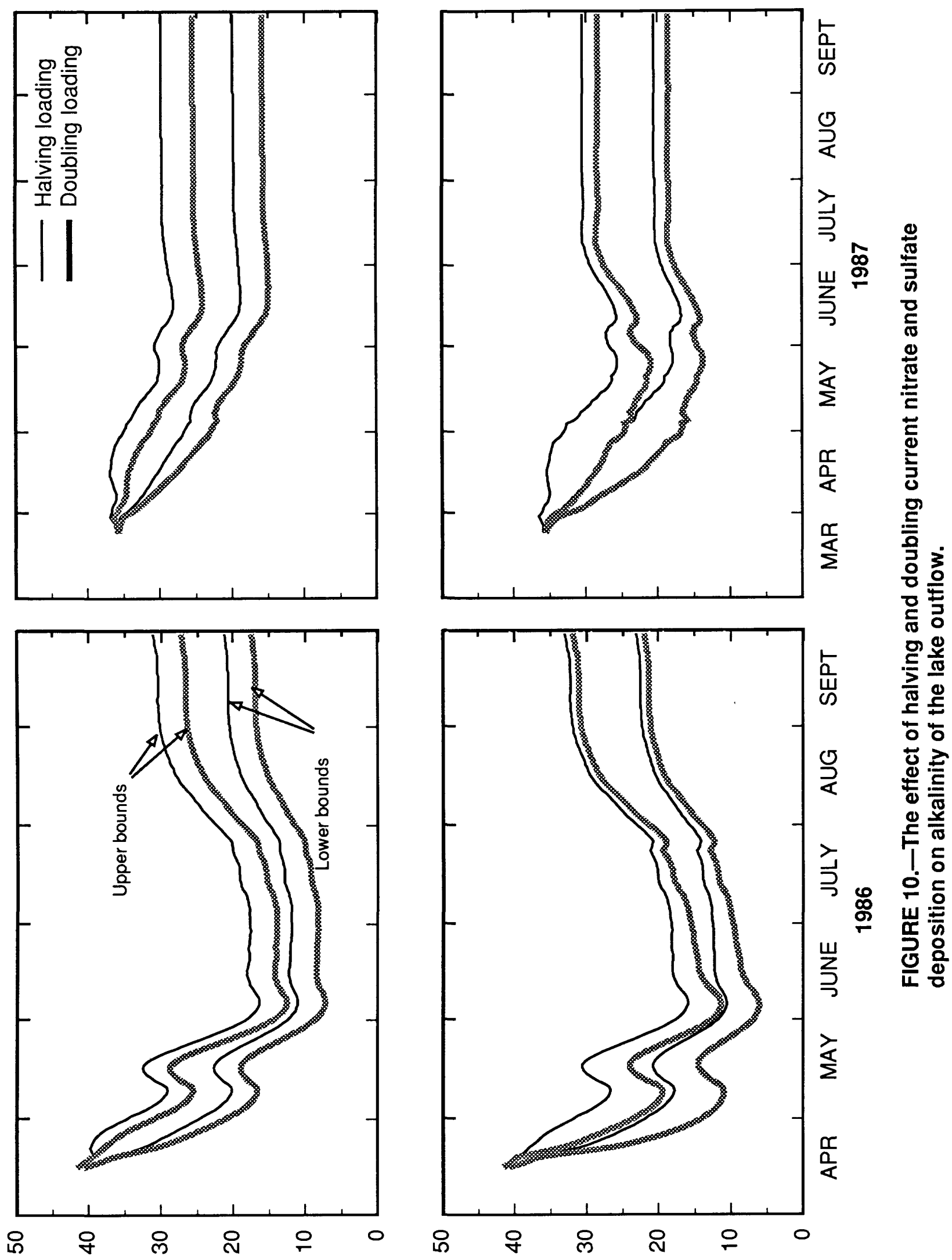

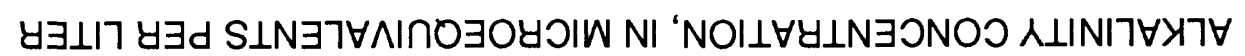




\section{SUMMARY}

This simple process-oriented model is able to capture the basic solute patterns during snowmelt in an alpine catchment where ground water is a minor contributor to streamflow. It includes an empirical representation of primary mineral weathering as the only alkalinity-generating mechanism. The model seems to be adequate during a heavy snow year, such as the one that served as the calibration year for this model. During a light snow year, there is evidence that cation exchange may be a substantial source of alkalinity during the initial phases of snowmelt. By not including cation exchange, the model overestimates the acidification during this period. The minimum observed alkalinity, which occurs through dilution, is predicted correctly by the model. The representation of the lake as simply a mixing volume with no additional chemical reactions is supported by the observations.

Model results indicate a change of 2 to $5 \mu \mathrm{eq} \mathrm{L}^{-1}$ in the minimum alkalinity if the deposition of both ammonium nitrate and sulfuric acid is doubled. This estimate represents an upper bound on the alkalinity change because cation exchange is ignored. The predicted change in alkalinity would be insufficient to exhaust the alkalinity of the lake. Deposition would have to increase between two and 18 times the current loadings to accomplish that; the precise increment depends on hydrologic conditions and on the pattern of solute release from the snowpack. Although these increases in deposition seem to be very large, one should remember that current loadings to the system are low. The most likely scenario for acidification of Emerald Lake under conditions ranging from current to double the present-day deposition is an acidic rainstorm occurring during the latter part of snowmelt when the lake is at its minimum alkalinity owing to dilution from the meltwater. Such an event was observed in summer 1984. The infrequency of rainstorms in the Sierra Nevada, however, makes intensive sampling of storms difficult.

\section{CONCLUSIONS}

From this analysis of the data collected at Emerald Lake, additional avenues of research can be suggested both for modeling and field investigation. The simple form of ALF and its modest data requirements should allow for its widespread application in watersheds that are less intensively studied than Emerald Lake. The model can be calibrated with only water-quality and quantity measurements from the outflow of the lake. To run the model for any particular year requires an estimate of solute loadings in the pack. If there are no internal sources or sinks of sulfate and chloride in the watershed, these loadings can be estimated from the mass export from the watershed. Application of ALF to other watersheds in the Sierra Nevada would permit a regional assessment of the risk of episodic acidification. 
The pattern of solute release from the snowpack is not consistent across the "nonreactive" solutes. In particular, sulfate, typically the mobile anion in such watersheds, has a surprisingly constant concentration in streamwater given the small amount of soil in the watershed. At a high altitude catchment in Scotland, sulfate concentration varied between 20 and $80 \mu \mathrm{eq} / \mathrm{L}$ during spring and summer, a factor of 4 (Cooper and others, 1987). Point measurements at Emerald Lake (Williams and Melack, 1988) and laboratory studies suggest that an acidic pulse should come from the pack at the beginning of snowmelt. However, stream concentrations of chloride, the least reactive solute, indicate a less intense ionic pulse than point measurements. Additional field observations and experiments need to be conducted to determine whether there are regulating mechanisms in the soil which control the sulfate concentration or whether these packs, due to the steep slope, ice lenses, mixing of waters at different stages of solute elution, or some other factor, do not in effect produce an acid pulse on the catchment scale. If the pack effectively elutes its solutes uniformly at this scale, an additional source for the observed nitrate and chloride peak must be identified. The apparent attenuation of the acid pulse, whatever its cause, renders this watershed much less sensitive to acidification from an acidified snowpack than if such a pulse existed.

The input-output budgets for sulfate and chloride were inconsistent between the two years of intensive study at Emerald Lake. The chloride input for 1986 is suspect due to sample contamination, but the sulfate budget deserves further study because the differences are too large to be attributable solely to sampling or analytical error. The most important distinction between the two years may be the size of the snowpack. The large amount of water in 1986 may have been able to leach more sulfate out of the watershed than in 1987, resulting in a net export in 1986 but a net retention in 1987. If this explanation is true, the chemical dynamics at Emerald Lake are more complicated than first thought both because sulfate is a reactive ion and because the flowpath through the watershed would determine the streamwater chemistry.

Paired mini-catchments having an area of several hundred square meters need to be identified at Emerald Lake to investigate sulfate regulation mechanisms. These catchments would represent the extremes in soil interaction; that is, one should have only bare bedrock and the other should be predominantly covered with soil. Meltwater draining the bare rock catchment would be affected by soil or talus, and thus, the existence or absence of an acidic pulse from the snowpack could be ascertained. In addition to runoff, soil solutions prior to and during the initial phases of melt need to be monitored to determine the effects of the soil on the "nonreactive" solutes.

Under current depositional loads and even with double the current loads, the Emerald Lake watershed is more susceptible to acidification from an acidic rainstorm which falls during the late melt period when the lake is its most dilute than to acidification from a acidic snowpack. The infrequency of such events in the Sierra Nevada makes sampling difficult. One field effort that is feasible and that may shed some light on the watershed's response to acidic pulses is intensive sampling over the daily melt cycle. Sampling during early, mid and late melt season would provide information on the watershed's chemical response to more acidic pulses, to clean pulses, and to clean pulses after the system has been strongly leached. In addition if sampling were carried out at points above and below the inflow meadow, then the influence of vegetation could be assessed. 


\section{REFERENCES CITED}

Brimblecombe, P., Clegg, S.L., Davies, T.D., Shooter, D., and Tranter, M., 1987, Observations of the preferential loss of major ions from melting snow and laboratory ice: Water Research, $v$. 21 , p. $1279-1286$.

Bytnerowicz, Andrew and Olszyk, D.M., 1988, Measurement of atmospheric dry deposition at Emerald Lake in Sequoia National Park: Sacramento, Ca., California Air Resources Board, Final Report, Contract A7-32-039, 48 p.

California Air Resources Board, 1986, The fourth annual report to the governor and the legislature on the Air Resources Board's acid deposition research and monitoring program: Sacramento, CA, 374 p.

Chen, C.W., Gherini, S.A., Hudson, R.J.M., and Dean, J.D., 1983, The integrated lakewatershed acidification study: Model principles and application procedures: Lafayette, Ca., Tetra Tech, Inc., EPRI Report EA-3221, v. 1, RP 1109-5, 188 p.

Christophersen, Nils, Dymbe, L.H., Johannessen, Merete, and Seip, H. M., 1984, A model for sulphate in streamwater at Storgama, southern Norway: Ecological Modelling, v. 21, p. 35-61.

Clow, David, 1987, Geologic controls on the neutralization of acid deposition and on the chemical evolution of surface and ground waters in the Emerald Lake watershed, Sequoia National Park, California: Fresno, Ca., unpublished Masters Thesis, California State University, 216 p.

Cooper, D.M., Morris, E.M. and Smith, C.J., 1987, Precipitation and streamwater chemistry in a subarctic Scottish catchment: Journal of Hydrology, v. 93, p. 221-240.

Dozier, Jeff, 1988, Topographic distribution of solar radiation over an alpine, snow-covered drainage basin [abs]: Eos Transactions of American Geophysical Union, v. 69, p. 1198.

Dozier, Jeff, Melack, J.M., Marks, Daniel, Elder, Kelly, Kattelmann, Richard, and Williams, Mark, 1989, Snow deposition, melt, runoff, and chemistry in a Sierra Nevada watershed: Sacramento, Ca., California Air Resources Board, Final Report, Contract A6-147-32, 268 p.

Dracup, J.A., Melack, J.M., Marks, Daniel, Kattelmann, Richard, and Sickman, J. O., 1989, The hydrologic mass balance of the Emerald Lake basin, Sequoia National Park, California: Sacramento, Ca., California Air Resources Board, Final Report, Contract A4-123-32, 160 p.

Drever, J.I., 1988, The Geochemistry of Natural Waters (2nd ed.): Englewood Cliffs, New Jersey, Prentice-Hall, 437 p.

Johannessen, Merete and Henriksen, Arne, 1978, Chemistry of snow meltwater-changes in concentration during melting: Water Resources Research, v. 14, p. 615-619.

Leivested, H. and Muniz, I.P., 1976, Fish kill at low pH in a Norwegian river: Nature, v. 259, p. 391-392.

Lund, L.J., Brown, A.D., Lueking, M.A., Nodvin, S.C., Page, A.L., Sposito, Garrison, 1987, Soil processes at Emerald Lake Watershed: Sacramento, Ca., California Air Resources Board, Final Report, Contract A3-105-32, 114 p. 
Marks, Daniel, 1988, Climate, energy exchange, and snowmelt in Emerald Lake watershed, Sierra Nevada: Santa Barbara, CA, unpublished Ph.D. thesis, Univ. of California, 158 p.

Melack, J.M., Cooper, S.D., Jenkins, T.M., Jr., Barmuta, Leon, Hamilton, Scott, Kratz, Kimberly, Sickman, James, and Soiseth, Chadwick, 1989, Chemical and biological characteristics of Emerald Lake and the Streams in its watershed, and the responses of the lakes and streams to acidic deposition: Sacramento, Ca., California Air Resources Board, Final Report, Contract A6-184-32, 377 p.

Miller, S.A., 1950, Some snow-melt runoff characteristics: Eos Transactions of the American Geophysical Union, v. 31, p. 741-745.

Morel, François and Morgan, J.J., 1972, A numerical method for computing equilibria in aqueous chemical systems: Environmental Science and Technology, v. 6, p. 58-66.

Nishida, A.I. and Schnoor, J.L., 1989, Steady state model to determine lake resources at risk to acid deposition in the Sierra Nevada, California: Sacramento, Ca., California Air Resources Board, Final Report, Contract A7-32-036, 189 p.

Peters, N. E., 1987, Chloride cycling in forested lake watersheds in the west-central Adirondack Mountains, New York [abs]: Prague, Czechoslovakia, GEOMON, International Workshop on Geochemistry and Monitoring in Representative Basins, May, 1987: Geological Survey, Prague, p. 264-266.

Skartveit, A. and Gjessing, K.T., 1979, Chemical budgets and chemical quality of snow and runoff during spring snowmelt, Nordic Hydrology: v. 10, p. 141-154.

Sorooshian, Soroosh, Bales, R.C., Gupta, V.K., Noppe, P.A., and Wolford, R.A., 1989, Development of watershed models for Emerald Lake watershed in Sequoia National Park and for other lakes of the Sierra Nevada: Sacramento, Ca., California Air Resources Board, Final Report, Contract A732-035, 64 p.

Stephenson, N.L., 1988, Climatic control of vegetation distribution-The role of the water balance with examples from North American and Sequoia National Parks: Ithaca, New York, unpublished Ph.D. dissertation, Cornell University, 295 p.

Swift, L.W., 1976, Algorithm for solar radiation on mountain slopes:Water Resources Research, v. 12 , p. $108-112$.

Weintraub, Jill, 1986, An assessment of the susceptibility of two alpine watershed to surface water acidification-Sierra Nevada, California: Bloomington, Ind., unpublished Masters Thesis, Indiana University, $186 \mathrm{p}$.

Williams, M. W. and Melack, J.M., 1988, Snowpack runoff contributions to the major solute chemistry of lake and stream waters in a high-altitude watershed in the Sierra Nevada [abs], Eos Transactions of the American Geophysical Union, v. 69, p. 1198.

Wyles, W.S., 1986, The buffering capacity of Sierra Nevadan soils exposed to simulated acid precipitation: Davis, Ca, Univ. of California, unpublished Masters Thesis, $188 \mathrm{p}$. 


\section{APPENDIX A.}

\section{Sample input/output from computer model}

This attachment contains sample input which are necessary to run the computer model and samples of the output which the computer generates. The files are annotated by using Times-Roman typeface, the same typeface as this is written in. The contents of the files and any prompts which the computer types are written in Helvetica typeface, as these words are.

As the model runs, it executes a series of prompts for the names of the input files. Note that no output file name is requested since they are based on the name of the main input file. A sample dialog follows.

RUN DIST.86.CPL *User types the appropriate system command to execute the program

15 Mar 89 11:16:36 Wednesday

ENTER NAME OF MAIN INPUT FILE:

ILWAS $>$ IN.WY86>1861/18A3.5*User enters names of files are requested

ENTER NAME OF RAIN INPUT FILE:

ILWAS $>$ IN.WY86>RAIN.WY86

ENTER NAME OF ICE ELEV INPUT FILE:

ILWAS>IN.WY86>ICELEV.WY86

ENTER NAME OF PRE 10 DAYS Q INPUT FILE:

ILWAS $>$ IN.WY86>Q10DAY

ENTER NAME OF OBS STREAM INPUT FILE:

ILWAS $>$ IN.WY86>IN.1

ENTER NAME OF OBS LAKE OUTPUT FILE:

ILWAS $>$ IN.WY86>OUT.CONC

ENTER NAME OF OBS STREAM TEMP FILE:

ILWAS $>$ IN.WY86>IN.TEMP

ENTER NAME OF OBS THERMOCLINE:

ILWAS $>$ IN.WY86>THERMO.WY86

$\mathrm{JD}=198 *$ Computer indicates which day it is working on

$\mathrm{JD}=199$

$\mathrm{JD}=200$

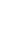

-

$\mathrm{JD}=\quad 362$

$\mathrm{JD}=363$

$J D=\quad 364$

$\mathrm{JD}=\quad 365$

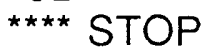


The required input files follow.

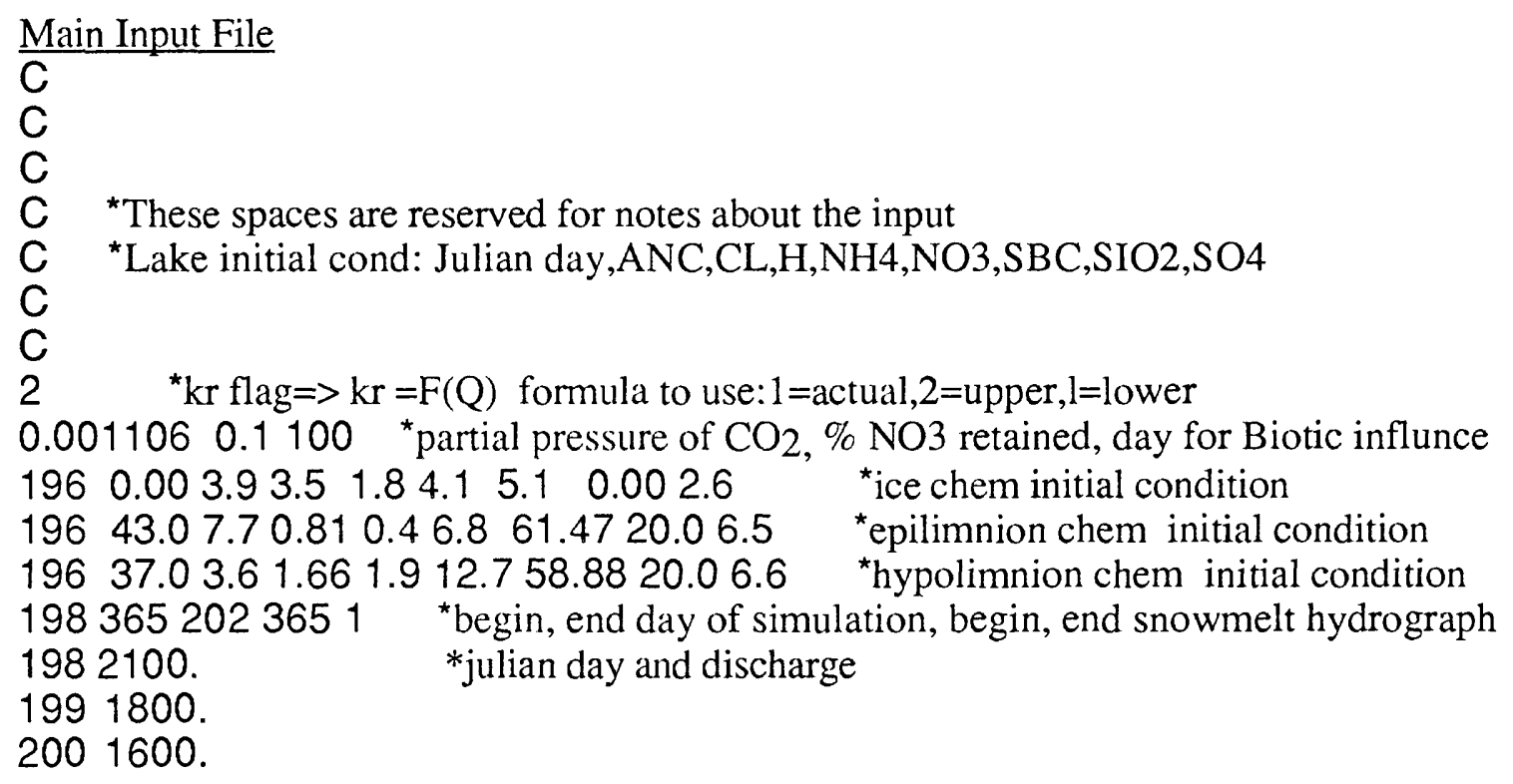


$\underline{\text { Rain data input file }}$

29714.87415 .359722 .924 .9420 .214 .79 *julian day, SBC CL NO3 NH4 SO4 H

$\begin{array}{lllllll}324 & 24.2725 & 10.437 & 25.8 & 8.869 & 9.369 & 4.467\end{array}$

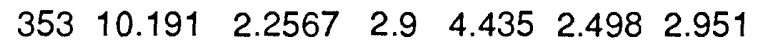

Ice elevation file (elevation of ice/epilimnion interface):

$1964.5 *$ julian day, elevation

1974.53125

1984.5625

36410.5

36510.5

10-day average flow file (assumed to cover entire water year):

2763.2

2198.7

1915.1

1606.7

2170.1

1962

1791

1616.7

1715.2

2053.2

Chemical observations from main inflow:

$198368.778 .047 .341 .47910 .861 .433 .5 *$ julian day, $\mathrm{ANC}, \mathrm{Cl}, \mathrm{NO}_{3}, \mathrm{SO}_{4}, \mathrm{H}, \mathrm{NH}_{4}, \mathrm{SBC}, \mathrm{SIO}_{2}$ 21327.76 .04510 .96757 .60251 .19770 .32547 .522537 .175

21426.26 .17511 .397 .790 .891490 .1548 .6936 .35

21726.84 .7959 .796 .661 .2466049 .3140 .85

Chemical Observations for lake outflow:

2135.98 1.0471E-06 0.2 32.5 5.8 10.15845 .6556 .4 *J-DAY,pH,H,NH $4, A N C, C L, N_{3}, \mathrm{SO}_{4}, \mathrm{SIO}_{2}, \mathrm{SBC}$ $2145.981 .0471 E-060.1355 .49 .97 .24553 .2$

$2186.049 .1201 E-070.1356 .910 .66 .643 .956 .7$ 
Inflow stream temperature file:

$1980.13875 *$ Julian day and temperature

1990.185

2000.23125

Thermocline elevation file:

0.00 .0 *elevation, julian day. Code interpolates to obtain daily values.

0.025 .0

7.672 .0

8.599 .

8.0126.

2.5191 .

2.5230 .

0.275 .

0.302.

5.5317 .

3.5337 .

1.0351 .

0.357 .

0.365 .

Output files There are fourteen output files produced by the program. All have a leading asterisk to allow for importation to a graphics package. Fields are tab delimited. The following is a list of these files with an explanation of what each contains.

$\begin{array}{ll}\text { D1861/18A3.5 } & \text { sub-unit \#1 } \\ \text { D2861/18A3.5 } & \text { sub-unit \#2 } \\ \text { D3861/18A3.5 } & \text { sub-unit \#3 } \\ \text { D3861/18A3.5 } & \text { sub-unit \#4 } \\ \text { D5861/18A3.5 } & \text { sub-unit \#5 } \\ \text { D6861/18A3.5 } & \text { sub-unit \#6 } \\ \text { D7861/18A3.5 } & \text { sub unit \#7 } \\ \text { I861/18A3.5 } & \text { snowmelt, calc inflow, observed inflow, for constructing bar } \\ \text { L861/18A3.5 } & \text { graphs } \\ \text { RL861/18A3.5 } & \text { calculput } \\ \text { RS861/18A3.5 } & \text { calculated vs observed, lake outflow } \\ \text { S861/18A3.5 } & \text { combined stream inflow (d1 through d7) } \\ \text { V861/18A3.5 } & \text { a text file for printing various daily information for visual } \\ & \text { review } \\ \text { VOL861/18A3.5 } & \text { jday, total, ice, epilimnion, and hypolinion volumes }\end{array}$


D1861/18A3.5

\begin{tabular}{|c|c|c|c|c|c|c|c|c|c|c|c|c|}
\hline JDAY & $Q$ & ANCST & CLST & DOCST & HST & NH4ST & NO3ST & SBCST & SIO2ST & SO4ST & $+/-B A L I$ & $\mathrm{PH}$ \\
\hline 202 & 368.094 & 34.467 & 2.439 & 0.000 & 0.598 & 0.000 & 1.941 & 43.141 & 39.444 & 4.295 & 0.000 & 6.223 \\
\hline 203 & 716.812 & 33.910 & 2.439 & 0.000 & 0.607 & 0.000 & 1.941 & 42.584 & 38.887 & 4.295 & 0.000 & 6.217 \\
\hline 204 & 908.620 & 33.140 & 2.439 & 0.000 & 0.621 & 0.000 & 1.941 & 41.814 & 38.117 & 4.295 & 0.000 & 6.207 \\
\hline 205 & 709.459 & 32.575 & 2.439 & 0.000 & 0.631 & 0.000 & 1.941 & 41.249 & 37.552 & 4.295 & 0.000 & 6.200 \\
\hline 06 & 700.403 & 32.039 & 2.439 & 0.000 & 0.641 & 0.000 & 1.941 & 40.713 & 37.016 & 4.295 & 0.000 & 6.193 \\
\hline U & 903.974 & 31.345 & 2.439 & 0.000 & 0.655 & 0.000 & 1.941 & 40.018 & 36.322 & 4.295 & 0.000 & 6.184 \\
\hline 8 & 948.512 & 30.626 & 2.439 & 0.000 & 0.669 & 0.000 & 1.941 & 39.300 & 35.604 & 4.295 & 0.000 & 6.174 \\
\hline
\end{tabular}

1861/18A3.5:

\begin{tabular}{lcrrrrrrrr} 
IONS & J DAY & SBC & ANC & CL & \multicolumn{1}{c}{ DOC } & \multicolumn{1}{c}{$H$} & NO3 & SO4 & NH4 \\
CATIONSINPUT(S) & 198 & 1.50 & 0.00 & 0.00 & 0.00 & 1.74 & 0.00 & 0.00 & 0.77 \\
ANIONSINPUT(S) & 198 & 0.00 & 0.00 & 1.99 & -0.01 & 0.00 & 1.08 & 0.94 & 0.00 \\
CATIONSCALC & 198 & 40.78 & 0.00 & 0.00 & 0.00 & 0.56 & 0.00 & 0.00 & 0.00 \\
ANIONSCALC & 198 & 0.00 & 36.89 & 1.99 & -0.01 & 0.00 & 0.97 & 0.94 & 0.00 \\
CATIONSOBS & 198 & 61.40 & 0.00 & 0.00 & 0.00 & 1.48 & 0.00 & 0.00 & 0.80 \\
ANIONSOBS & 198 & 0.00 & 36.00 & 8.77 & -3.53 & 0.00 & 8.04 & 7.34 & 0.00 \\
& & & & & & & & & \\
CATIONSINPUT(S) & 199 & 1.50 & 0.00 & 0.00 & 0.00 & 1.74 & 0.00 & 0.00 & 0.77 \\
ANIONSINPUT(S) & 199 & 0.00 & 0.00 & 1.99 & -0.01 & 0.00 & 1.08 & 0.94 & 0.00 \\
CATIONSCALC & 199 & 40.82 & 0.00 & 0.00 & 0.00 & 0.56 & 0.00 & 0.00 & 0.00 \\
ANIONSCALC & 199 & 0.00 & 36.93 & 1.99 & -0.01 & 0.00 & 0.97 & 0.94 & 0.00
\end{tabular}

\section{L861/18A3.5:}

\begin{tabular}{lllllllllllll} 
JDAY & $\mathrm{Q}$ & \multicolumn{1}{c}{ ANC LK } & CL LK & DOCLK & HLK & NH4 LK & NO3 LK & SBCLK & SIO2 LK & SO4 LK & PHLK \\
198 & 2100.8 & 41.9 & 7.3 & -1.2 & 0.8 & 0.4 & 6.4 & 60.0 & 21.4 & 6.1 & 6.1 \\
199 & 1744.5 & 40.8 & 6.9 & -1.1 & 0.8 & 0.4 & 6.0 & 57.8 & 22.0 & 5.7 & 6.1 \\
200 & 1551.3 & 39.7 & 6.6 & -1.1 & 0.9 & 0.4 & 5.7 & 55.9 & 22.5 & 5.4 & 6.1 \\
201 & 1732.2 & 38.8 & 6.3 & -1.0 & 0.9 & 0.4 & 5.4 & 54.1 & 23.0 & 5.1 & 6.0 \\
202 & 3500.0 & 37.7 & 5.8 & -0.9 & 0.9 & 0.4 & 5.0 & 52.1 & 24.3 & 5.0 & 6.0 \\
203 & 6800.0 & 36.5 & 5.2 & -0.7 & 0.9 & 0.3 & 4.5 & 49.6 & 26.6 & 4.8 & 6.0 \\
204 & 8600.0 & 35.3 & 4.6 & -0.5 & 0.9 & 0.3 & 3.9 & 47.3 & 28.8 & 4.7 & 6.1 \\
205 & 6700.0 & 34.3 & 4.2 & -0.4 & 0.9 & 0.3 & 3.6 & 45.6 & 29.9 & 4.6 & 6.1 \\
206 & 6600.0 & 33.5 & 3.9 & -0.4 & 0.9 & 0.2 & 3.3 & 44.2 & 30.6 & 4.5 & 6.1 \\
207 & 8500.0 & 32.7 & 3.6 & -0.3 & 0.9 & 0.2 & 3.0 & 42.8 & 31.4 & 4.4 & 6.1 \\
208 & 8900.0 & 31.9 & 3.3 & -0.2 & 0.9 & 0.2 & 2.8 & 41.5 & 31.9 & 4.4 & 6.1
\end{tabular}




\section{APPENDIX B.}

\section{Model Listing}

The following is a listing of the program code. It has been written in standard FORTRAN77. The only system-specific statements are the \$INSERT statements, which are called \$INCLUDE in some operating systems.

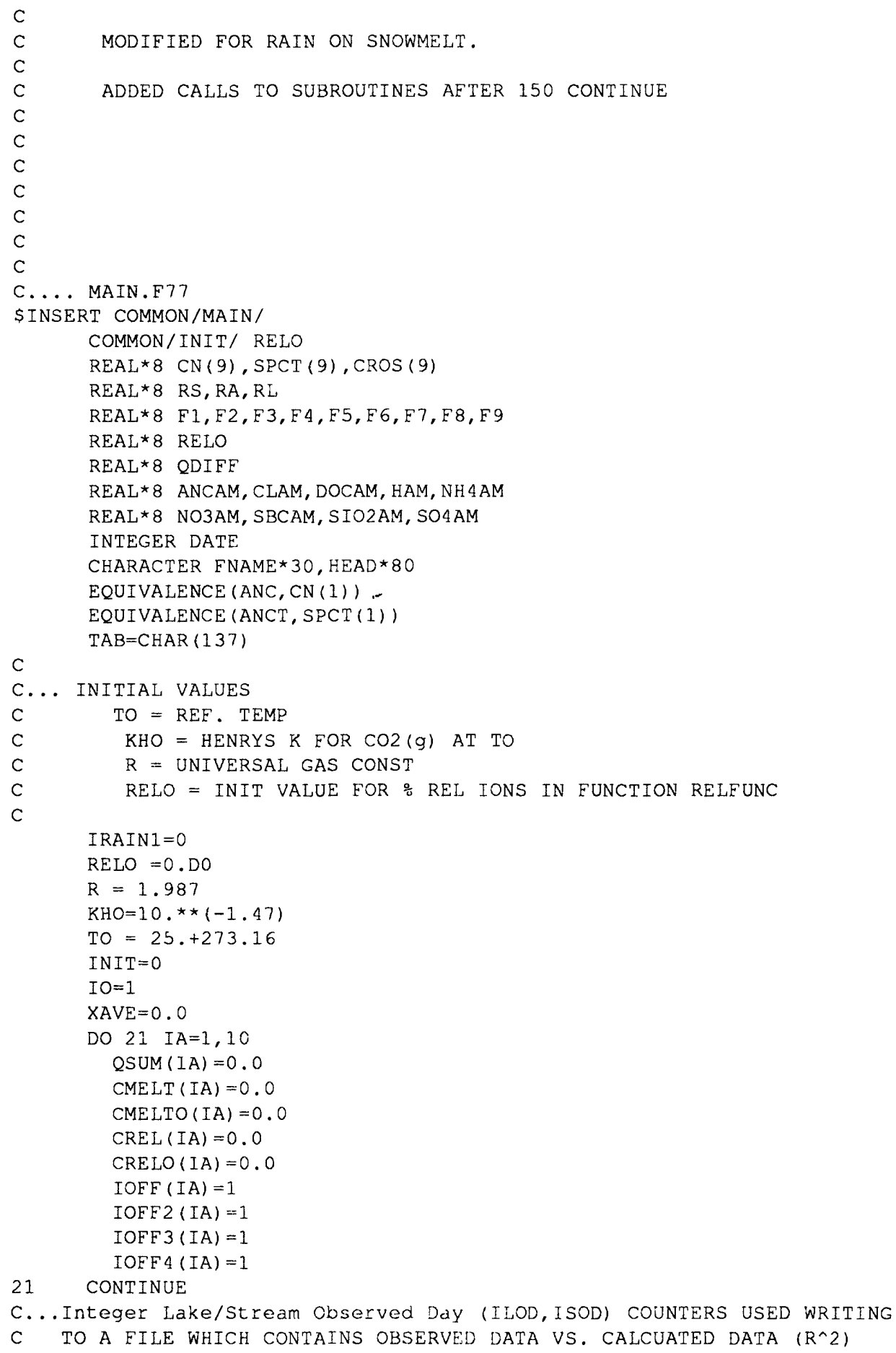


$I L O D=1$

$I S O D=1$

C...IR IS A DAILY COUNTER FOR RAIN DAY CONCENTRATIONS $I R=1$

C

C... CALL FILER TO OPEN IN/OUTPUT FILES, READ INITIAL CONDITIONS CALL FILER

C... CALL LAKE AND GIVE IT THESE CONDITIONS:

CALL LAKE (1)

C... CALL DISTM AND DISTRIBUT IHE DISCHARGE AND IONS, CALC RELEASE RULE CALL DISTM

C

C... BEGIN DAILY TIME STEPS

IPC $=1$

NPTS $=J D N-J D 1+1$

DO $50 \mathrm{I}=\mathrm{JD} 1, \mathrm{JDN}, 1$

$\mathrm{NRR}=0$

$X D A T(I P C)=F L O A T(I)$

JDAY $==I$

WRITE $(*, *)$ ' JD $=$ ', JDAY

C WRITE $(*, *) \operatorname{QSU}(4, \operatorname{JDAY})$

C...READ DAILY INFLOW TEMP IN CELCIUS

$\operatorname{READ}(20$, *) JY, ST

C

C... CONVERT INFLOW TEMP TO KELVINS

$\mathrm{ST}=\mathrm{ST}+273.16$

$\mathrm{C}$

C...MEMORY, FOR Q vs. Kr

IF (MEM.EQ.1) THEN

$\mathrm{QT}=0.0$

52

DO $52 \mathrm{~J}=0,9$

QT $=Q T+S H(I-J)$

ELSE

$\mathrm{QT}=\mathrm{SH}(\mathrm{I})$

ENDIF

C

C... ARE WE BEFORE, DURING, OR AFTER THE MELT.

IF (JDAY. LT. JBM) THEN

GOTO 200

ELSEIF (JDAY.GT. JEM) THEN

GOTO 300

ENDIF

C

$\mathrm{C}$

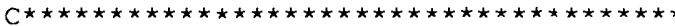

C... HERE WE DO DISTRIBUTED MELT, JDAY . GE. JBM . AND. JDAY .LT. JEM

C... THE Q FOR EACH SUB UNIT IS IN ARRAY AQSU(IA, ND) WHERE IA IS THE

C... SUB UNIT AND ND IS THE DAY. ANOTHER ARRAY, ND(IA) HAS THE DAY

C... THAT EACH SUB UNIT DRIES UP

c

C... FIRS'T WE CHECK FOR RAIN ON SNON.

c

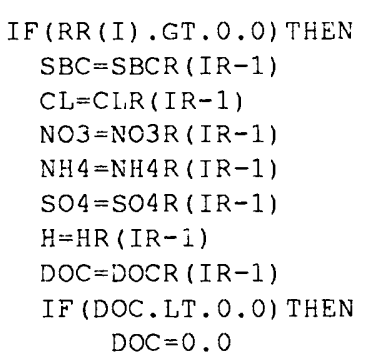


ENDIF

C WRITE(*,*)'CALL NRWEATH 1'

CALL NRWEATH

DO 152 IJK=1, 9

CROS $(I J K)=C N(I J K)$

152

CONTINUE

ENDIF

C

C... CALCUlate PRECENTAGE OF IONS RELEASED FROM EACH SUB UNIT

C... CONVERT EQ/M**3 TO UEQ/I, WHERE QSU IS IN METERS CUBED

DO 150 IA $=1$, NSU

IF (JDAY.GT.ND (IA, 1)) GOTO 150

DO 151 IC $=1,9$

IF (IC.EQ.1.OR. IC.EQ.8) THEN

$\mathrm{CN}(I C)=0 . \mathrm{DO}$

GOTO 151

ENDIF

$\mathrm{T}=\mathrm{T} I \mathrm{IME}(\mathrm{JDAY}, I \mathrm{~A}, \mathrm{IC})$

C. . UNITS UEQ/L

IF (JDAY.GT.TSTAR (JDAY, IA, IC) ) THEN

C

c

IF (IC.EQ.2. AND. IA.EQ.4) WRITE(*,*)'AFTER T*'

$C N(I C)=A B(J D A Y, I A, I C, 3) \star E X P(-A B(J D A Y, I A, I C, 4) \star T) \star 1000$.

ELSE

C IF (IC.EQ.2.AND.IA.EQ.4)WRITE $\left(\star^{\star},{ }^{\star}\right)$ 'BEFORE T*'

$C N(I C)=A B(J D A Y, I A, I C, 1) \star E X P(-A B(J D A Y, I A, I C, 2) \star T) \star 1000$. ENDIF

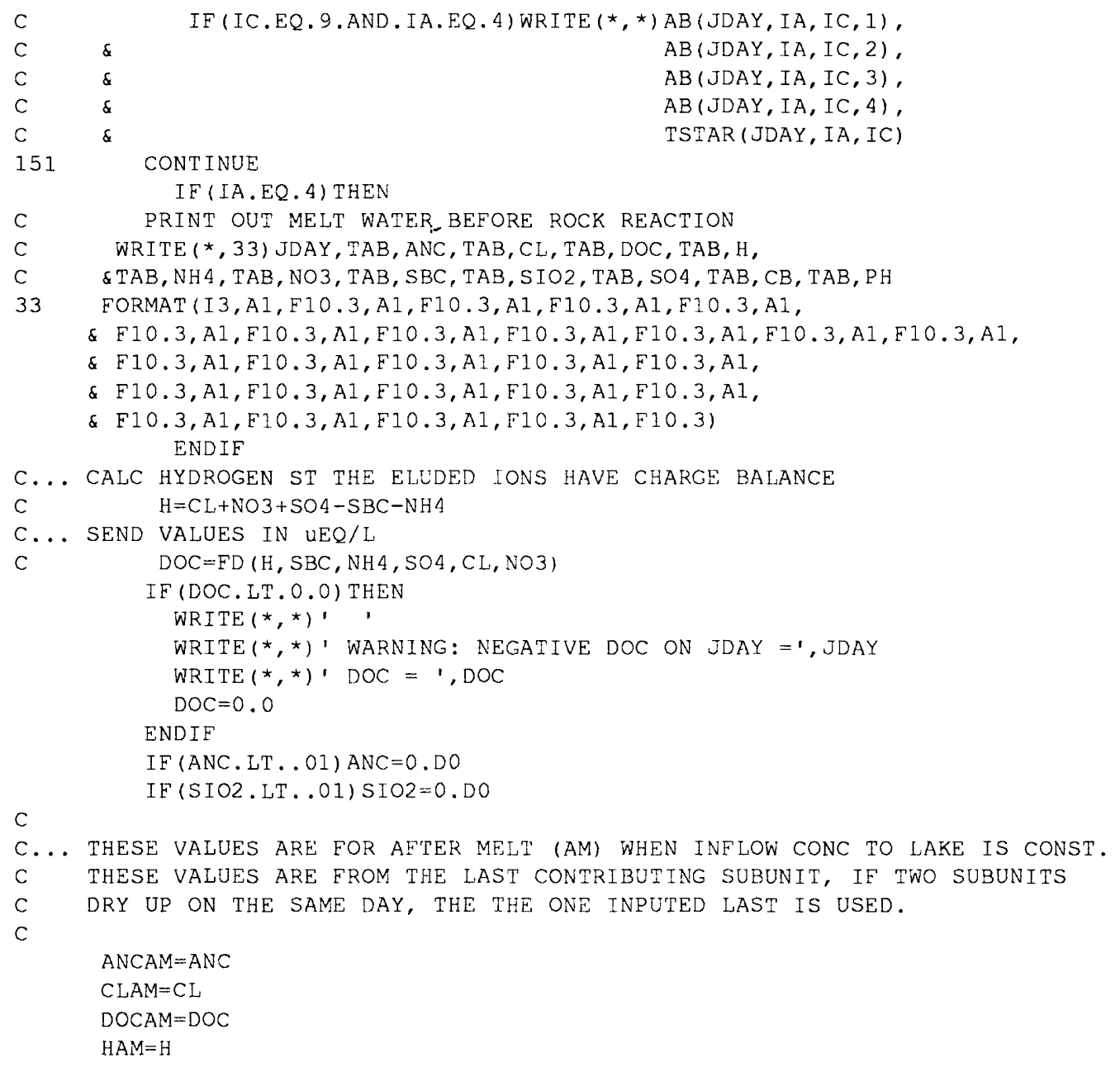




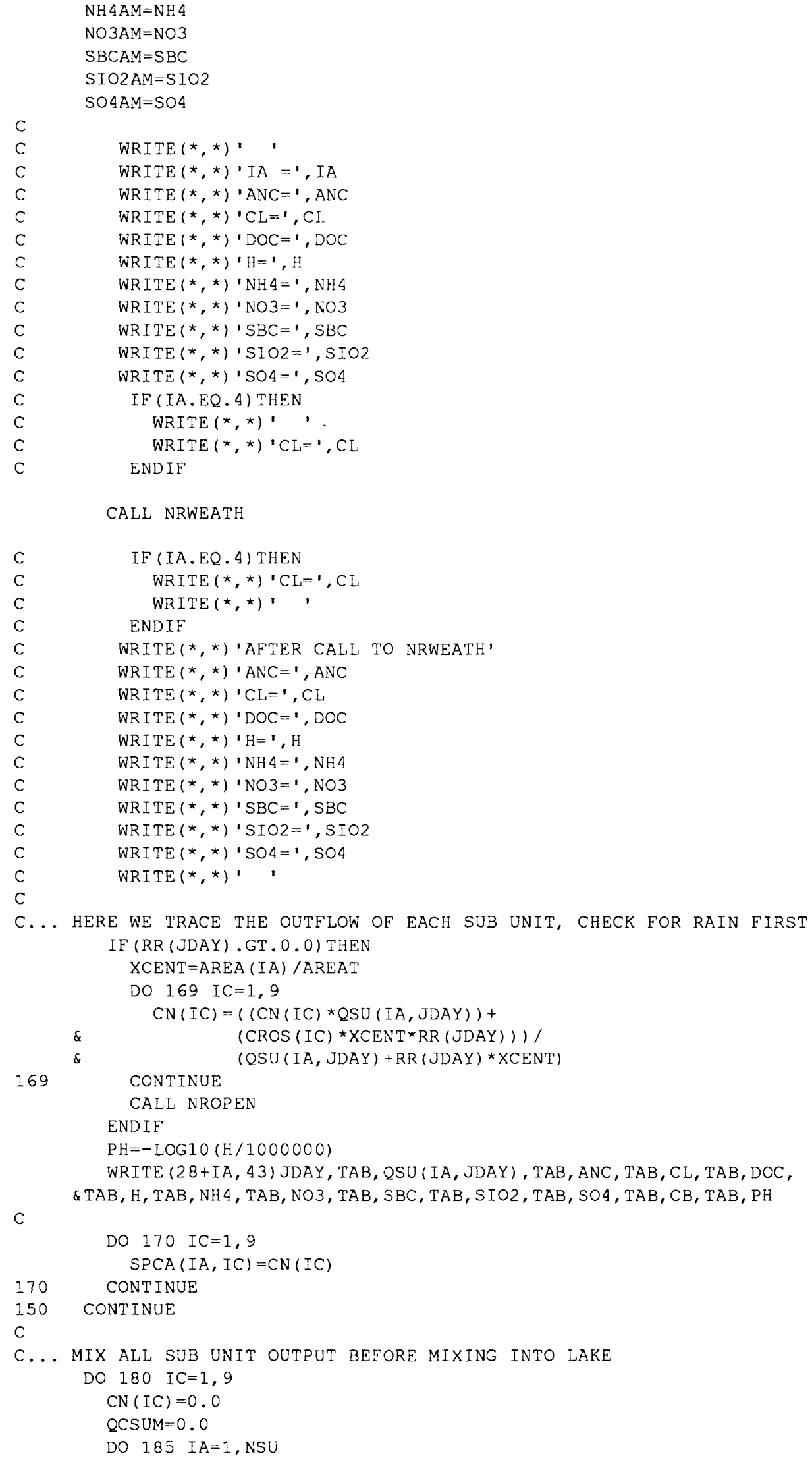




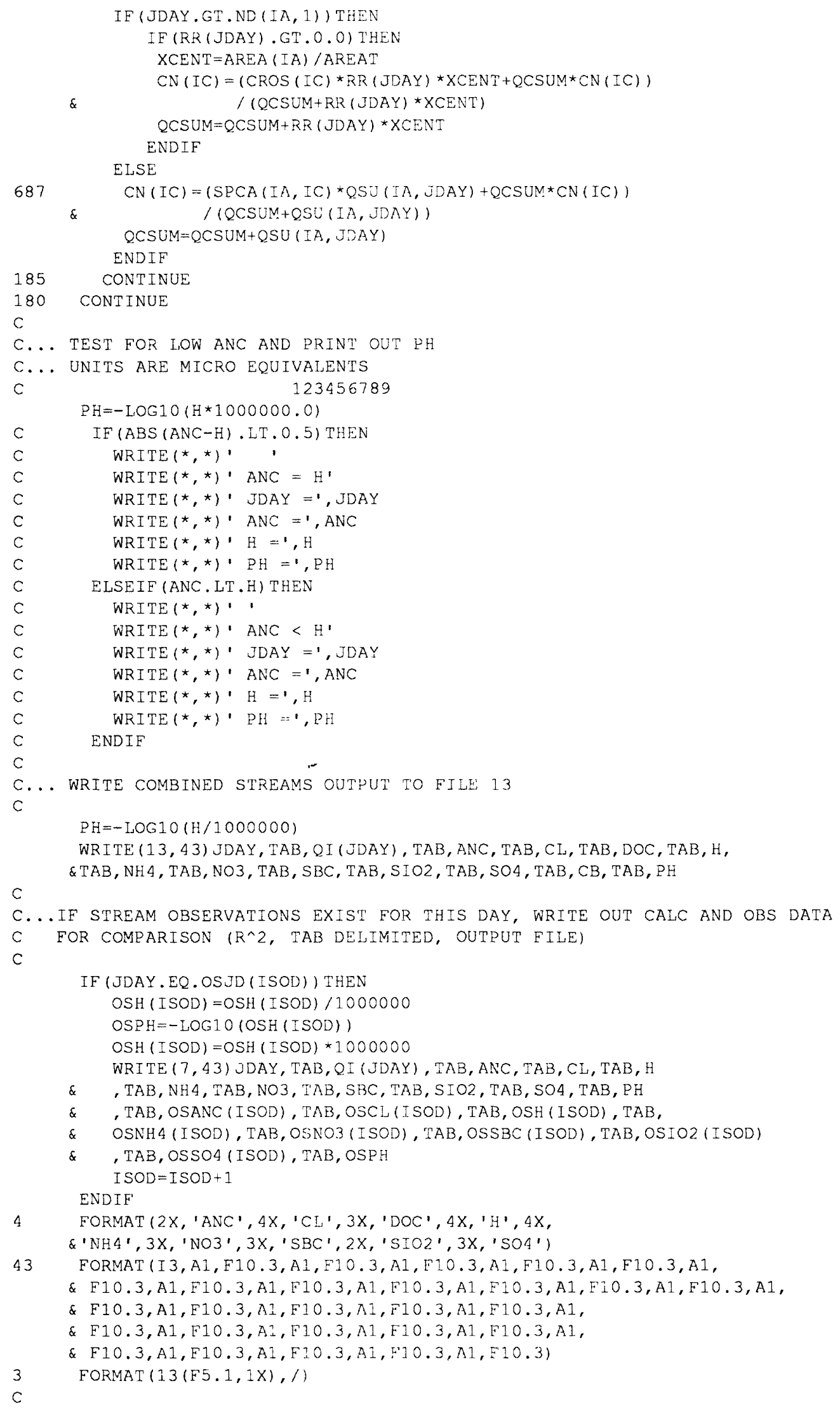




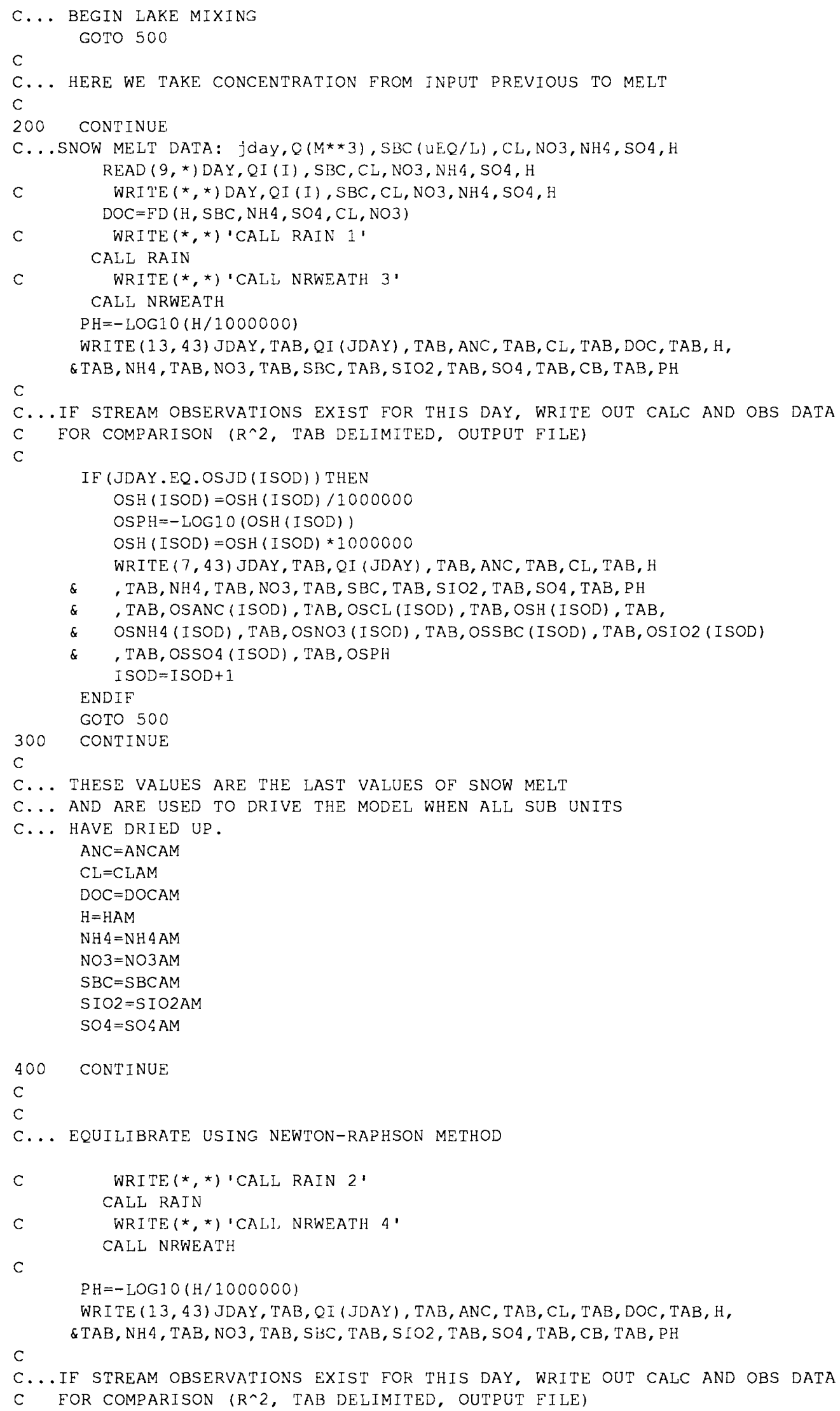


C

IF (JDAY.EQ.OSJD (ISOD) ) THEN

OSH (ISOD $)=O S H($ ISOD $) / 1000000$

OSPH $=-L O G 10(O S H(I S O D))$

OSH (ISOD) $=O S H($ ISOD $) \star 1000000$

WRITE (7, 43) JDAY, TAB, QI (JDAY), TAB, ANC, TAB, CL, TAB, H

\& , TAB, NH4 $, T A B, N O 3, T A B, S B C, T A B, S I O 2, T A B, S O 4, T A B, P H$

\& , TAB, OSANC (ISOD), TAB, OSCL (ISOD), TAB, OSH (ISOD), TAB,

\& OSNH4 (ISOD), TAB, OSNO3 (ISCD), TAB, OSSBC (ISOD), TAB, OSIO2 (ISOD)

$\& \quad, T A B, O S S O A$ (ISOD), TAB, OSPH

ISOD $=I S O D+1$

ENDIF

$\mathrm{C}$

C... HERE WE JUMP BACK IN AFTER THE DISTRIBUTED MELT, MELT ENDED

C... AND BEFORE THE BEGINNING OF MELT

500 CONTINUE

C

C... OUTPUT IONIC STRENGTHS OF INPUT (SNOW MELT OR RAIN),

C... CALCULATED LAKE INELOW, AND OBS STREAM INFLOW.

C

C WRITE $(*, *)$ ' CALL IONIC I'

CALL IONIC

C

C... MIX WITH LAKE VOLUME

C WRITE $(*, *)$ ' CALL LAKE 1 '

CALL LAKE (0)

$\mathrm{C}$

C... PRINT OUTPUT

DO $40 \mathrm{~J}=1,9$

$40 \quad \mathrm{CN}(\mathrm{J})=\mathrm{QI}(\mathrm{JDAY}){ }^{\star} \mathrm{CN}(\mathrm{J}) \star 0.001$

C WRITE $\left(15,{ }^{*}\right)$ ' OUTFLOW LOADING, EQ'

C WRITE $(15,4)$

C WRITE $(15,7)(\mathrm{CN}(I J I), I J I=1,9)$

7 FORMAT $(13(\mathrm{~F} 8.1,1 \mathrm{X}), 1)$

88 FORMAT $(13(\mathrm{~F} 8.2, \mathrm{~A} 2))$

$I P C=I P C+1$

IRAIN $1=0$

50 CONTINUE

C

C

C CLOSE (6)

CLOSE (18)

CLOSE (17)

CLOSE (8)

CLOSE (9)

CLOSE (10)

CLOSE (11)

CLOSE (12)

CLOSE (13)

CLOSE (14)

C CLOSE (15)

CLOSE (5)

CLOSE (7)

CLOSE (19)

CLOSE (20)

$C \star \star \star$ USED TO CHECK LAKE MIXING

CLOSE (29)

CLOSE (30)

CLOSE (31)

CLOSE (32)

CLOSE (33)

CLOSE (34) 


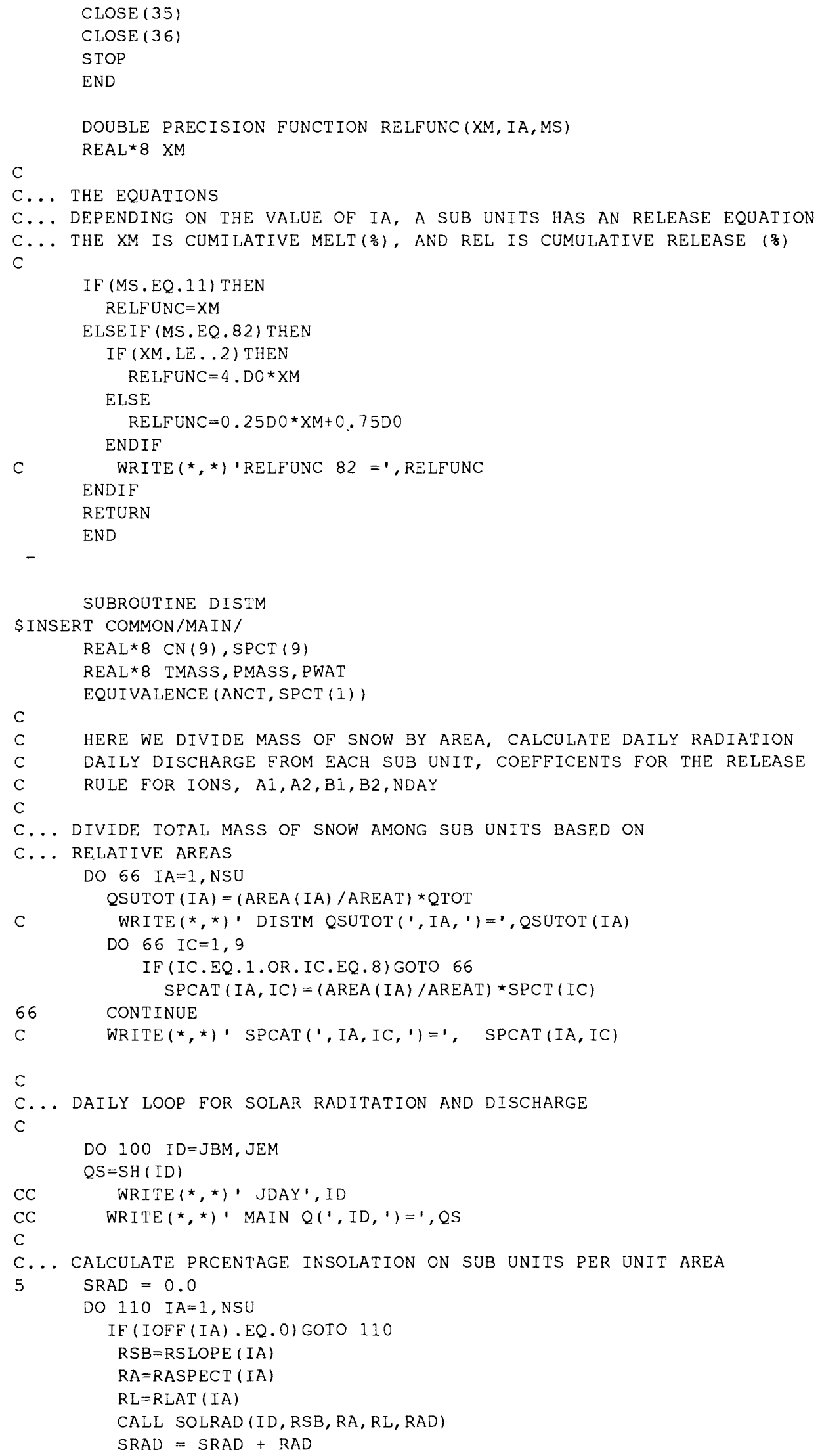




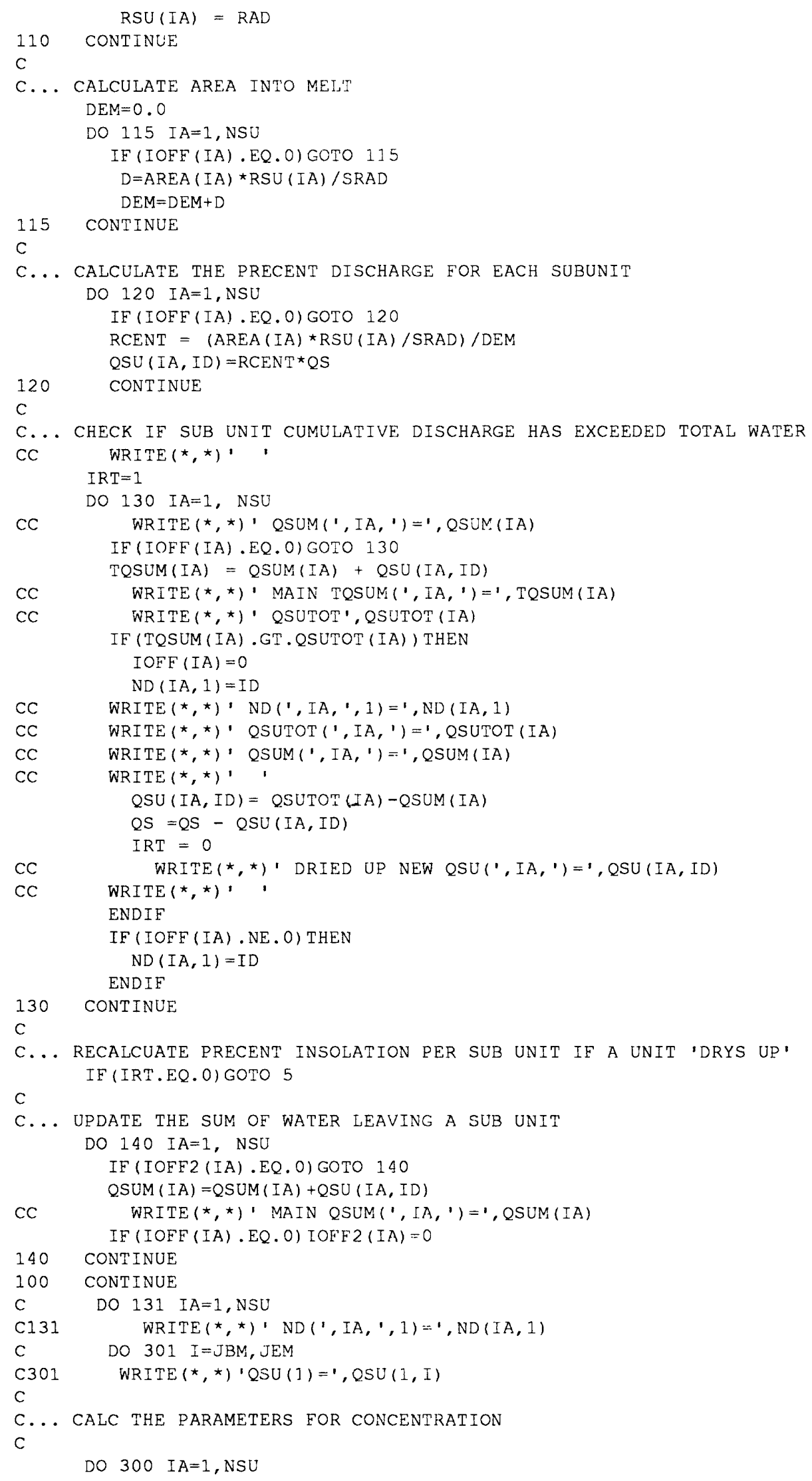


C

$$
\text { DO } 250 \text { IC }=1,9
$$

WRITE (*, *)' IA $=$ ', IA, ' IC $=$ ', IC

$$
K I=1
$$

$\mathrm{JBS}=\mathrm{JBM}$

450 CONTINUE

C... NO ANC AND SIO2 CONTRIBUTED, DOC IS CALCULATED LATER

IF (IC.EQ.1.OR. IC.EQ.8.OR. IC.EQ.3) GOTO 250

PMASS $=$ DBLE $(M S E L(I A, 1)) / 100$.

PWAT $=D B L E(M S E L(I A, 2)) / 100$.

TMASS $=\operatorname{SPCAT}(I A, I C)$

$\mathrm{NQ}=\mathrm{ND}(I A, 1)$

$C F S=C F(I A)$

CALL ELUTR(QSU, JBS, NQ, IA, TMASS, PWAT, PMASS, CFS, A1, B1, A2, B2, NDAY)

ND $(I A, 2)=$ NDAY

C WRITE (*, 43) JBS, TAB, IA, TAB, IC, TAB, A1, TAB, B1, TAB

$C \quad \& \quad A 2, T A B, B 2, T A B, \operatorname{SPCAT}(I A, I C), T A B, N D(I A, 2)$

43 FORMAT(I3,A1, I 1, A1, I1, 5 (A1,E12,6E2), A1, I 3)

$\mathrm{T}=1$

IF (MSEL (IA, 1) . EQ. MȘEL (IA, 2)) THEN

$\operatorname{QSUM}(I A)=0.0$

DO $399 \mathrm{I}=J B S, J E M$

QSUM $(I A)=Q S U M(I A)+Q S U(I A, I)$

399

CONTINUE

ENDIF

DO $400 \quad \mathrm{I}=\mathrm{JBS}, \mathrm{JEM}, 1$

$A B(I, I A, I C, 1)=A 1$

$A B(I, I A, I C, 2)=B 1$.

$A B(I, I A, I C, 3)=A 2$

$A B(I, I A, I C, 4)=B 2$

IF (MSEL (IA, 1) .EQ.MSEL (IA, 2)) THEN

$A B(I, I A, I C, 1)=$ TMASS $/$ QSUM (IA)

$A B(I, I A, I C, 2)=0.0$

$A B(I, I A, I C, 3)=$ TMASS $/ Q S U M(I A)$

$A B(I, I A, I C, 4)=0.0$

ENDIF

IF (I.GT.ND (IA, 2) ) THEN

$C N(I C)=A B(I, I A, I C, 3) \star \operatorname{EXP}(-A B(I, I A, I C, 4) \star T)$

ELSE

ENDIF

$C N(I C)=A B(I, I A, I C, 1) \star E X P(-A B(I, I A, I C, 2) * T)$

$\operatorname{TIME}(I, I A, I C)=T$

$\operatorname{TSTAR}(I, I A, I C)=N D(I A, 2)$

IF (I.EQ.ND (IA, 2) ) $T=0$

$\mathrm{T}=\mathrm{T}+1$

$\operatorname{SPCAT}(I A, I C)=\operatorname{SPCAT}(I A, I C)-C N(I C) * Q S U(I A, I)$

$X G A N G=C N(I C) \times Q S U(I A, I)$

C

57

400

410

C
WRITE $(*, 57)$ I, TAB, SPCAT (IA, IC), TAB, XGANG

FORMAT (I3, A1, E12.6E2, A1, E12.6E2)

IF (I.EQ.JDR(KI)) GO'IO 410

CONTINUE

GOTO 250

IF (IC.EQ.2) THEN

BANG $=C L R(K I)$

WRITE $(*, *)$ BANG

ELSEIF (IC.EQ.4) THEN

$B A N G=H R(K I)$

ELSEIF (IC.EQ.5) THEN

$B A N G=N H 4 R(K I)$

ELSEIF (IC.EQ. 6) THEN

$B A N G=N O 3 R(K I)$

ELSEIF (IC.EQ. 7) THEN

$B A N G=S B C R(K I)$

ELSEIF (IC.EQ.9) THEN

$B A N G=S O 4 R(K I)$ 
ENDIF

C... ADD RAIN STORAGE * RAIN CONC TO SNOW PACK ON THIS RAIN DAY

$B A N G=R S(I) \star(A R E A(I A) / A R E A T) \star B A N G / 1000$.

C WRITE $(*, *)$ BANG

$\operatorname{SPCAT}(I A, I C)=\operatorname{SPCAT}(I A, I C)+B A N G$

C WRITE $(*, *) \operatorname{SPCAT}(I A, I C)$

$\mathrm{JBS}=\mathrm{JDR}(\mathrm{KI})+1$

C WRITE(*, *) 'RAIN DAY $=1, \operatorname{JDR}(K I)$

$\mathrm{KI}=\mathrm{KI}+\mathrm{I}$

IF (JBS.GT.ND (IA, I)) THEN

GOTO 250

ELSE

GOTO 450

ENDIF

250 CONTINUE
300 CONTINUE

C

RETURN

END

C

SUBROUTINE ELUTR (Q, JBM, NQ, IA, TMASS, PWAT, PMASS, CE, A1, B1, A2, B2, NDAY) IMPLICIT DOUBLE PRECISION $(\mathrm{A}-\mathrm{H}, \mathrm{O}-\mathrm{Z})$

DIMENSION Q(10,1000)

REAL* 8 MPR, MPR2

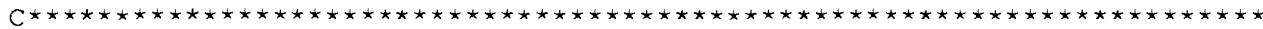

C This program takes an elution rule (e.g., $80 \%$ of the ions in $20 \%$ of $\star$

$C$ the melt), and the concentration on a given day and returns the two *

C parameters for an exponentialiy declining concentration. A simple

C Newton's method of solution is used.

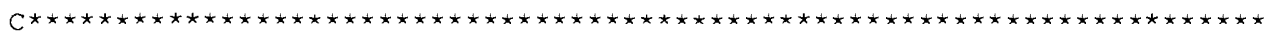

C

TWAT $=0$

DO $10 \quad \mathrm{I}=\mathrm{JBM}, \mathrm{NQ}$

TWAT $=T W A T+Q(I A, I)$

10 CONTINUE

C WRITE (*, *)'TWAT=', TWAT, ' JBM=', JBM, ' NQ=', NQ

$\mathrm{SUMQ}=0$

DO $20 \quad I=J B M, N Q$

$S U M Q=S U M Q+Q(I A, I)$

IF (SUMQ. LT.PWAT*TWAT) THEN

GOTO 20

ELSE

GOTO 30

ENDIF

20

CONTINUE

WRITE (*,*) 'ERROR IN CALC. OF DAYS REQD FOR FLOW.'

STOP

$C$ * ROUND UP THE NUMBER OF DAYS REQUTRED FOR WATER TO FLOW OUT

$30 \quad$ NDAY $=I$

C WRITE (*,*)'NDAY = ', NDAY

$C^{\star}$ ready to begin Newton's method solution; MAKE INITIAL GUESS

$\mathrm{BI}=.03$

CAVE $=$ TMASS $/$ TWAT

$M P R=T M A S S * P M A S S$

$\mathrm{CO}=\mathrm{CF}{ }^{\star} \mathrm{CAVE}$

$50 \quad X S U M=0.0$

$F B R=0.0$

$J=J B M$

$\mathrm{CK}=\mathrm{NDAY}-\mathrm{JBM}+1$

DO $100 \mathrm{I}=1, C K$

$\mathrm{CN}=\mathrm{CO}{ }^{\star} \mathrm{DEXP}\left(-\mathrm{BI}{ }^{\star} \mathrm{DBIE}(I)\right)$

$X S U M=X S U M+C N \star Q(I A, J)$

$F B R=F B R+D B L E(I) \star Q(I A, J) \star C O \star D E X P(-B I \star D B L E(I))$

$J=J+I$ 


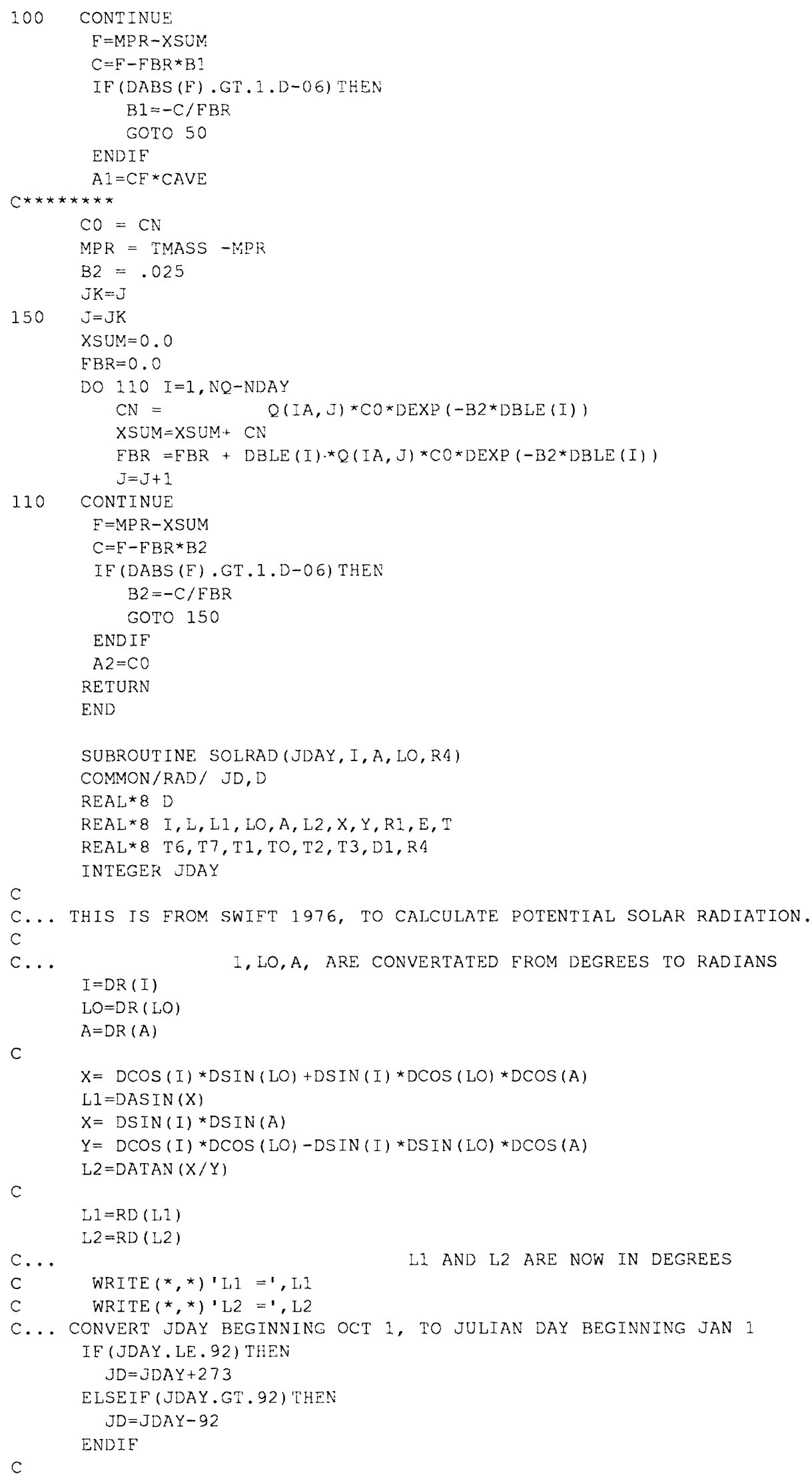




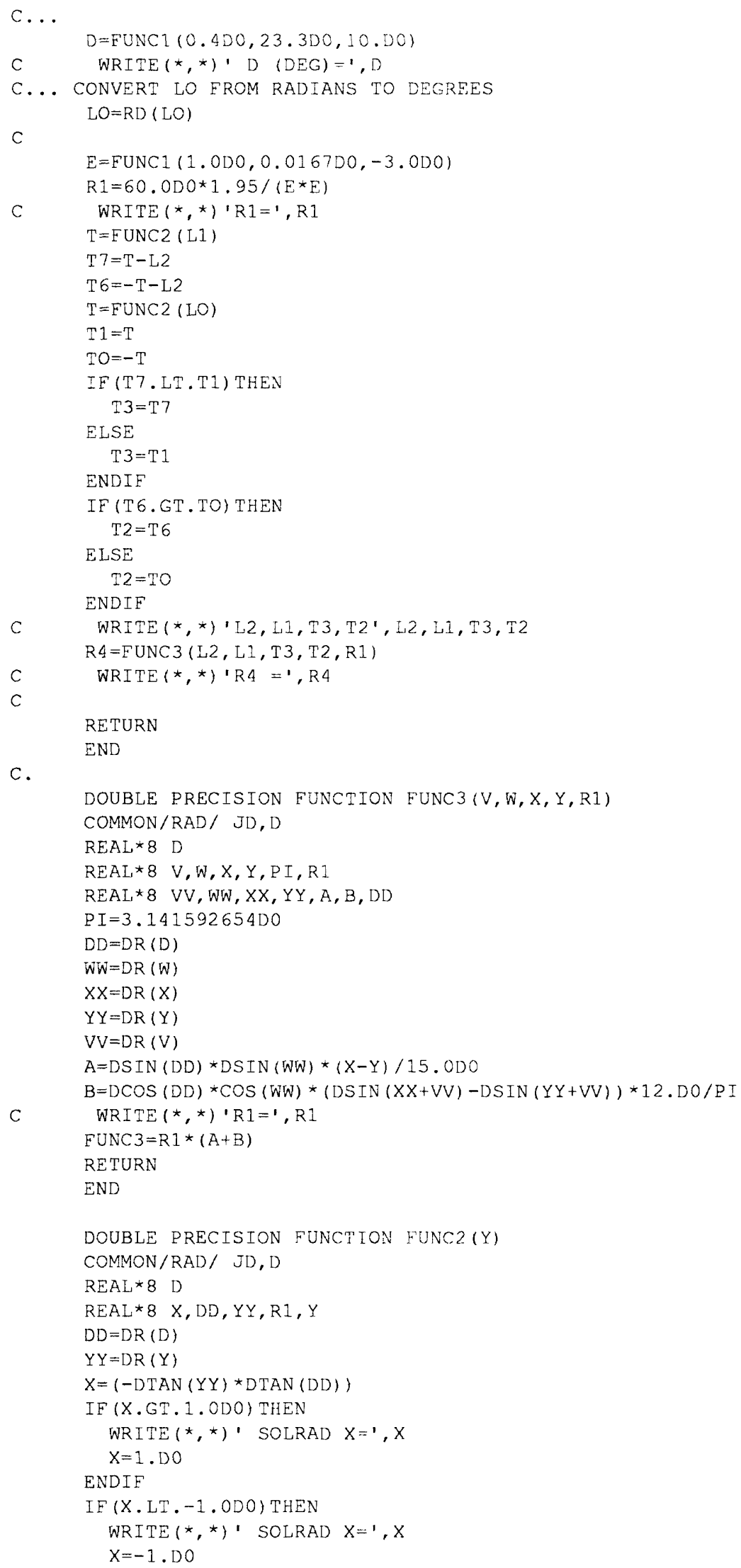




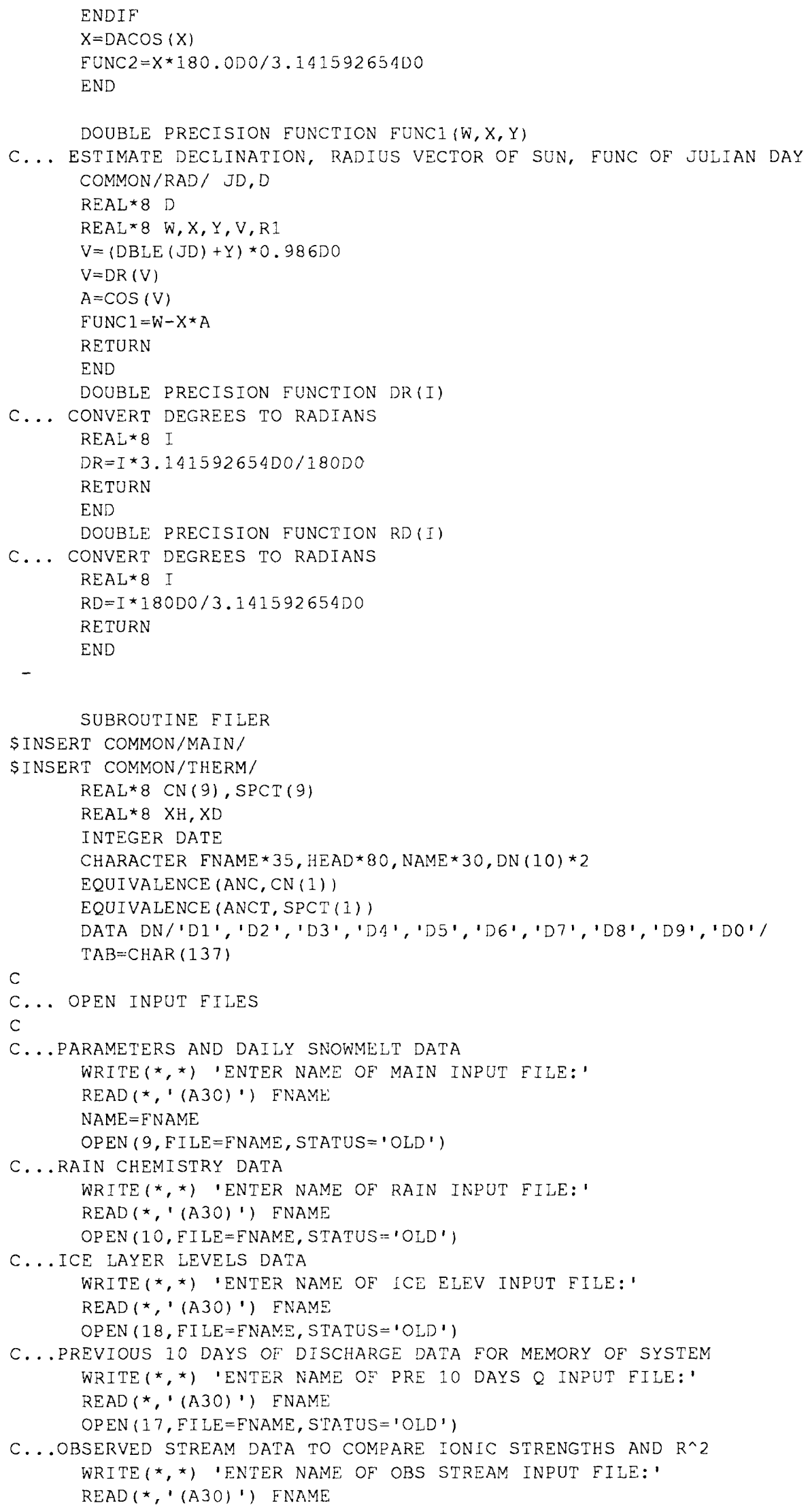


OPEN (11, FILE=FNAME, STATUS= 'OLD')

C...OBSERVED LAKE DATA TO COMPARE R^?

WRITE $(*, *)$ 'ENTER NAMF, OF OBS IAAKE OUTPUT FILE:'

$\operatorname{READ}(*, '(A 30)$ ') ENAMF

OPEN (5, FILE =FNAME, STALUS= 'OLD')

C...DAILY INFIOW TEMPERATURES, BEGIN WI/ J-DAY OF BEGIN OF SIMULATION

WRITE $(*, *)$ 'ENTER NAME OF OBS S*REAM TEMP FILE:'

READ $(*, '(A 30)$ ') ENAME

OPEN (2O, FILE=FNAME, STATUS = 'OLD')

C...THERMOCLINE OBSERVATIONS

WRITE $(*, *)$ 'ENTER NAME OF OBS THERMOCLINE: '

READ (*,' (A30)') FNAME

OPEN $(29$, FI LE=FNAME, STATUS= ' OLD')

C

C... READ THERMOCLINE ELEVATIONS (MAXIMUM OF 14 VALUES), AND THE J-DAY

$\mathrm{C}$

IC $=1$

$43 \operatorname{READ}(29, *, E N D=10) \times H(I C), X D(1 C)$

$I C=I C+1$

GOTO 43

10 CONTINUE

C

C... OUtPut File NAMES, CREATEd BASEd ON NAME OF MAIN INPUt File

$\mathrm{C}$

C...MAIN OUTPUT FILE (VISUAL)

FNAME = I ILWAS $>$ OUT.WY'//NAME $(1.7: 18) / / 1>$ V'//NAME $(17: 30)$

OPEN (15, EILE=FNAME, STATUS='UNKNOWN')

C...STREAM CALCULATIONS FILE (TAB DELIMITED FOR MACINTOSH) FNAME = ILWAS>OUT. WY'//NAME $(17: 18) / /$ '>S'//NAME $(17: 30)$ OPEN (13,FILE=FNAME, STATUS= 'UNKNOWN')

C...STREAM CALC. VS. OBSERVATIONS EILE (TAB DELIMITED FOR MACINTOSH) FNAME = ILWAS >OUT. WY'//NAME (17:18)//'>RS'//NAME $(17: 30)$ OPEN (7, FILE=ENAME, STATUS= 'UNKNOWN')

C...LAKE CALC. VS. OBSERVATIONS FILE (TAB DELIMITED FOR MACINTOSH) FNAME = ' ILWAS>OUT.WY'//NAME $(17: 18) / / 1>$ RL'//NAME $(17: 30)$ OPEN $(6, F I L E=$ FNAME, STATUS $=$ ' UNKNOWN')

C...LAKE CALCULATIONS FILE (TAB DELIMITED FOR MACINTOSH) FNAME =' ILWAS>OUT.WY'//NAME $(17: 18) / /$ ' $>$ L'//NAME $(17: 30)$ OPEN (12, FILE=FNAME, STATUS = UNKNOWN')

C...IONIC STRENGTH OF STREAM, MACINTOSH FORMAT, CRICKET BAR GRAPH STYLE FNAME $=$ ' ILWAS $>$ OUT. WY'//NAME $(17: 18) / /$ ' $>I 1 / /$ NAME $(17: 30)$ OPEN $(14$, FILE=FNAME, STATUS= ' UNKNOWN')

C... LAKE LAYER VOLUMES FNAME $=$ ' ILWAS $>$ OUT. WY $/ /$ NAME $(17: 18) / /$ ' $>$ VOL' $/ /$ NAME $(17: 30)$ OPEN (19, FILE=FNAME, STATUS=' UNKNOWN')

$\mathrm{C}$

C... INITIALIZE OUTPUT FILES

$\mathrm{C}$

$\operatorname{WRITE}(12,1)$

1 FORMAT $\left(1 H^{*}\right)$

WRITE(12,' '(13(A,A1))') 'JDAY', TAB, 'Q', TAB, 'ANC LK', TAB, 'CL LK', TAB, \&'DOC LK', TAB, 'H LK', TAB, 'NH4 LK', TAB, 'NO3 LK', TAB, 'SBC LK',

\&TAB, 'SIO2 LK', TAB, 'SO4 LK', TAB, 'PH LK'

WRITE $(14, *)$ 'IONS', TAB, 'J DAY', TAB, 'SBC', TAB, 'ANC', TAB,

\&'CL', TAB, 'DOC', TAB, 'H', TAB, 'NO3', TAB, 'SO4', TAB, 'NH4'

$\operatorname{WRITE}(13,1)$

WRITE $(13, '(13(A, A 1))$ ') 'JDAY', TAB, 'Q', TAAB, 'ANC ST',

\&TAB, 'CL ST', TAB, 'DOC ST', TAB,'H ST'

\&, TAB, 'NH4 ST', TAB, 'NO3 ST', TAB, 'SBC ST', TAB

\&,'SIO2 ST', TAB, 'SO4 ST', TAB, '+/- BALANCE ST',

\& $T A B, ' P H '$

WRITE $(7, *)$ 'JDAY ST', TAB, 'O ST', TAB, 'ANC ST',

\& TAB, 'CL ST', TAB, 'H ST'

\&, TAB, 'NH4 ST', TAB, 'NO3 S'T', TAB, 'SBC ST', TAB 


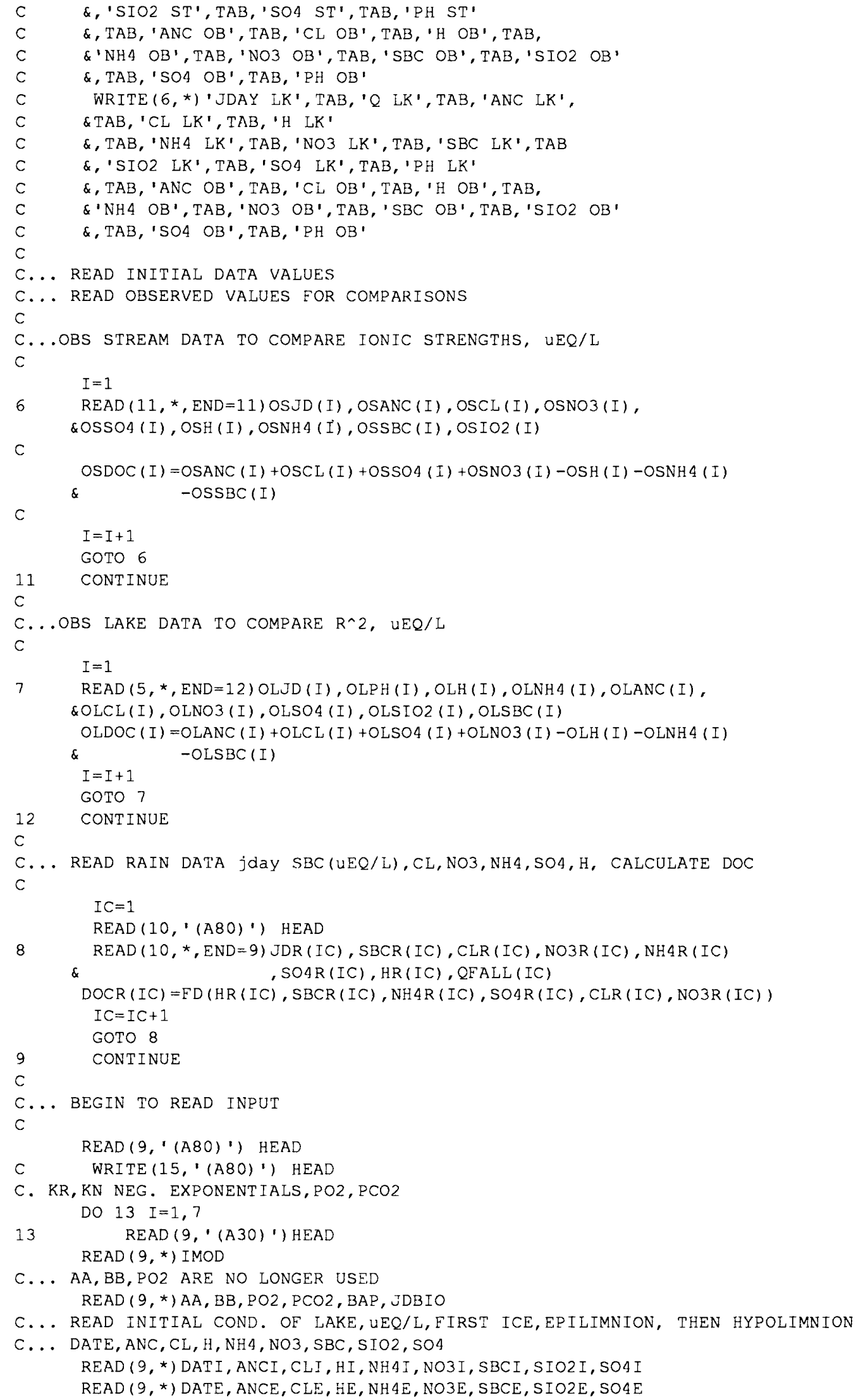


$\operatorname{READ}(9, *)$ DATE, ANCH, CLH, HH, NH4H, NO3H, SBCH, SIO2H, $\mathrm{SO} 4 \mathrm{H}$

C...NO TEMP CORRECTIONS HERE YET

$\mathrm{DOCE}=\mathrm{HE}+\mathrm{SBCE}+\mathrm{NH} 4 \mathrm{E}-\mathrm{SO} 4 \mathrm{E}-\mathrm{CLE}-\mathrm{NO} 3 \mathrm{E}-\mathrm{ANCE}-(10 . * *(-2).) / \mathrm{HE}$

DOCI $=\mathrm{HI}+\mathrm{SBCI}+\mathrm{NH} 4 \mathrm{I}-\mathrm{SO} 4 \mathrm{I}-\mathrm{CLI}-\mathrm{NO} 3 \mathrm{I}-\mathrm{ANCI}-(10 . \star \star(-2).) / \mathrm{HI}$

C

$\mathrm{DOCH}=\mathrm{HH}+\mathrm{SBCH}+\mathrm{NH} 4 \mathrm{H}-\mathrm{SO} 4 \mathrm{H}-\mathrm{CLH}-\mathrm{NO} 3 \mathrm{H}-\mathrm{ANCH}-(10 . \star \star(-2).) / \mathrm{HH}$

C... FIRST DAY, LAST DAY OF SIMULATION, FIRST DAY AND LAST DAY OF MELT

C... AND IF USE MEMORY $(=1$, USE MEM)

C...

C

$\operatorname{READ}(9, *)$ JD 1, JDN, JBM, JEM, MEM

C... READ ALL DISCHARGES IN METERS CUBED

C... SNOW MELT DATA: jdaY, $Q(M * \star 3)$

DO $22 \mathrm{I}=\mathrm{JD} 1, \mathrm{JDN}, \mathrm{I}$

$22 \operatorname{READ}(9, \star) \operatorname{DAY}, \mathrm{QI}(\mathrm{I})$

C

C... CREATE SNOW HYDROGRAPH SH()

C RAIN STORAGE RS()

C RAIN RUNOFF RR()

C SH - RS SHRS()

$\mathrm{C}$

199

DO $199 I=1,365$

$\operatorname{RS}(I)=0$.

$R R(I)=0$.

$K I=1$

DO $200 \mathrm{I}=\mathrm{JBM}, \mathrm{JEM}, I$

IF (I.EQ.JDR (KI)) THEN

$R R(I)=Q I(I)-Q I(I-I)$

$\operatorname{IF}(R R(I) . L T .0 .0) \quad R R(I)=0.0$

$\operatorname{IF}(R R(I)$. GT. QFALL(KI)) RR(I) $=$ QFALL (KI)

$S H(I)=Q I(I)-R R(I)$

$R S(I)=Q F A L L(K I)-R R(I)$

$\operatorname{SHRS}(I)=S H(I)-R S(I)$

$K I=K I+1$

ELSE

$S H(I)=Q I(I)$

ENDIF

C WRITE (*, 137) I, TAB, QI (I), TAB,SH(I), TAB, RR (I), TAB, RS (I)

137 FORMAT (I3, A1, 4(F12.2, A1))

200 CONTINUE

C

C... SUM DISCHARGE FOR THE MELT TIME

$\mathrm{QTOT}=0 . \mathrm{DO}$

DO $23 \mathrm{I}=\mathrm{JBM}, \mathrm{JEM}, \mathrm{I}$

23

QTOT=QTOT $+S H(I)$

C

C... BEGIN ADDITION OF DIST. MELT MODIFICATIONS

$\mathrm{C}$

C... READ TOT LOAD OF IONS IN SNOWPACK IN EQUIVALENTS

READ (9, *) SBCT, CLT, NO3T, NH $4 T, S O 4 T, H T$

C... CALC THE HYDORGEN SUCH THAT THE SNOW PACK MASS HAS CHARGE BALANCE

C $\quad H T=C L T+N O 3 T+S O 4 T-S B C T-N H 4 T$

C WRITE $(*, *)$ ' FILER QTOT $=$ ', QTOT

DOCT $=\mathrm{HT}+\mathrm{SBCT}+\mathrm{NH} 4 \mathrm{~T}-\mathrm{SO} 4 \mathrm{~T}-\mathrm{CLT}-\mathrm{NO} 3 \mathrm{~T}$

C.

WRITE $(*, *) \cdot D O C$ OF SNOWPACK $=$ ', DOCT

C... READ \# OF SUB UNITS, TOTAL AREA, AND THEIR RESPECTIVE AREAS

$\operatorname{READ}(9, *)$ NSU, AREAT, (AREA (IA), IA=1, NSU)

C WRITE $\left({ }^{*},{ }^{*}\right)$ 'NSU $=$ ', NSU

C

C... CREATE NAME OF SUB UNITS FOR THE OUTPUT FILES

IWP $=29$

DO $111 I=1$, NSU

FNAME $=$ ' ILWAS $>$ OUT. WY'//NAME $(17: 18) / /$ ' $>1 / /$ DN (I) //NAME $(17: 30)$ 


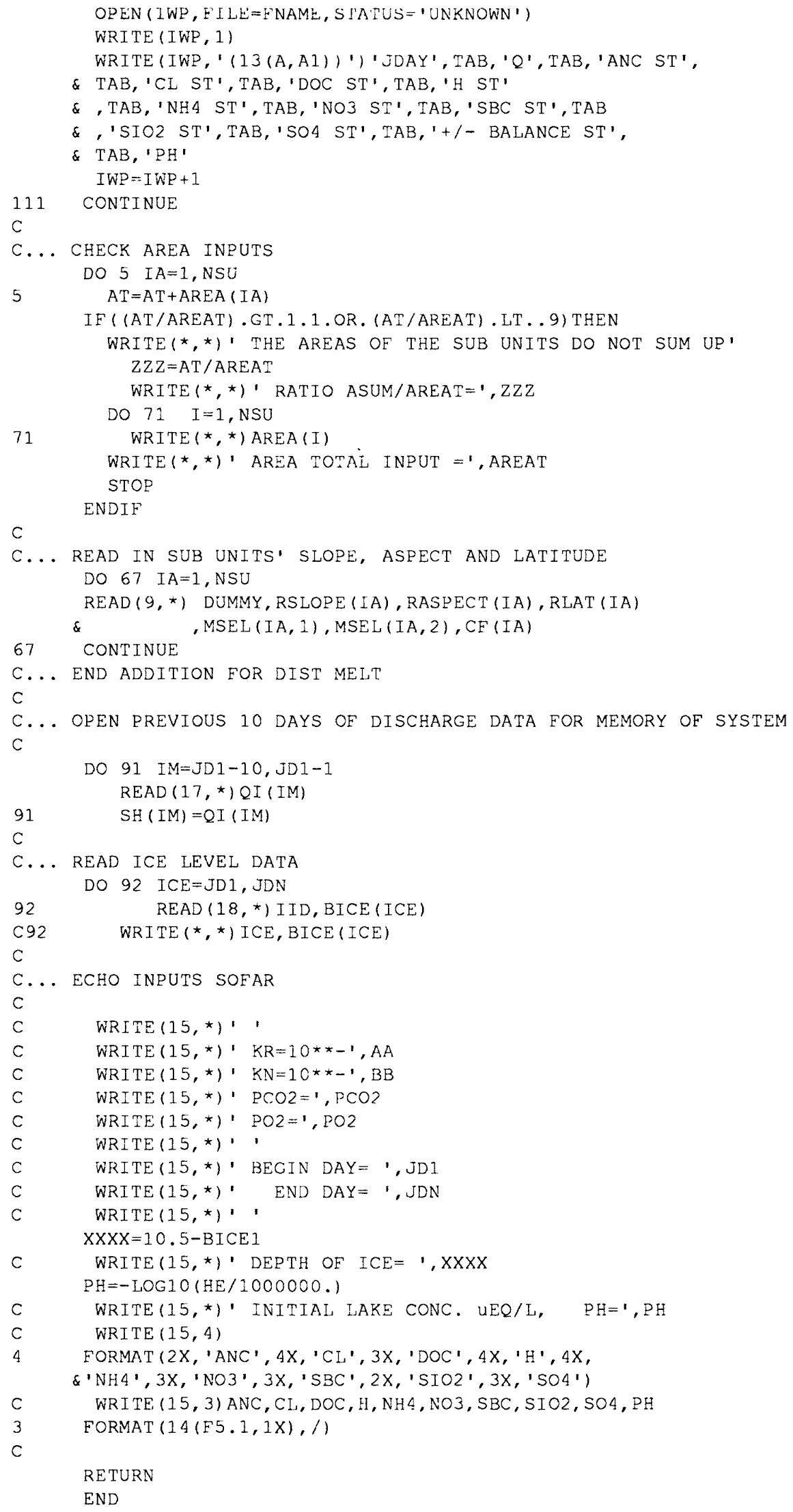


DOUBLE PRECISION FUNCTION FD (H, SBC, NH4, SO4, CL, NO3)

$\mathrm{REAL} \star 8 \mathrm{H}, \mathrm{SBC}, \mathrm{NH} 4, \mathrm{SO} 4, \mathrm{CL}, \mathrm{NO} 3$

C...CONVERT UEQ/L TO EQ/L (WHICH IS SAME AS MOLES, IN THIS CASE)

$\mathrm{H}=\mathrm{H} / 1000000$.

$S B C=S B C / 1000000$.

$\mathrm{NH} 4=\mathrm{NH} 4 / 1000000$.

$\mathrm{SO} 4=\mathrm{SO} 4 / 1000000$.

$\mathrm{CL}=\mathrm{CL} / 1000000$.

$\mathrm{NO} 3=\mathrm{NO} 3 / 1000000$

C...CALCULATE DOC AND CONVERT BACK TO UEQ/L

$F D=(H+S B C+N H 4-S O 4-C L-N O 3-(10 . \star \star(-14)) / H.) \star 1000000$.

$\mathrm{H}=\mathrm{H} * 1000000$.

$\mathrm{SBC}=\mathrm{SBC} * 1000000$.

$\mathrm{NH} 4=\mathrm{NH}_{4} * 1000000$.

$\mathrm{SO} 4=\mathrm{SO} 4 * 1000000$

$C L=C L * 1000000$.

$\mathrm{NO} 3=\mathrm{NO} 3 * 1000000$.

RETURN

END

SUBROUTINE RAIN

\$INSERT COMMON/MAIN/

$\mathrm{REAL} * 8$ CN (9), $\operatorname{SPCT}(9)$

EQUIVALENCE (ANC, CN (1))

EQUIVALENCE (ANCT, SPCT (1))

$T A B=C H A R(137)$

C... TEST FOR RAIN

C... IF ITS A RAIN DAY, REPLACE SNOWMELT CHEM WITH RAIN CHEM IFLAG $=0$

WRITE (*,*)' JDAY, JDAY OF RAIN', JDAY, JDR (IR)

IF (JDAY.EQ. JDR (IR)) THEN

$\operatorname{IRAIN} 1=1$

$S B C=S B C R(I R)$

$C L=C L R(I R)$

NO3 $=$ NO3R $(I R)$

$\mathrm{NH} 4=\mathrm{NH} 4 \mathrm{R}(\mathrm{IR})$

$\mathrm{SO} 4=\mathrm{SO} 4 \mathrm{R}(I R)$

$\mathrm{H}=\mathrm{HR}(\mathrm{IR})$

DOC $=$ DOCR $(I R)$

IF (IYEST.NE. JDAY) THEN

$I R=I R+1$

ENDIF

IYEST $=J D A Y$

IF LAG $=1$

WRITE $(15, \star) \cdot \operatorname{RAIN}$ DAY !

END IF

WRITE $(15, *) '$ JULIAN DAY', JDAY

WRITE $(15, *)$ ' DISCHARGE $M \times \star 31$, QI (JDAY)

$\operatorname{WRITE}(15, *) \cdot$,

FORMAT $(6 \mathrm{X}, 6(\mathrm{~F} 5.1,1 \mathrm{X}), 6 \mathrm{X}, \mathrm{F} 5.1,1)$

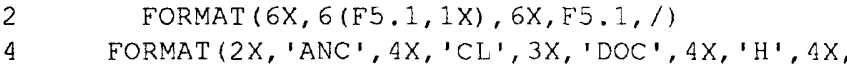

\&'NH4', 3X, 'NO3', 3X, 'SBC', 2X,'SIO2', 3X, 'SO4')

C... THESE ARE THE INPUT DATA USED TO COMPARE IONIC STRENGTH

$I P D O C=D O C$

$I P S B C=S B C$

IPCL $=C L$

$I P N O 3=\mathrm{NO} 3$

IPNH $4=$ NH 4

IPSO $4=504$

IP $\mathrm{H}=\mathrm{H}$

c

RETURN 
END

SUBROUTINE NRWEATH

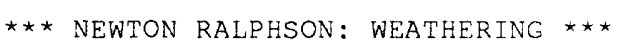

REMOVED NITROGEN EQUATION; NOW ALL NH $4 \Rightarrow>$ H

INPUT: PCO2, PH, NH4, SBC, CL, SO4, NO3, ANC

REEQUILIBRATE: H, NO3, NH4, $\mathrm{HCO} 3, \mathrm{CO} 3$

CALCULATE: SIO2, SBC

INPUT IS IN EQ/L. OUTPUT IS IN EQ/L.

EXCEPTION: SIO2 IS ALWAYS IN MOLES/L.

INTERNAL EQUILIBRIUM CALCULATIONS ARE IN MOLES/L.

$$
\begin{aligned}
X, Y, Z & =\text { UNKNOWNS } \\
X & =\mathrm{H}+ \\
Y & =\text { NO3- } \\
Z & =\text { SiO2 }
\end{aligned}
$$

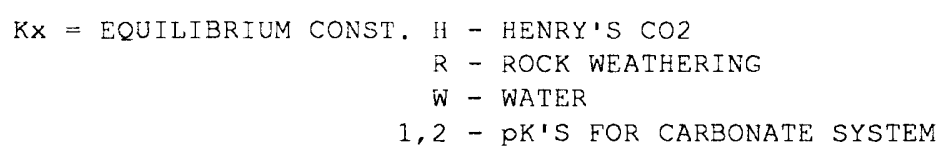


TOL $=0.0000000000001$

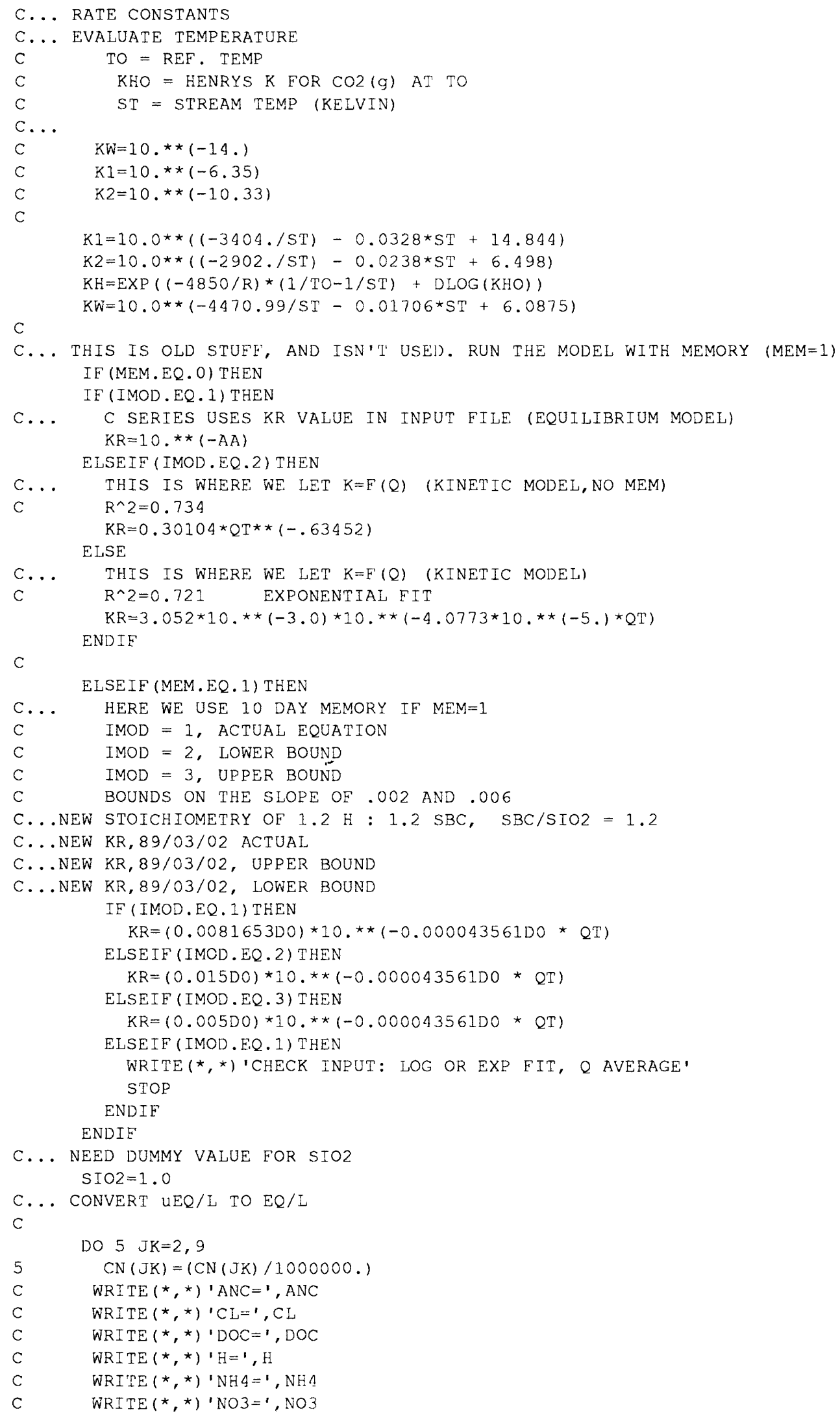




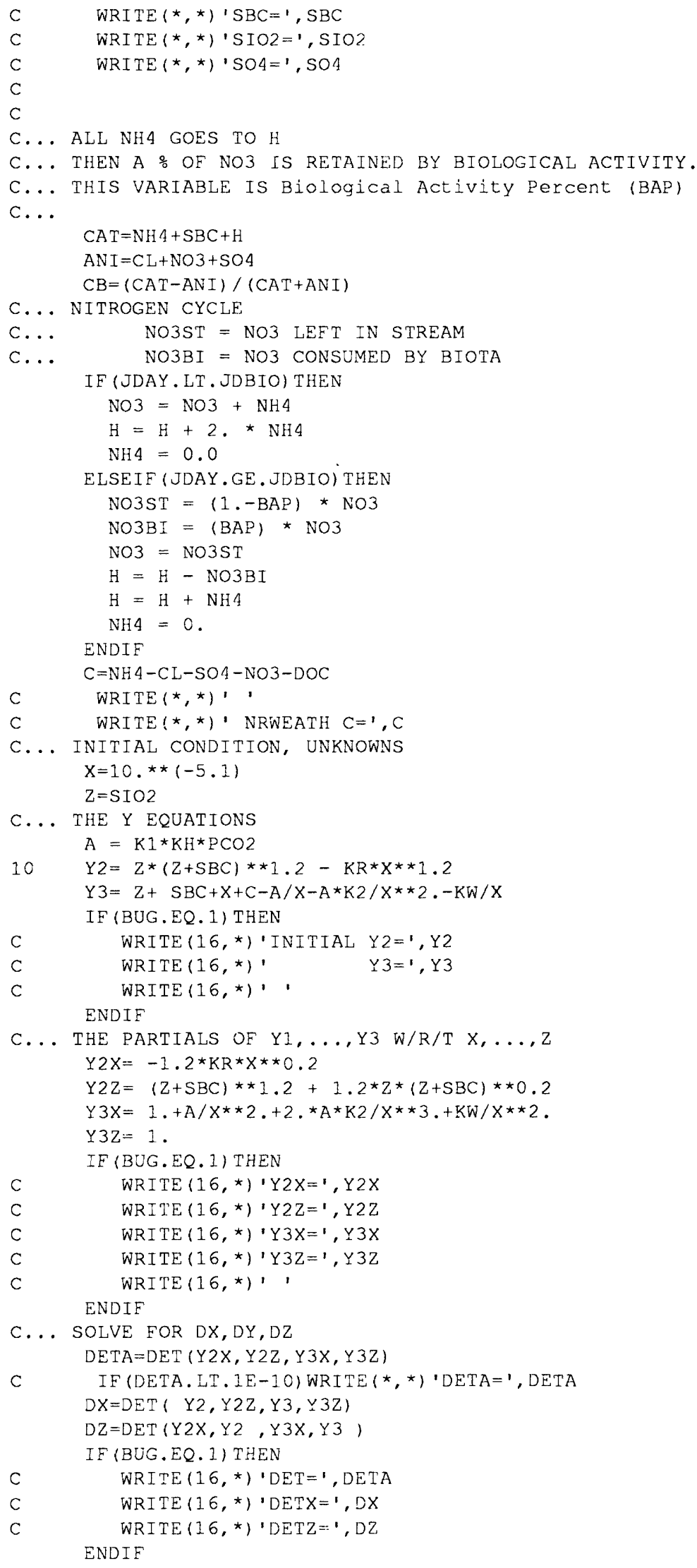




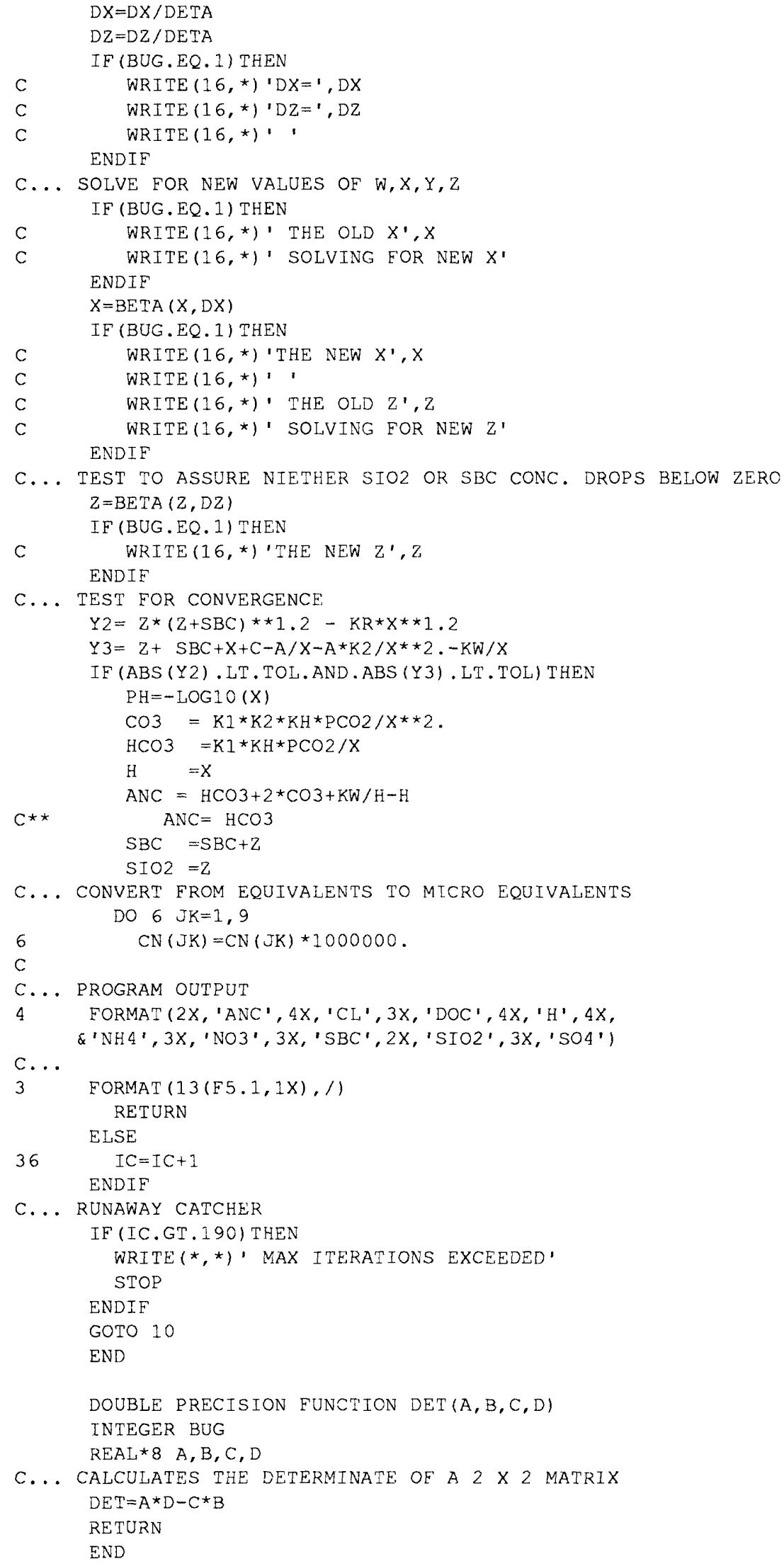


DOUBLE PRECISION EUNCTION BETA $(X C, D X C)$

\section{\$INSERT COMMON/MAIN/}

$R E A L \star \& \quad X C, D X C, U$

$11 \quad \mathrm{U}=\mathrm{XC}$

IF (BUG.EQ.1) THEN

C WRITE $\left(16,{ }^{\star}\right)$ 'DU $=$ ', DXC

ENDIF

$\mathrm{U}=\mathrm{U}-\mathrm{D} X \mathrm{C}$

IF (BUG.EQ.1) THEN

c $\operatorname{WRITE}\left(16,{ }^{\star}\right) \cdot U=1, U$ ENDIF

IF'(U.LT.O.) THEN $\mathrm{DXC}=\mathrm{DXC} / 10$. GOTO 11

ELSE

$B E T A=U$

ENDIF

RETURN

END

SUBROUTINE NROPEN

C

*** NEWION RALPHSON: OPEN CARBONATE

UNKNOWNS

$$
\mathrm{X}=\mathrm{H}+
$$

$\mathrm{Z}=\mathrm{ANC}$

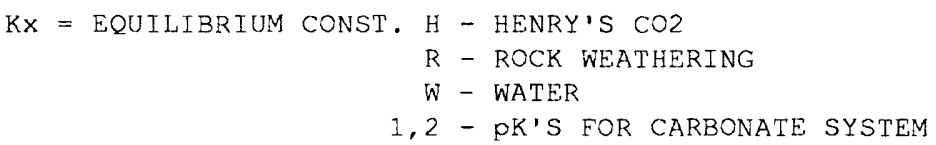




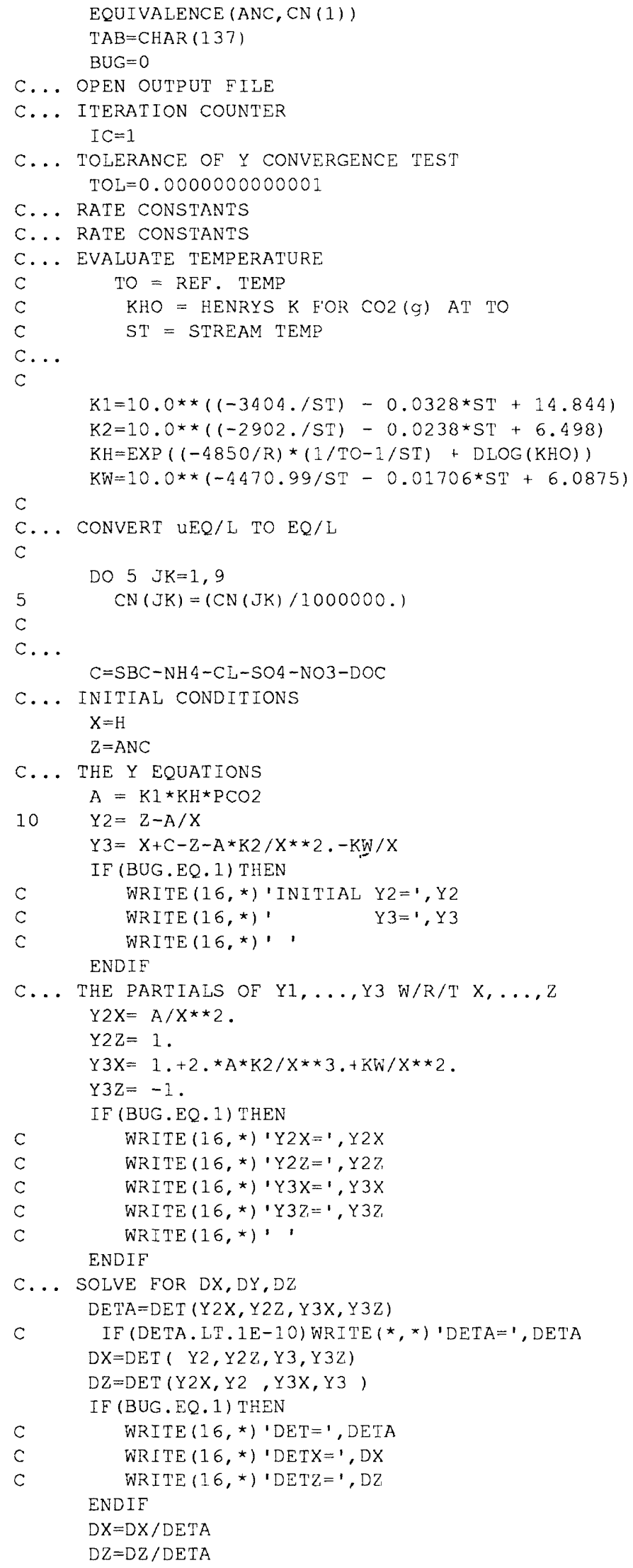




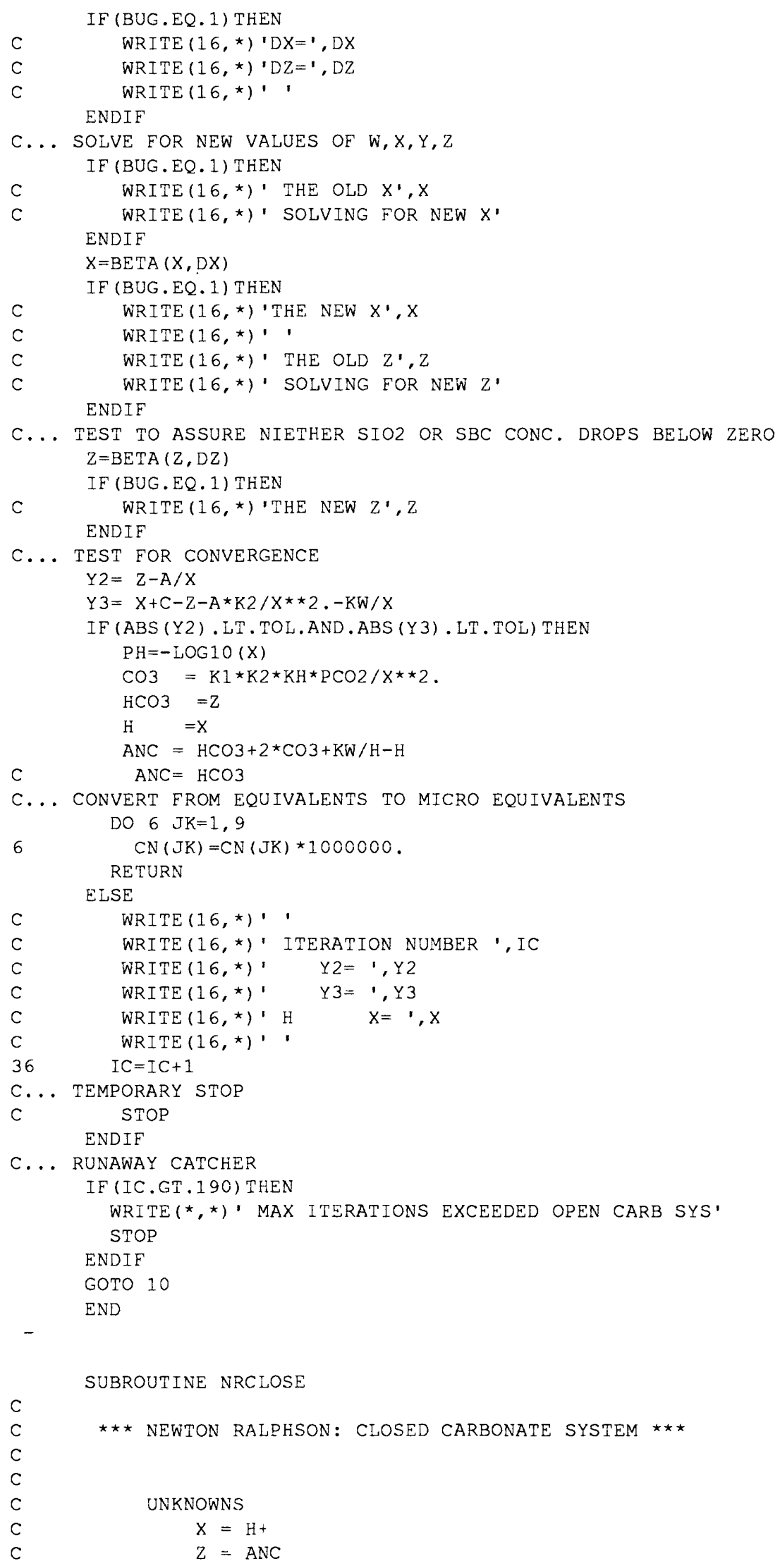




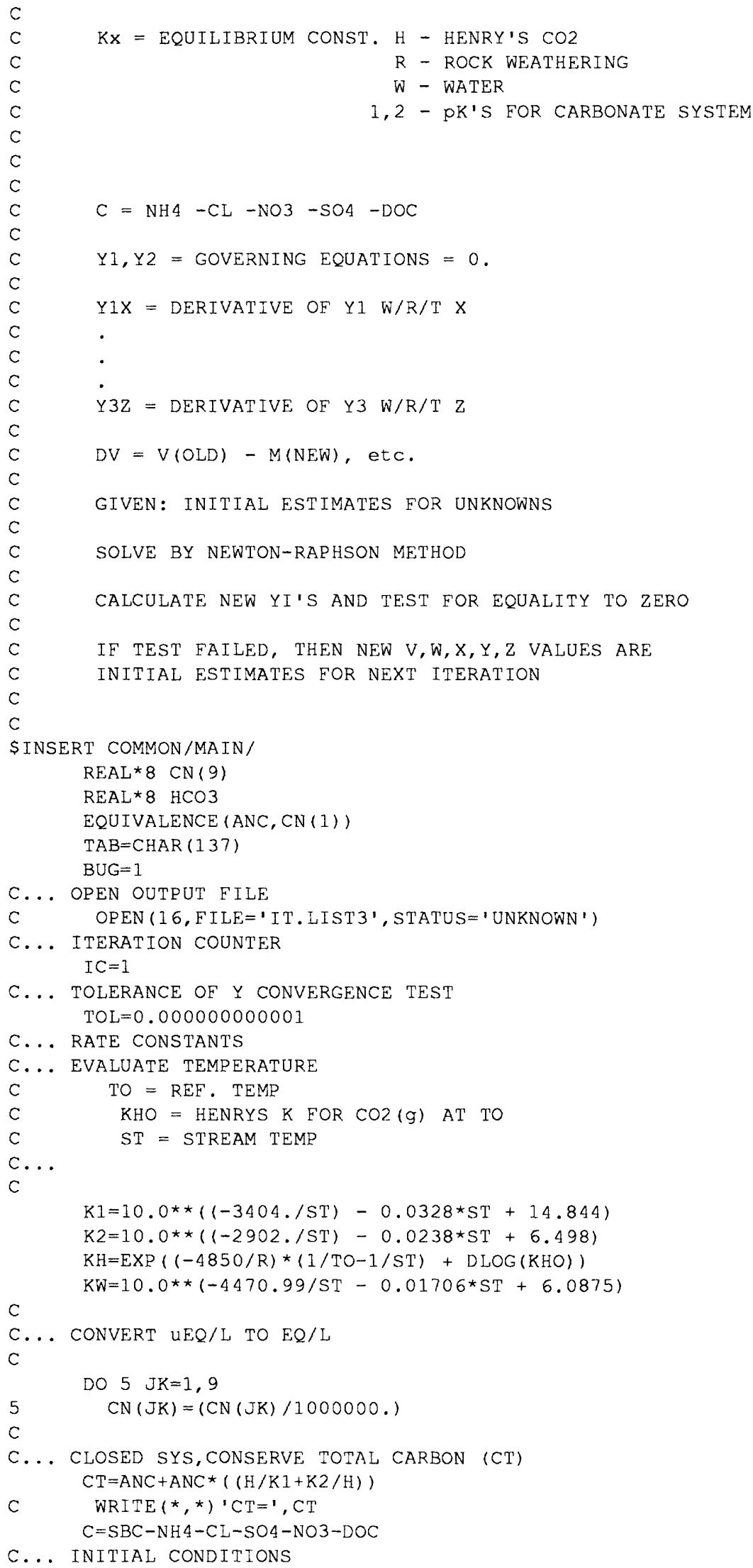




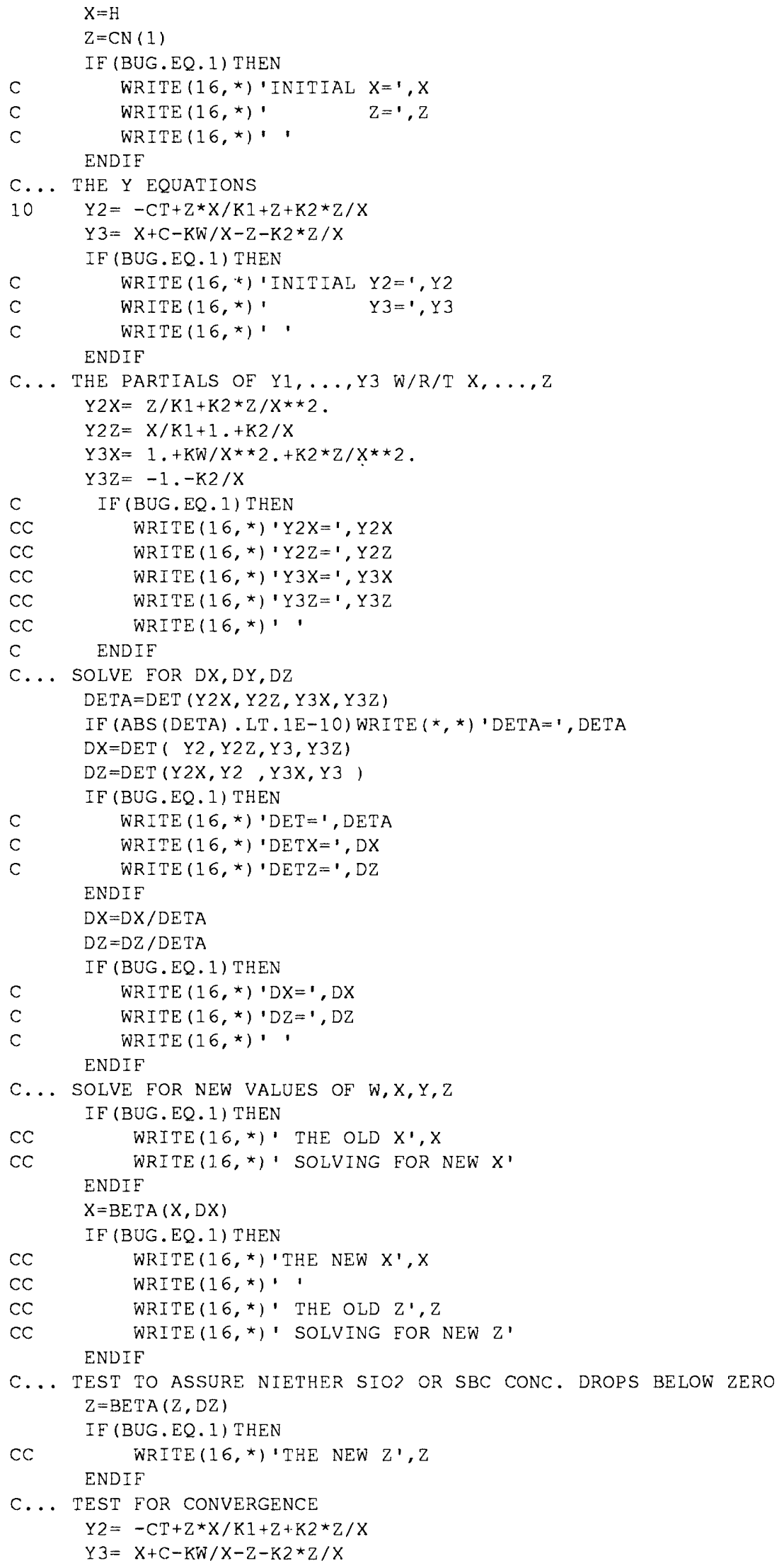




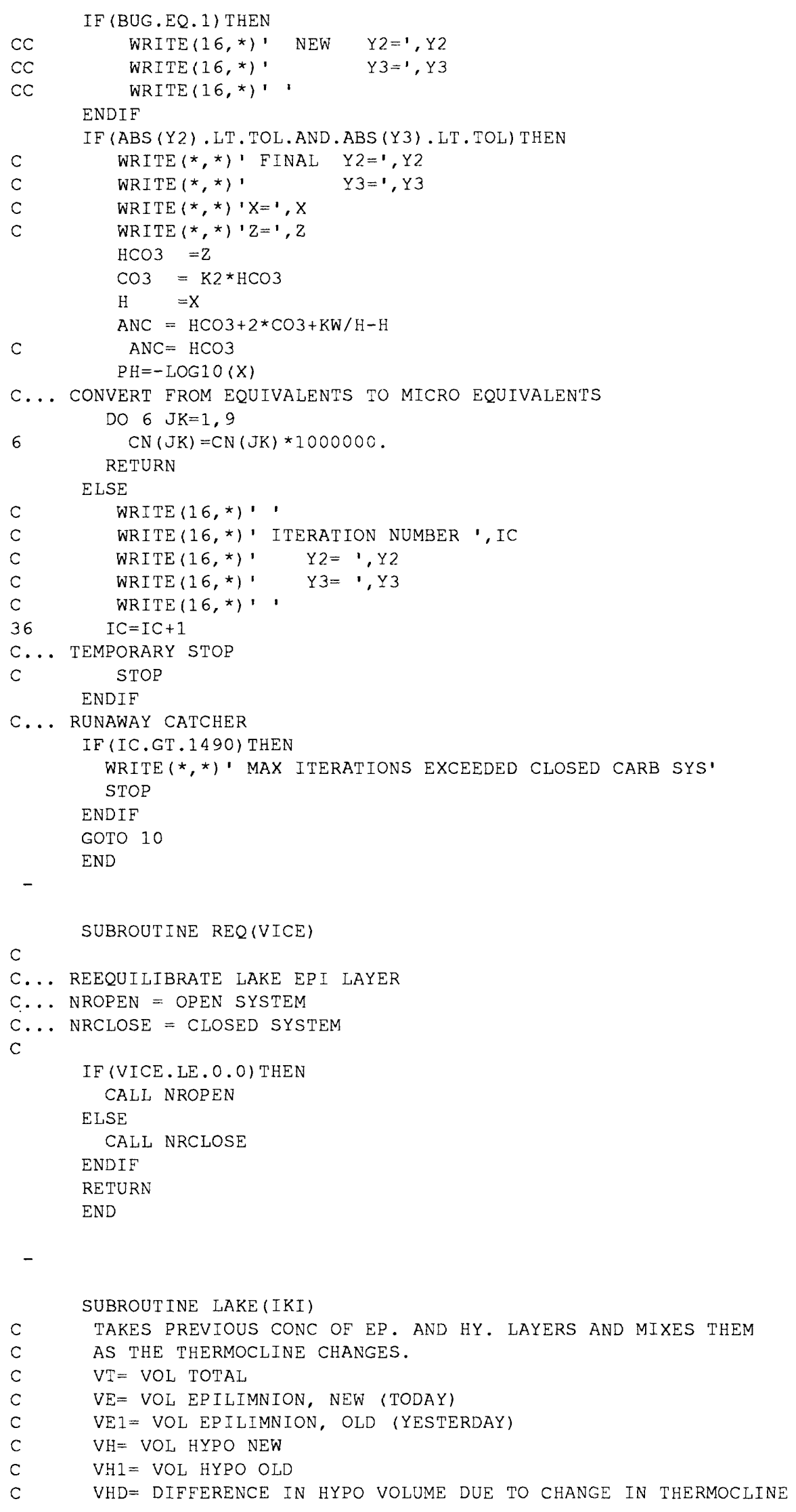




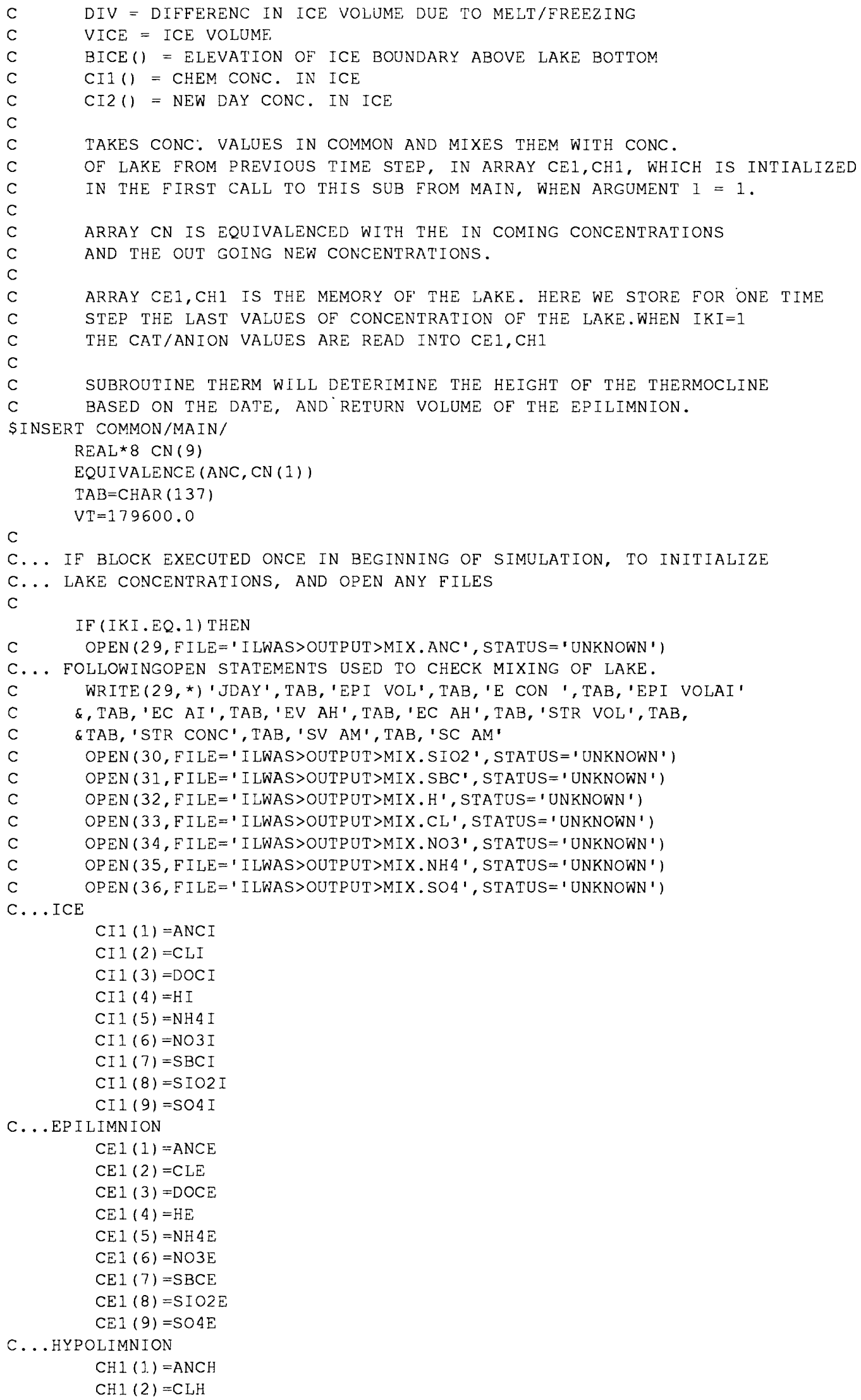




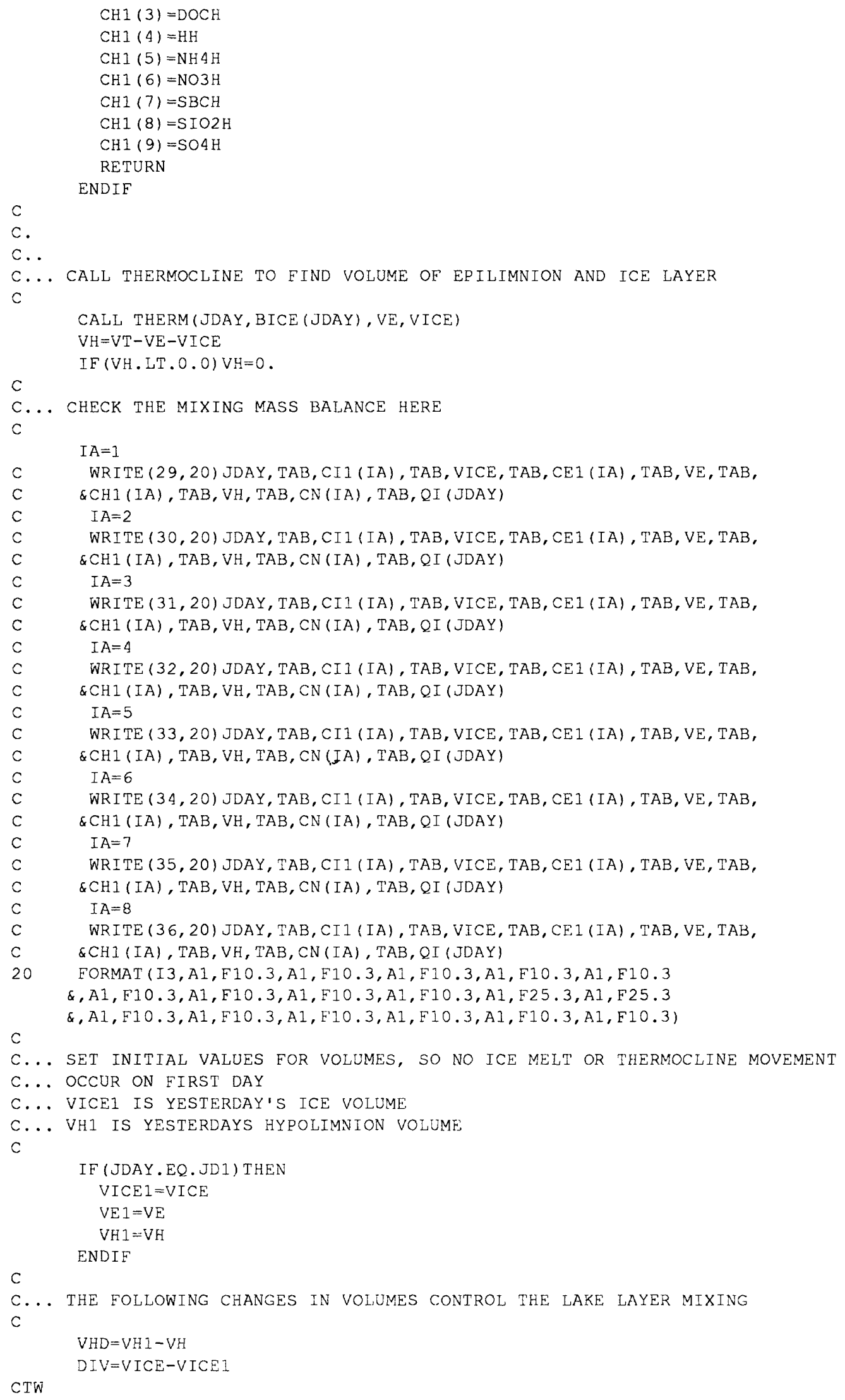




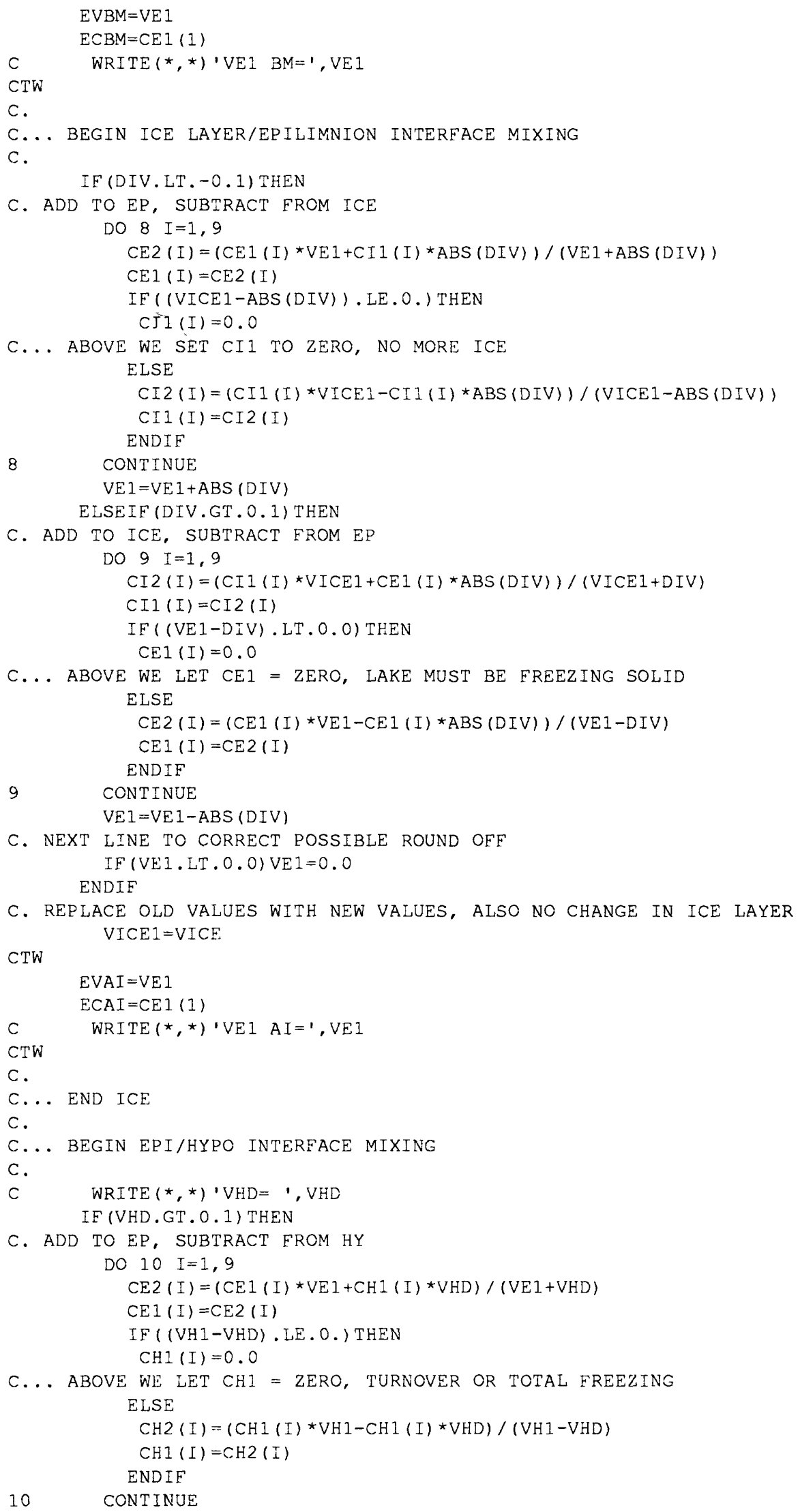




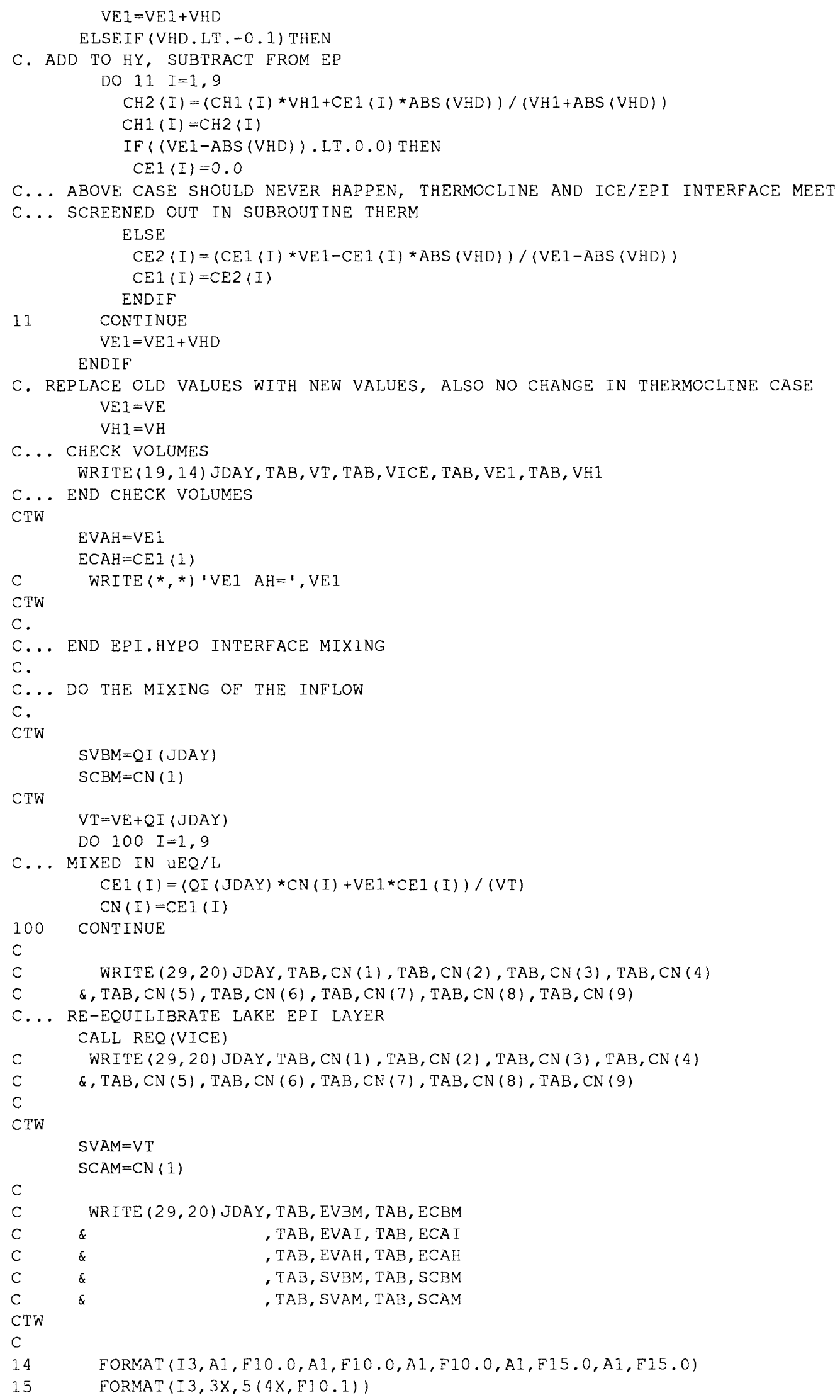




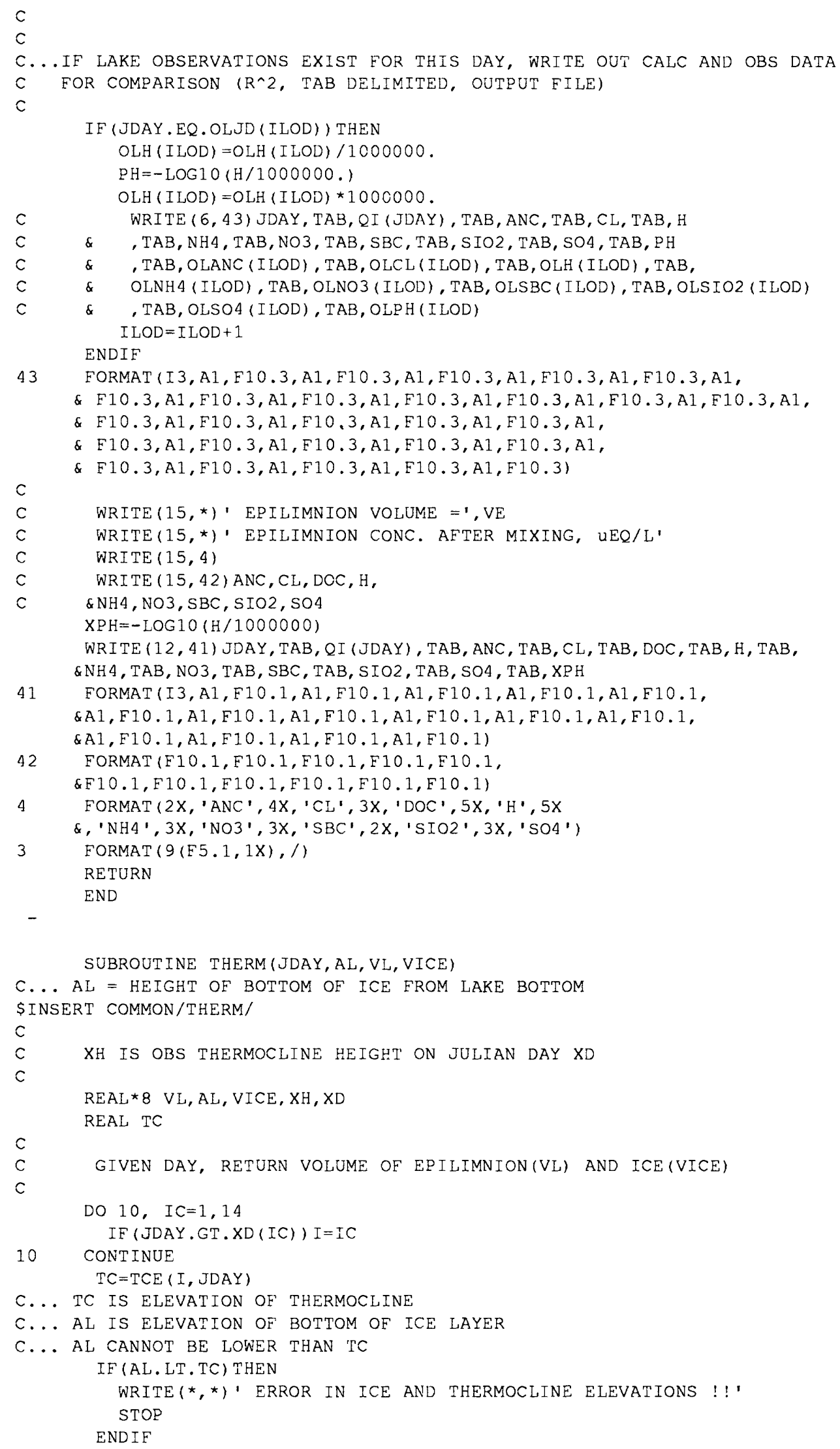




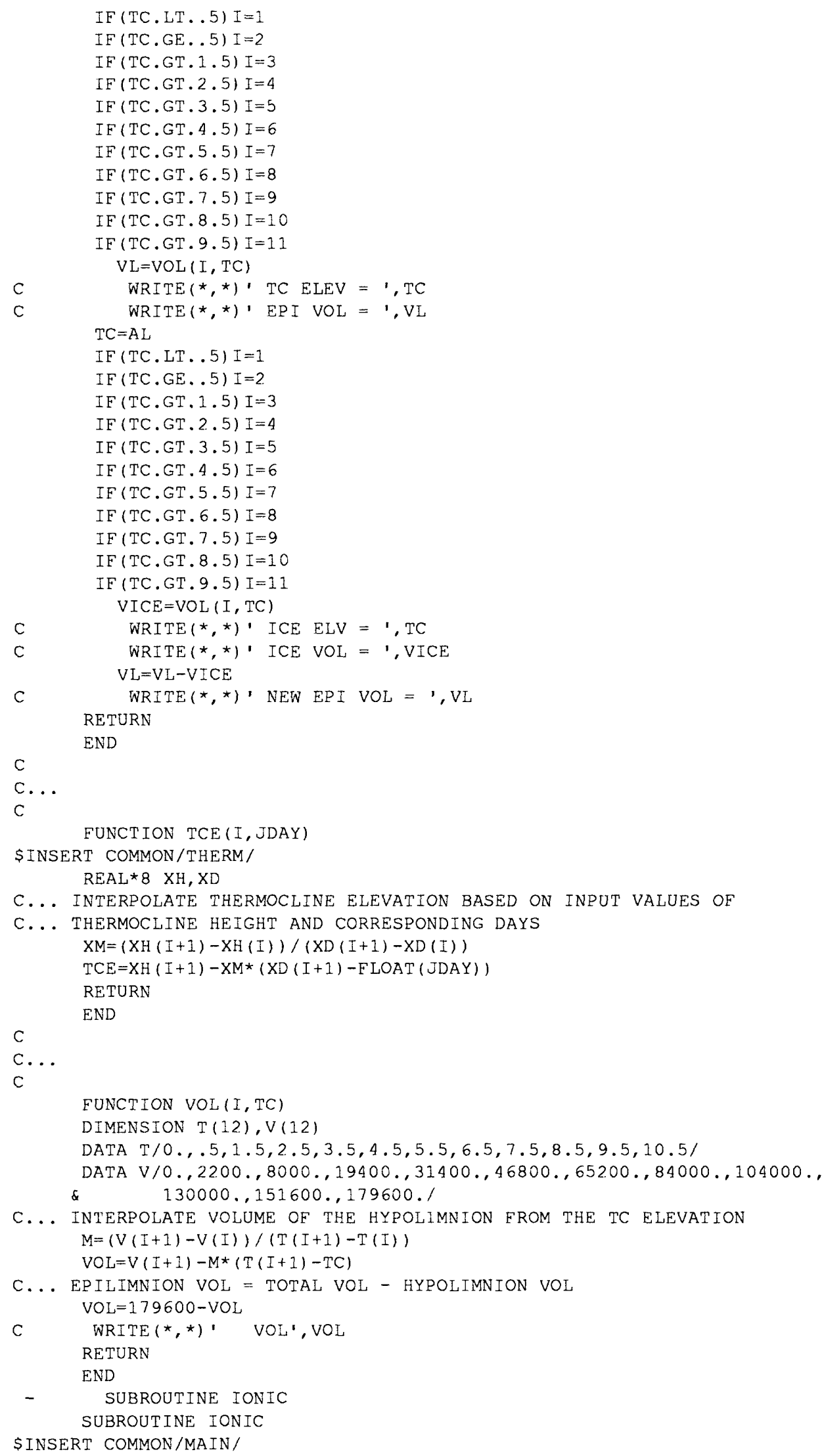


$T A B=C H A R(137)$

C... WRITES IN A SPECIFIED FORMAT FOR MAKEING BAR GRAPHS IN CRICKET GRAPH

C... A MACINTOSH APPLICATION. USEFUL FOR COMPARING IONIC STRENGTHS

$\mathrm{C}$

$\mathrm{Z}=0$.

C. .

IF (IFLAG.EQ.1) THEN

WRITE (14, 1) TAB, JDAY, TAB, IPSBC, TAB, Z, TAB

$\&, Z, T A B, Z, T A B, I P H, T A B, Z, T A B, Z, T A B, I P N H 4$

FORMAT (16HCATIONS INPUT (R), A1, I3, 8(A1, F14.2))

WRITE $(14,3) \mathrm{TAB}$, JDAY, TAB, Z, TAB, Z, TAB

\&, IPCL, TAB, IPDOC, TAB, Z, TAB, IPNO3, TAB, IPSO4, TAB, Z

FORMAT (16H ANIONS INPUT (R),A1, I3, 8(A1, F14.2)

ELSE

WRITE (14,2) TAB, JDAY, TAB, IPSBC, TAB, Z, TAB

$\&, Z, T A B, Z, T A B, I P H, T A B, Z, T A B, Z, T A B, I P N H 4$

2 FORMAT (16HCATIONS INPUT(S), A1, I 3, 8 (A1, F14.2))

WRITE $(14,4)$ TAB, JDAY, TAB, Z, TAB, Z, TAB

$\&$, IPCL, TAB, IPDOC, TAB, $2, T A B, I P N O 3, T A B, I P S O 4, T A B, 2$

4 FORMAT(16H ANIONS INPUT(S), A1, I3, 8(A1,F14.2))

ENDIF

C...

WRITE $(14,5) \mathrm{TAB}, \mathrm{JDAY}, \mathrm{TAB}, \mathrm{SBC}, \mathrm{TAB}, 2, \mathrm{TAB}$

$\&, Z, T A B, Z, T A B, H, T A B, Z, T A B, Z, T A B, N H 4$

5 FORMAT(12HCATIONS CALC, A1, I 3,8(A1, F14.2))

WRITE $(14,6) T A B, J D A Y, T A B, Z$, TAB, ANC, TAB

$\&, C L, T A B, D O C, T A B, Z, T A B, N O 3, T A B, S O 4, T A B, Z$

6 FORMAT(11HANIONS CALC, A1, I 3, 8(A1, F14.2))

C...

C WRITE $(*, *) ' J D A Y ', J D A Y, ' \operatorname{OSJD}(1, I O, ') \quad$ 'OSJD(IO)

IF (JDAY.EQ.OSJD (IO)) THEN

WRITE $(14,7) \mathrm{TAB}$, OSJD (IO) , TAB, OSSBC (IO), TAB, Z, TAB

$\&, Z, T A B, Z, T A B, O S H(I O), T A B, Z, T A B, Z, T A B, O S N H 4$ (IO)

7 FORMAT (11HCATIONS OBS, A1, 13,8(A1, F14.2))

WRITE $(14,8) \mathrm{TAB}$, OSJD (IO), TAB, $2, T A B$, OSANC (IO), TAB

$\&$, OSCL (IO) , TAB, OSDOC (IO), TAB,Z,TAB, OSNO3 (IO) , TAB

$\&, O S S O 4(T O), T A B, Z$

$\mathrm{IO}=10+1$

ENDIF

$\operatorname{WRITE}(14, *) \operatorname{TAB}$

8 FORMAT $\{11 \mathrm{H}$ ANIONS OBS, $\mathrm{A} 1, \mathrm{I} 3,8(\mathrm{~A} 1, \mathrm{~F} 14.2))$

RETURN

END 